\title{
1 Runs of Homozygosity in sub-Saharan African populations provide insights into a complex
}

\section{2 demographic and health history}

3 Francisco C. Ceballos ${ }^{1}$, Scott Hazelhurst ${ }^{1,3}$ and Michele Ramsay ${ }^{1,2}$

\section{Affiliations}

5 1. Sydney Brenner Institute for Molecular Bioscience, Faculty of Health Sciences, University of the

6 Witwatersrand, Johannesburg, South Africa.

7 2. Division of Human Genetics, School of Pathology, Faculty of Health Sciences, University of the

8 Witwatersrand, Johannesburg, South Africa.

9 3. School of Electrical \& Information Engineering, University of the Witwatersrand, Johannesburg, South Africa.

11 Correspondence Author: ceballoscamina@gmail.com

\section{Abstract}

13 The study of runs of homozygosity $(\mathrm{ROH})$, contiguous regions in the genome where an individual is 14 homozygous across all sites, can shed light on the demographic history and cultural practices. We present 15 a fine-scale ROH analysis of 1679 individuals from 28 sub-Saharan African (SSA) populations along with 161384 individuals from 17 world-wide populations. Using high-density SNP coverage, we could accurately

17 obtain $\mathrm{ROH}$ as low as $300 \mathrm{~Kb}$ using PLINK software. The analyses showed a heterogeneous distribution of 18 autozygosity across SSA, revealing a complex demographic history. They highlight differences between 19 African groups and can differentiate between the impact of consanguineous practices (e.g. among the 20 Somali) and endogamy (e.g. among several Khoe-San groups ${ }^{1}$ ). The genomic distribution of ROH was 21 analysed through the identification of $\mathrm{ROH}$ islands and regions of heterozygosity (RHZ). These

\footnotetext{
${ }^{1}$ The term Khoe-San is often used in the literature, but is regarded by some as offensive as it conflates two distinct groups. The impact of colonialism had a very traumatic effect on population size and structure. We use the phrase Khoe and San to describe people who have either Khoe and/or San ancestry as a neutral term to describe people who live in similar regions and have had some shared history in the last centuries.
} 
22 homozygosity cold and hotspots harbour multiple protein coding genes. Studying ROH therefore not only

23 sheds light on population history, but can also be used to study genetic variation related to the health of

24 extant populations.

\section{INTRODUCTION}

African human genetic diversity provides the ideal backdrop to reconstruct modern human origins, the

27 genetic basis of adaptation to different environments and the development of more effective vaccines ${ }^{1}$.

28 Studies on African population genetics and genomics have multiplied over the past decade, boosted by many efforts to genotype and sequence more populations from the continent ${ }^{2-4}$, though one of the "grand challenges" of the post-genome era, "To characterize genetic variation among individuals and populations" ${ }^{5}$, is yet to be fully achieved. Testament to the value of this approach is the recent study of the deep whole genome sequencing of 24 South African individuals where roughly $0.8 \mathrm{M}$ new variants were identified ${ }^{6}$. Due to the significant advances in genotyping and sampling of African populations, a study on runs of homozygosity provides an interesting opportunity for a deep dive into the demographic history of Africans.

Runs of homozygosity $(\mathrm{ROH})$ are contiguous regions of the genome where an individual is homozygous

37 (autozygous) across all sites ${ }^{7}$. $\mathrm{ROH}$ arise when two copies of an ancestral haplotype are brought together in an individual. The size of the $\mathrm{ROH}$ is inversely correlated with its age: longer ROH will be inherited from recent common ancestors while shorter $\mathrm{ROH}$ from distant ancestors because they have been broken

41 disequilibrium (LD) among markers, are not always considered autozygous but nevertheless are due to

42 the mating of distantly related individuals. A different source of apparent homozygosity, hemizygous deletions, can masquerade as $\mathrm{ROH}$, but such copy number variation has a minor effect in $\mathrm{ROH}$ studies ${ }^{7-9}$. 
44 Since their discovery in the mid-1990s ${ }^{10} \mathrm{ROH}$ were found to be ubiquitous. We are all inbred to some

45 degree and $\mathrm{ROH}$ capture this aspect of our demographic histories, with runs of homozygosity being the

46 genomic footprint of the phenomenon known as pedigree collapse ${ }^{11}$. $\mathrm{ROH}$ are present in all populations,

47 even in admixed or outbred populations and arise by two different processes: a limited effective

48 population size $(\mathrm{Ne})$ and by consanguineous unions. Independently of how they were generated, $\mathrm{ROH}$ can

49 be used to obtain the genomic inbreeding coefficient or $\mathrm{FROH}^{7 ; 8}$. Traditionally, the inbreeding coefficient

50 (the probability that an individual receives two alleles that are identical-by-descent at a given locus which

51 is also the expected proportion of the genome being autozygous) is obtained using pedigrees and its

52 accuracy depends on the depth and reliability of the pedigree ${ }^{12 ; 13} . \mathrm{F}_{\mathrm{ROH}}$ measures the actual proportion of

53 the autosomal genome that is autozygous over and above a specific minimum length ROH threshold.

54 When this cut-off is set at $1.5 \mathrm{Mb}, \mathrm{F}_{\mathrm{ROH}}$ correlates most strongly $(r=0.86)$ with the $\mathrm{F}$ obtained from an

55 accurate six-generation pedigree $\left(\mathrm{FPED}_{\mathrm{PED}}\right)^{8}$. Using 20-generation depth genealogies with more than 5000

56 individuals of European Royal dynasties, with many complex inbreeding loops, it has been found that

57 above the $10^{\text {th }}$ generation the change in the coefficient of inbreeding $(F)$ is less than $1 \%^{14}$. Also, it has been

58 found that individuals with no inbreeding loops in at least 5 generations (and probably 10) carried $\mathrm{ROH}$

59 up to $4 \mathrm{Mb}$ in length but not longer ${ }^{8}$. $\mathrm{F}_{\mathrm{ROH}}$, using a genomic approach, captures the total inbreeding

60 coefficient of the individual independently of pedigree accuracy, or depth within the resolution of the

61 data available and the size of $\mathrm{ROH}$ that can be called ${ }^{7}$ i5.

62 The $\mathrm{ROH}$ approach provides a window to explore individual and demographic history, to understand the

63 genetic architecture of traits and diseases and to study concepts in genome biology ${ }^{7}$. Different population

64 histories give rise to divergent distributions of long and short $\mathrm{ROH}$. The number and length of ROH reflect

65 individual and population history and have been used to detect consanguineous practices, endogamy and

66 isolation 7 ; 9 ROH were found to be associated with different diseases and traits and its analysis is capable

67 of detecting directional dominance and inbreeding depression when phenotype data are available ${ }^{16 ; 17}$. 
The non-random patterns of the genomic distribution of $\mathrm{ROH}$ provides an interesting approach to studying

genome biology ${ }^{7}$ 18-20. As expected, $\mathrm{ROH}$ are common in regions of high LD, low recombination and low genetic diversity ${ }^{19 ;}$. There is an uneven distribution along the genome, with a number of comparatively

71 short regions with a high population-specific prevalence of $\mathrm{ROH}$ - known as $\mathrm{ROH}$ islands - on each

72 chromosome, as well as coldspots with a paucity of $\mathrm{ROH}^{20 ;}{ }^{21}$. These $\mathrm{ROH}$ islands are prevalent in all

73 populations and dominate the $\mathrm{ROH}$ in outbred groups; however they are overshadowed by much larger

$74 \mathrm{ROH}$ arising from recent pedigree loops that are randomly distributed across the genome ${ }^{7}$. In some cases,

$75 \mathrm{ROH}$ islands are due to homozygosity of one common haplotype, but in other cases, multiple haplotypes contribute to a single $\mathrm{ROH}$ island ${ }^{20}$. The origin of these islands is still a subject of debate. In some cases, the haplotypes segregating at high frequencies in the population may be due to positive selection; for example, a $\mathrm{ROH}$ island around the lactase persistence $(L C T)$ gene on chromosome $2 q 21$ was found in

79 Europeans ${ }^{21}$. In addition, numerous genes that are targets of recent positive selection have been found in multiple $\mathrm{ROH}$ islands in populations around the globe ${ }^{20}$. Another potential biological explanation is that $\mathrm{ROH}$ islands include small inversions that suppress recombination ${ }^{21}$.

Sub-Saharan Africa (SSA) is a sub-continent with a complex demographic history where a deep ROH analysis provides interesting insights. Previous studies on $\mathrm{ROH}$ were hampered by small sample sizes and inadequate African population representation, genotype panels with low SNP coverage, non-optimized $\mathrm{ROH}$ calling conditions and in some cases poor ROH classification and analysis. Gibson et al. ${ }^{18}$, in one of the first articles that included African samples, published in 2006, used the Hap Map I dataset with 60

87 Yoruba individuals to conclude that Western Africans had the smallest number of long ROH tracks per individual, but showed that $\mathrm{ROH}$ are common even in outbred populations. Four years later, Kirin et al. ${ }^{9}$ used the Human Genome Diversity Project to analyse five SSA populations: three agricultural heritage and 
and that there is an increase in $\mathrm{ROH}$ with distance from Africa. The article also suggested that the huntergatherers (17 Biaka and Mbuti pygmies and 15 !Xun San) have a larger ROH burden between 0.5 and 16Mb compared to farmer communities. Henn et al. ${ }^{22}$ used 90 hunter gatherer individuals from three populations (Hadza, Sandawe and $\neq$ Komani) to calculate the cumulative $\mathrm{ROH}(\mathrm{cROH})$ as the sum of $\mathrm{ROH}$ $>500 \mathrm{~kb}$. They concluded that the Hadza population differ strongly from the other groups and its elevated mean and variance of $\mathrm{CROH}$ is indicative of a severe population bottleneck. Further evidence of the heterogeneity among the hunter-gathered populations from SSA was reported by Schlebusch et al. ${ }^{23}$. Using a sliding window of $5 \mathrm{Mb}$ and a coverage of $297 \mathrm{~K}$ SNPs, a minimum length of $500 \mathrm{~kb}$ and $50 \mathrm{~kb} / \mathrm{SNP}$ in PLINK they obtained the $\mathrm{cROH}$ for 147 individuals from 21 populations (9 farmers and 12 huntergatherer populations). Considering the heterogeneity among hunter-gatherers the study concluded that northern San groups like /Gui and //Gana, Nama and the two Pygmy populations have generally an average $\mathrm{CROH}$ higher than farming populations for every ROH size class. However, southern San groups (Karretjie and $\neq$ Khomani) have a lower burden than farmers. In one of the first studies to provide a meaningful world context of the distribution of $\mathrm{ROH}$, Pemberton et al. ${ }^{20}$ analysed 64 worldwide populations (1839 individuals in total) including 10 from SSA ( 2 hunter-gatherer and 8 farmer-pastoralist populations (386 individuals in total)). After identifying ROH by a LOD score methodology, and using a mixture of three Gaussian distributions, $\mathrm{ROH}$ were classified by length into 3 groups: Class A (short ROH of about tens of $\mathrm{kb}$ with an LD origin), Class $\mathrm{B}$ (intermediate $\mathrm{ROH}$ of hundreds of $\mathrm{kb}$ to $2 \mathrm{Mb}$, resulting from background relatedness owing to genetic drift) and Class $\mathrm{C}$ (long ROH over $1-2 \mathrm{Mb}$ arising from recent parental relatedness). The study concluded that Class A and B ROH increase with distance from Africa, a trend similar to the negative correlation observed for expected heterozygosity ${ }^{24}$. Class $\mathrm{C} \mathrm{ROH}$ did not show this geographical stepwise increase; however, African populations tended to have few ROH in this class.

Representation of SSA populations has increased with projects such as the AGVP², 1000 Genomes Project $^{25}$, the HGDP ${ }^{26}$, the Simons Genome Diversity Project ${ }^{27}$, and others ${ }^{22 ; 23}{ }^{26 ; 28}$, making it possible to 
study 3000 individuals in over 60 SSA populations. Recent studies have, however, shown that the

117 distribution of ROH in SSA may not be as homogeneous as previously thought. Hollfelder et al. ${ }^{29}$ genotyped

118244 new individuals from 18 Sudanese populations and, notwithstanding some technical issues,

119 concluded that Coptic, Cushitic, Nubian and Arabic populations from North Sudan have a higher burden

120 of ROH in comparison to Southern Sudan populations. ROH distribution heterogeneity in SSA was also

121 shown by Choudhury et al. ${ }^{6}$ by analysing roughly 1600 individuals from 28 SSA populations, in a

122 preliminary superficial exploration. Finally, Ceballos et al. ${ }^{7}$ gathered more than 4200 individuals from 176

123 worldwide populations to analyse ROH distribution. Although this study included 924 SSA individuals from

12430 population, the low SNP coverage (147K SNPs) prevented fine-scale analysis, but concluded that some

125 hunter gatherer populations like the Hadza have a ROH burden similar to the most isolated populations

126 from Oceania and South America.

127 The objective of this study was to perform fine-scale analysis of the ROH distribution in SSA, in a world

128 context, in order to learn more about the demographic history of the continent and its populations. Public

129 data from the Africa Genome Variation Project (AGVP), the 1000 Genome Project (KGP) and Schlebusch

130 et al. were analysed and included 1679 individuals from 28 SSA populations and 1384 individuals from 17

131 worldwide populations. By analysing the sum and number of $\mathrm{ROH}$ and deconstructing probable patterns

132 of inbreeding, we present interpretations for the demographic histories of different SSA populations.

$134 \quad$ Materials and Methods

135 Description of the Data

136 The study included a total of 3063 individuals from 45 populations from the 1000 Genomes Project 137 Phase $3(\mathrm{KGP})^{25}{ }^{30}$, the African Genome Variation Project (AGVP) ${ }^{2}$ and Schlebusch et al. $(2012)^{23}$. All 
individuals were genotyped using the Infinium Omni 2.5 array from Illumina, and all datasets were subjected to extensive QC procedures.

140 The KGP - Phase 3, includes a total of 1558 individuals from 19 populations ${ }^{25}$. From Europe: FIN (Finish in 141 Finland, n=97), GBR (British in England and Scotland, n=91), IBS (Iberian populations in Spain, $n=99$ ), TSI

142 (Tuscany in Italy, $\mathrm{n}=92$ ) and CEU (Utah residents with European ancestry=95). From America: ASW 143 (Americans of African ancestry in Houston, $n=49$ ), ACB (African Caribbean in Barbados, $n=72$ ), PUR (Puerto 144 Rican in Puerto Rico with admixed ancestry, n=72), PEL (Peruvian in Lima, Peru with Amerindian ancestry, $145 \mathrm{n}=50$ ), CLM (Colombian in Medellin, Colombia with admix ancestry, $n=65$ ) and MXL (Mexican with 146 admixed ancestry in Los Angles, USA, n=47). From South Asia: GIH (Gujarati Indian from Houston, Texas $147 \mathrm{n}=95)$. From East Asia: CDX (Chinese Han in Xishuangbanna, China, n=83), CHB (Chinese Han in Beijing, 148 China, n=98), CHS (Southern Han Chinese, n=86), JPT (Japanese in Tokyo, Japan, n=96) and KHV (Kinh in 149 Ho Chi Minh city, Vietnam n=96). From Africa Guinean Gulf: YRI (Yoruba in Ibadan, Nigeria, n=100), and 150 from East Africa: LWK (Luhya in Webuye, Kenya, n=74).

151 The AGVP includes 1318 individuals from 17 populations from SSA ${ }^{2}$. Niger-Congo speakers from Western 152 Africa: Wolof (Senegambian sub-group speakers from The Gambia, n=78), Fula (Senegambian from The 153 Gambia, n=74), Mandinka (Mande sub-group speakers from The Gambia, $n=88$ ) and Jola (Bak sub-group 154 speakers from The Gambia, n=79). Niger-Congo speakers from the Guinean Gulf: Ga-Adangbe (Kwa sub155 group speakers from Ghana, $\mathrm{n=100}$ ) and Igbo (Igboid sub-group speakers from Nigeria, $\mathrm{n}=99$ ). Afro-Asiatic 156 speakers from the Horn of Africa: Amhara (Semitic sub-group speakers from Ethiopia, $\mathrm{n}=42$ ), Oromo 157 (Cushitic sub-group speakers from Ethiopia,n=26) and Somali (Cushitic from Ethiopia and Somalia, $n=39$ ). 158 Niger-Congo speakers from Eastern Africa: Baganda (Bantoid sub-group speakers from Uganda, n=100), 159 Banyarwanda (Bantoid from Uganda, $n=100$ ), Barundi (Bantoid from Uganda, $n=97$ ) and Kikuyu (Bantoid 


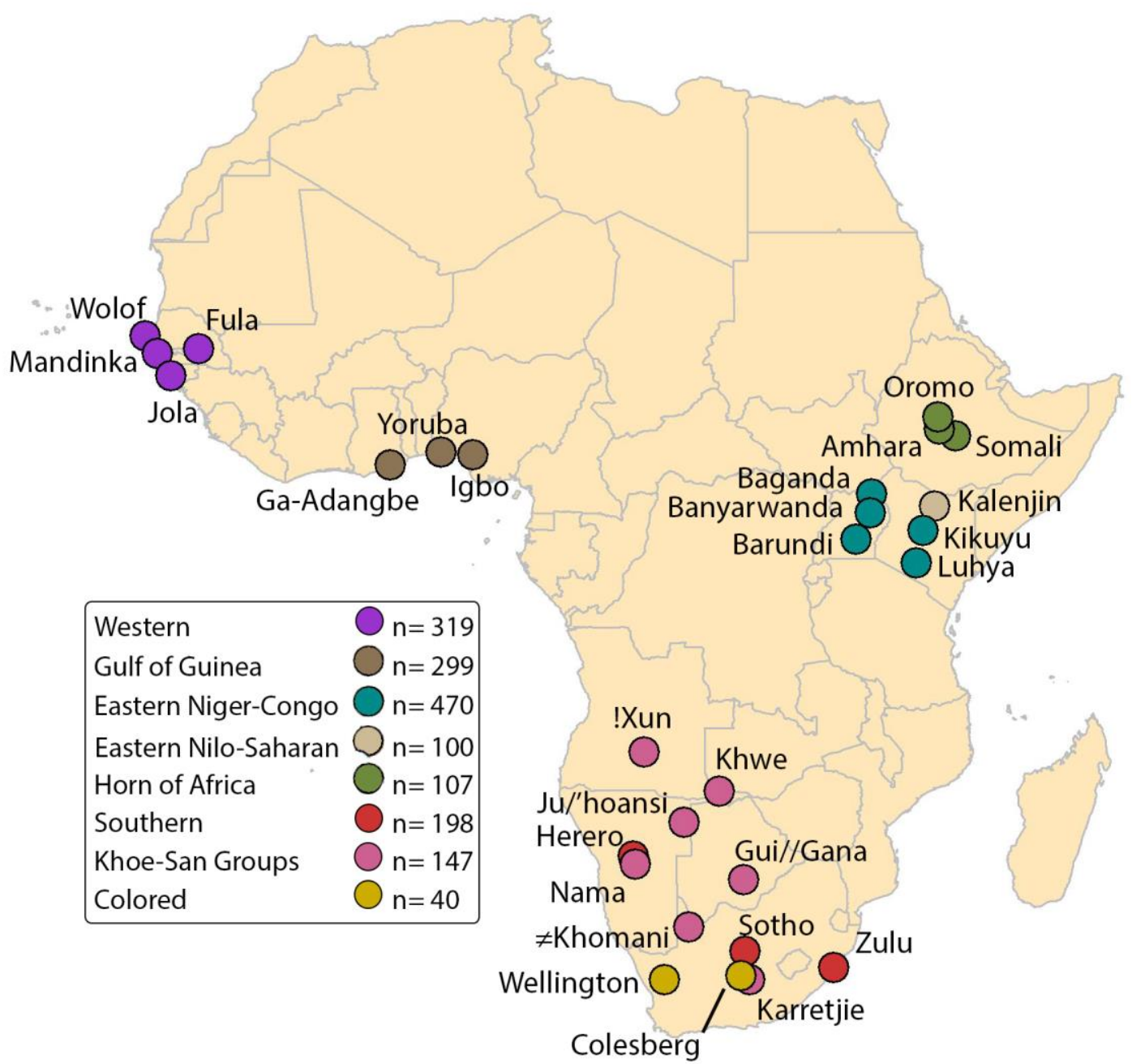
In addition, 147 individuals from 7 different groups with Khoe and San ancestry, 40 South African Colored

Figure 1. Sub-Saharan African populations included in the study: 28 African populations in total including 16 from the African Genome Variation Project (AGVP), 2 from the 1000 Genomes Project (KGP) and 10 from Schlesbusch et al. 2012. Populations were organized in 8 groups according to their geographic, linguistic and/or admixture origins. Western Africa (shown in deep purple), Gulf of Guinea (shown in brown), Eastern Africa Niger-Congo populations (shown in light blue), Eastern Africa Nilo-Saharan population (shown in wheat), Horn of Africa (shown in dark green), Southern Africa (shown in red), Khoe and San populations (shown in pink) and Colored admixed populations (shown in yellow). The number of individuals from each group is shown in Table $1 . g$

individuals (20 from Colesberg and 20 from Wellington, both in South Africa) and 12 Herero Bantoid 
speakers from Namibia from the Schlebusch study were added ${ }^{23}$. The term Khoe-San designates two groups of people: the pastoralist Khoe and the hunter-gatherer San ${ }^{23 ;} 31$. The following were included in this study: Ju/'hoansi (San Ju speakers from Namibia, $n=18$ ), !Xun (San Ju speakers Angola, $n=19$ ), Gui//Gana (San Khoe-Kwadi speakers from Botswana, $n=15$ ), $\neq$ Khomani (San Tuu speakers from South Africa, n=39), Nama (Khoe Khoe-Kwadi speakers from Namibia), Khwe (San Khoe-Kwadi speakers from the Caprivi strip: Namibia, Angola and Botswana) and Karretjie people (San Tuu speakers from South Africa, $n=20)$.

SSA samples were grouped according to geographic region and principal components analysis into 8 groups (Figure 1): Western Africa ( $n=319)$, Gulf of Guinea ( $n=299)$, Eastern Africa Niger-Congo populations ( $n=470)$, Eastern Nilo-Saharan population $(n=100)$, Horn of Africa $(n=107)$, Southern Africa $(n=198)$, Khoe and San groups $(n=147)$ and Colored South Africans $(n=40)$. KGP populations from the rest of the world were grouped as follows: Mixed African-American populations $(n=121)$, Europeans $(n=474)$, Southern Asians ( $n=95)$, Eastern Asians ( $n=459)$, South Americans $(n=50)$ and Mixed Hispanic-Americans $(n=184)$. Since the three datasets used in this study were genotyped using the same SNP genotyping array they could easily be merged ${ }^{15 ; 16}$. Only autosomal SNPs were included in this analysis. For each population, array data were filtered to remove SNPs with minor allele frequencies $<0.05$ and those that divert from $\mathrm{H}-\mathrm{W}$ proportions with $p<0.001$. This filtering serves to limit the effects of ascertainment bias caused by the small number of individuals in the SNP discovery panel. After QC, there were 1.3M SNPs on average in Western Africa populations, 1.4M in Gulf of Guinea, 1.4M in Eastern Africa Niger-Congo populations, 1.4M in Eastern Nilo-Saharan population, 1.3M in Horn of Africa populations, 1.3M in Bantu-speaking Southern Africa populations, 1.4M in Khoe and San populations from Southern Africa, 1.4M in Colored populations from Southern Africa, 1.4M in Africa-American admixed populations, 1.2M in European populations, $1.2 \mathrm{M}$ in southern Asia populations, $1.1 \mathrm{M}$ in Eastern Asian populations, $1.1 \mathrm{M}$ in South America populations and 1.2M in Hispanic-American admixed populations. 
200 To enrich the data further we merged the above datasets (KGP, AGVP and Schlebusch) with the Human

201 Genome Diversity Project dataset (HGDP) ${ }^{26}$ since this dataset includes isolates and urban populations

202 from across four continents. The HGDP includes 1043 individuals from 51 populations from different parts

203 of the world: 6 populations from Europe, 4 from the Middle East, 10 from Central and South Asia, 17 from

204 East Asia, 7 from Africa, 2 from Oceania and 5 from Africa. 650K SNPs were genotyped in these populations

205 using the Illumina BeadStation technology. After merging all datasets and filtering for MAF and $\mathrm{H}-\mathrm{W}$

206 proportions we have a dataset of 4106 individuals with genotypes for 382,840 SNPs. In order to

207 differentiate it from the main dataset described above, this merged dataset is called "worldata0.3".

\section{Identification of runs of homozygosity}

209 The observational approach implemented by PLINK v1.932 was used to call ROH. The simplicity of the

210 approach used by PLINK allows efficient execution on data from large consortia and even different array

211 platforms or sequencing technologies ${ }^{7}, 16$. Tests on simulated and real data showed that the approach

212 used by PLINK outperformed its competitors in reliably detecting $\mathrm{ROH}^{33}$.

213 The following PLINK conditions were applied to search for ROH:

$214--$ homozyg-snp 30. Minimum number of SNPs that a ROH is required to have

$215--$ homozyg-kb 300 . Length in $\mathrm{Kb}$ of the sliding window

216 --homozyg-density 30. Required minimum density to consider a ROH (1 SNP in $30 \mathrm{~Kb}$ )

$217-$-homozyg-window-snp 30. Number of SNPs that the sliding window must have

218 --homozyg-gap 1000 . Length in Kb between two SNPs in order to be considered in two different 219 segments.

$220-$-homozyg-window-het 1 . Number of heterozygous SNPs allowed in a window

221 --homozyg-window-missing 5. Number of missing calls allowed in a window

$222-$-homozyg-window-threshold 0.05 . Proportion of overlapping window that must be called

223 homozygous to define a given SNP as in a "homozygous" segment. 
224 The objective of this study is to use autozygosity to learn more about demographic history in SSA

225 populations. To achieve this goal short and long ROH need to be explored, since they provide different

226 types of information ${ }^{7}$ 15. The high SNP coverage of 1.2M SNPs on average for all the populations included

227 in the study, makes it possible to find a single SNP, on average, in a track of $2.4 \mathrm{~Kb}$. The Supplemental

228 Methods and Figures S1, S2, S3, S4 and S5 demonstrate that this coverage allows accurate detection of

$229 \mathrm{ROH}$ longer than $300 \mathrm{~Kb}$ by considering 30 as a minimum number of SNPs per ROH and/or the required

230 minimum SNP density to call ROH. To obtain a window with 30 SNPs, on average (assuming a

231 homogeneous distribution of SNP along the genome), a tract of just $72 \mathrm{~Kb}$ is needed. A threshold of 300

$232 \mathrm{~Kb}$ was set for the minimum length in order to capture small $\mathrm{ROH}$ originating far in the past and also to

233 ensure that these are true $\mathrm{ROH}$ that originated by genetic drift or consanguinity. An alternative source of

234 homozygosity originating from linkage disequilibrium (LD) typically produces tracts measuring up to about

$235100 \mathrm{~Kb}$, based on empirical studies ${ }^{34-36}$. By using a minimum-length cutoff of $300 \mathrm{~Kb}$, most short ROH

236 resulting from LD will be eliminated.

237 Analyses

238 Different variables were obtained and analyses performed in order to fully exploit the usefulness of the

$239 \mathrm{ROH}$ in the understanding of demographic history and possible cultural practices of populations. First, we

240 obtained the total sum of $\mathrm{ROH}$ for six $\mathrm{ROH}$ length classes: $0.3-0.5,0.5-1,1-2,2-4,4-8$ and $>8 \mathrm{Mb}$.

241 This exploratory data analysis allows us to delve into aspects of population history, since, due to

242 recombination, the size of a $\mathrm{ROH}$ is inversely proportional to its age. Thus, plotting the total sum of $\mathrm{ROH}$

243 for these size classes will inform, for example, the relative change of the effective population size across

244 generations.

245 We also conducted a preliminary examination at a global level using worldata.03. The interest in this

246 exploratory data analysis is to provide a rough relative comparison among populations not an absolute

247 quantification, as the lower SNP density affects the accuracy of analysis (it is apparent in Figure S6 that 
very short and large $\mathrm{ROH}$ are underestimated in worldata.03 due to the lower SNP coverage, and the

249 degree of bias depends on the population and its genetic characteristics). However, in further analysis,

250 where absolute quantification and comparison is mandatory in order to obtain meaningful conclusions,

251 the underestimation of short and very long $\mathrm{ROH}$ prevents the use of worldata.03.

252 For comparison purposes four variables were defined: (1) Mean number of ROH as the population average

253 number of $\mathrm{ROH}$ longer than $1.5 \mathrm{Mb}$; (2) Mean $\mathrm{ROH}$ size as the population average size of ROH longer than

$2541.5 \mathrm{Mb}$; (3) Total sum of $\mathrm{ROH}>1.5 \mathrm{Mb}$ as the population average total sum of $\mathrm{ROH}$ longer than $1.5 \mathrm{Mb}$; and

255 (4) Total sum of $\mathrm{ROH}<1.5$ as the population average total sum of ROH shorter than $1.5 \mathrm{Mb}$. Exploratory

256 data analysis and data representation were illustrated using violin plots. These plots combine a box plot

257 with a kernel density plot, where the interval width is obtained by the rule of thumb. The violin plot shows

258 a colored density trace with the interquartile range as a black line and median as a white dot. This

259 representation is especially useful when dealing with asymmetric distributions where median is more

260 informative than the mean. Statistical comparisons between total sum of ROH longer and shorter than

$261 \quad 1.5 \mathrm{Mb}$ between populations and geographic regions were performed using the Whitney-Wilcoxon non-

262 parametrical test (MWW). All the analyses were performed using R (v.3.4.1) ${ }^{37}$.

263 Measuring different sources of inbreeding

264 Population geneticists use the word inbreeding to mean different things, as pointed out by Jacquard and

265 Templeton in their respective classic articles ${ }^{38 ;}{ }^{39}$. Inbreeding can be produced by a deviation from

266 panmixia, in what G. Malecot called systematic inbreeding, or by genetic drift and low effective population

267 size, also called panmictic inbreeding ${ }^{40}$. Systematic inbreeding has a direct effect on the H-W proportions

268 of a population and can be measured using the Wright's fixation index or $\mathrm{F}_{I S}{ }^{41}$. In this study this component

269 of the total inbreeding coefficient is measured using the --het function in PLINK. In this context $F_{\text {IS }}$ is the

270 average SNP homozygosity within an individual relative to the expected homozygosity of alleles randomly

271 drawn from the population. PLINK use the following expression: 


$$
F_{\mathrm{IS}}=\frac{\text { Observed Hom }- \text { Expected Hom }}{N-\text { Expected Hom }}
$$

273 where Observed Hom is the observed number of homozygous SNPs, Expected Hom is the expected

274 number of homozygous SNPs considering $\mathrm{H}-\mathrm{W}$ proportions and $\mathrm{N}$ is the total number of non-missing

275 genotyped SNPs. $F_{I S}$ thus measures inbreeding in the current generation with $F_{I S}=0$ indicating random

276 mating, $F_{I S}>0$ indicating consanguinity and $F_{I S}<0$ indicating inbreeding avoidance.

277 The two different sources of inbreeding, namely, genetic drift (denoted by $\mathrm{F}_{\text {ST}}$ ) and non-random mating

$278\left(F_{I S}\right)$ are both components of the total inbreeding coefficient $\left(F_{I T}\right)$, defined as the probability than an

279 individual receives two alleles that are identical-by-descent. Sewall Wright developed an approach to

280 consider these three different $F$ coefficients in his $F$ statistics $\left(1-F_{I T}\right)=\left(1-F_{I S}\right)\left(1-F_{S T}\right)^{41 ;} 42$. First defined as

281 correlations, Nei showed how these coefficients can be expressed in terms of allele frequencies and

282 observed and expected genotype frequencies ${ }^{43}$. In this framework, $F_{S T}$ can be considered a measure of

283 the genetic differentiation of a subpopulation in comparison with an ideal population with a large $N_{\text {e. }} F_{I T}$

284 is the total inbreeding coefficient, traditionally obtained using deep genealogies, and can be calculated

285 using the $\mathrm{F}_{\mathrm{ROH}}(\mathrm{ROH}>1.5 \mathrm{Mb})$ :

$$
F_{R O H}=\frac{\sum_{i=1}^{n} l_{i}}{\text { len autosomal genome }}
$$

288 Where the numerator is the sum of $\mathrm{nOH}$ of length $\mathrm{I}_{\mathrm{i}}(>1.5 \mathrm{Mb})$ and the denominator is the total autosomal 289 length.

\section{Genomic distribution of ROH}

291 The study of the genomic distribution of ROH can be used for different purposes. By identifying the regions

292 where $\mathrm{ROH}$ are very prevalent, or completely absent in the population it is possible to identify candidate

293 regions (including protein coding genes) under selection. Furthermore, the identification of common and

294 unique ROHi in the different regional groups considered in this study can also shed light on population 
demographic history. In order to study the spatial distribution of ROH across the genome two different

variables were defined: islands of runs of homozygosity (ROHi) and regions of heterozygosity (RHZ) (see

definitions below). In order to identify protein coding genes in these regions biomartR package for $\mathrm{R}$ was

used. Differences in $\mathrm{ROHi}$ and $\mathrm{RHZ}$ between populations were used as genetic distances as a source to

build a rooted dendrogram by using optimal leaf ordering (OLO) for hierarchical clustering available in the

heatmaply R package ${ }^{44}$. The OLO clusters similar groups (or leaves) taken from the UPGMA (Unweighted

Pair Grouping with Arithmetic Mean) algorithm and yields the leaf order that maximizes the sum of the similarities of adjacent leaves in the ordering ${ }^{45}$.

\section{Islands of Runs of Homozygosity (ROHi)}

$\mathrm{ROHi}$ are defined as regions in the genome where the proportion of individuals of a population have $\mathrm{ROH}$

in a specific region that is more than expected by a binomial distribution. In order to search for ROHi a

According to this procedure two variables could introduce bias when comparing populations across the globe: different population sizes and $\mathrm{ROH}$ background. In order to mitigate this source of bias the were collapsed creating the following groups: Europe ( $n=474$ individuals), Eastern Asia ( $n=459$ individuals), 
In order to compare ROHi between populations it was considered that two ROHi from two different populations are indeed the same $\mathrm{ROHi}$ if they share at least $50 \%$ of their length. Results were compared using an alternative value of $75 \%$ without significant changes (data not shown).

\section{Regions of Heterozygosity (RHZ)}

$323 \mathrm{RHZ}$ are defined as regions in the genome where $<5 \%$ of individuals in a population have $\mathrm{ROH}$. In order 324 to search for RHZ an extra step of QC consisting of removing the SNPs in LD using PLINK was performed 325 before calling for ROH. For this analysis, ROH longer than $100 \mathrm{~Kb}$ were called using 25 SNPs per window 326 in PLINK. With this procedure all ROH longer than $100 \mathrm{~Kb}$, independent of their origin (LD or IBD), were 327 detected with accuracy due to the SNP coverage available. Removing SNPs in LD, on average 1.1M SNPs 328 were still available for every population, enabling detection of ROH longer than $100 \mathrm{~Kb}(2.8 \mathrm{~Kb}$ per SNP, 329 in $100 \mathrm{~Kb}$ would be on average 35 SNPs, and a window of 25 SNPs is appropriate to cover genomic regions 330 with less than the average number of SNPs). Once every ROH is called, it is straightforward to obtain 331 regions outside $\mathrm{ROH}$, and since SNPs in LD were pruned, these regions will be mostly heterozygous. In 332 order to only identify informative heterozygous haplotypes, regions that have anomalous, unstructured, 333 high signal/read counts in next generation sequence experiments were removed. These 226 regions, 334 called ultra-high signal artifact regions, include high map-ability islands, low map-ability islands, satellite 335 repeats, centromere regions, snRNA and telomeric regions ${ }^{46}$. Regions not covered by the Human Omni 336 Chip 2.5 were also removed from the analyses (Like $p$ arms of chromosomes 13, 14, 15, 21 and 22). By 337 moving a $100 \mathrm{~Kb}$ window through the genome, two different cutoffs were considered to call $\mathrm{RHZ}$ in each 338 window: no individual is in homozygosis $(\mathrm{RHZ} 0 \%)$ or $5 \%$ or less of the individuals are in homozygosis ( $\mathrm{RHZ}$ $3395 \%)$. Consecutive windows that fulfill this requirement were considered part of the same RHZ. 


\section{$343 \quad$ Results}

\section{Comparison of different ROH sizes across world populations}

345

346

347

348

349

350

351

352

Data analysis of mean total lengths (sum of $\mathrm{ROH}$ ) of different ROH length classes were plotted (Figure 2).

Three different situations were considered: $\mathrm{ROH}<1 \mathrm{Mb}, 1<\mathrm{ROH}<4 \mathrm{Mb}$ and $\mathrm{ROH}>4 \mathrm{Mb}$. Within Sub-Saharan Africa (SSA), Figure 2A shows different scenarios for short $(<1 . \mathrm{Mb})$ and long $(>4 \mathrm{Mb}) \mathrm{ROH}$ : short $\mathrm{ROH}$, unlike the long $\mathrm{ROH}$, display differences between regions and commonality among then. The populations with the longest average sum of short $\mathrm{ROH}$ are from the Horn of Africa (Amhara, Oromo, Somali). Populations from Western Africa, Gulf of Guinea, Eastern Africa and Southern Africa, in this order and with slight differences, have intermediate levels of short $\mathrm{ROH}$, and Colored populations from South Africa are the ones with the lowest levels of short ROH. Populations from these regions are reasonably homogeneous, unlike the Khoe and San populations. A completely different situation arises when long $\mathrm{ROH}(>4 \mathrm{Mb})$ are considered, in this case no population or geographic structure is observed. Three populations, Wolof and Fula, from western Africa, and Somali from the Horn of Africa, present the largest mean total length. Differences between long and short $\mathrm{ROH}$ can also been seen when considering populations around the world (Figure 2B). African populations have the smallest mean total length of $\mathrm{ROH}$, but this applies only to short $\mathrm{ROH}$. When considering long ROH, African populations like the Wolof, Fula and Somali have mean total lengths larger than most of the KGP populations. Just the indigenous but partially admixed populations from Lima, Peru (PEL), had a larger mean total ROH length. Interestingly, for the vast majority of the populations the mean total length of very short $\mathrm{ROH}(0.3$ to $0.5 \mathrm{Mb})$ is several times larger than the mean total length for long $\mathrm{ROH}(>4 \mathrm{Mb})$. This is not the case for the Khwe, Wolof and Fula populations. 
bioRxiv preprint doi: https://doi.org/10.1101/470583; this version posted November 14, 2018. The copyright holder for this preprint (which was not certified by peer review) is the author/funder. All rights reserved. No reuse allowed without permission.
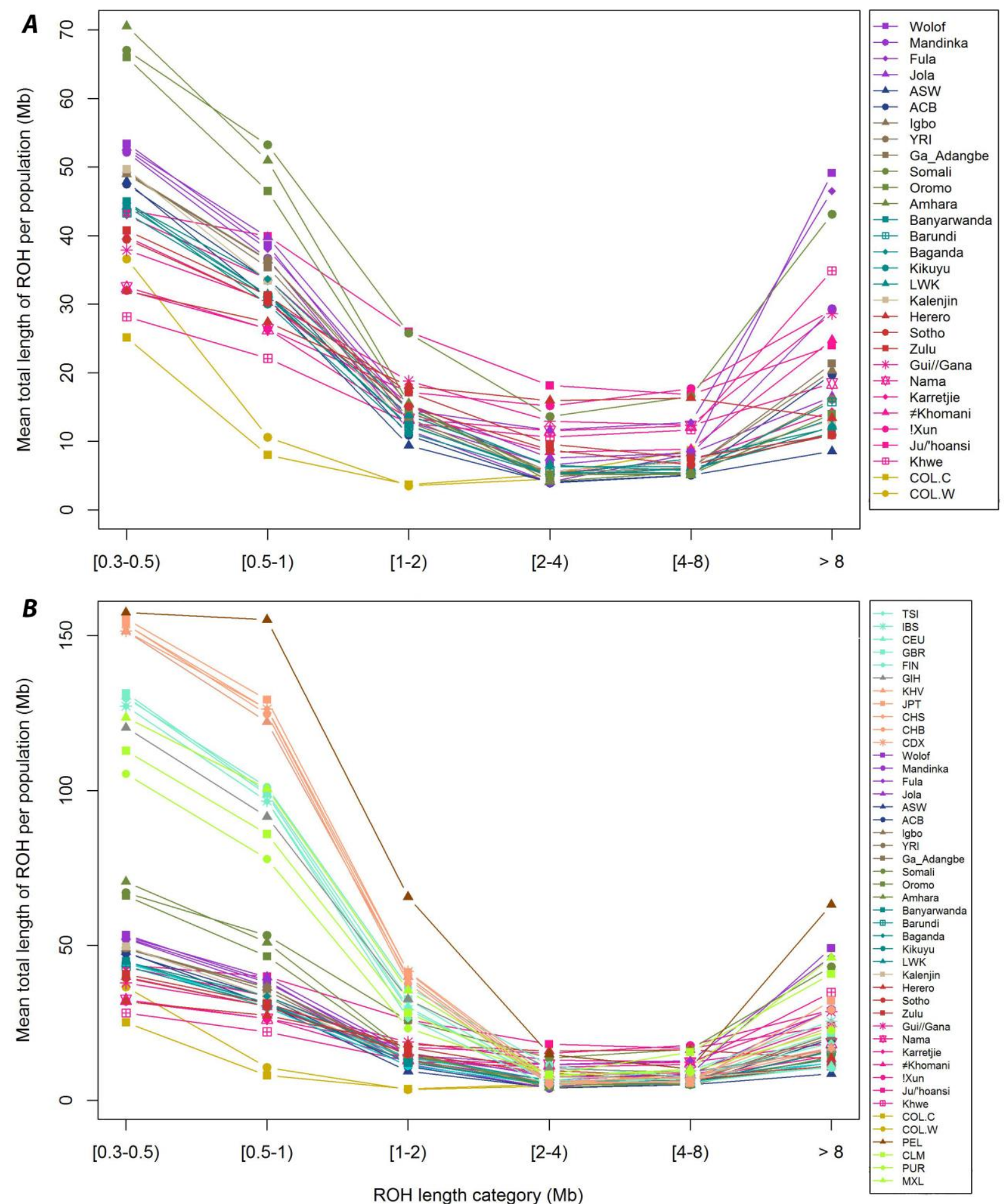

$\mathrm{ROH}$ length category $(\mathrm{Mb})$

Figure 2. Mean total length of $R O H$ over 6 classes of $R O H$ tract lengths. $R O H$ classes: $0.3 \leq R O H<0.5 \mathrm{Mb}, 0.5 \leq R O H<1 \mathrm{Mb}, 1 \leq R O H<2$ $\mathrm{Mb}, 2 \leq \mathrm{ROH}<4 \mathrm{Mb}, 4 \leq \mathrm{ROH}<8 \mathrm{Mb}$ and $\mathrm{ROH} \geq 8 \mathrm{Mb}$. A. Sub-Saharan African populations and admixture populations with African ancestry ( $A S W$ and $A C B$, shown in dark blue). Color coding corresponds to the legend in Figure 1. B. All populations from the KGP, AGVP and Schlesbusch et al. 2012. European populations are shown in aquamarine, Southern Asian population (GIH) is shown in grey, Eastern Asia populations are shown in light salmon, South America population (PEL) is shown in dark orange, admixture Hispanic - American populations are shown in light green. 
375 level, the Khoe and San groups like Ju/'hoansi, !Xun and Khwe, have a higher mean total length for ROH from 2 to $8 \mathrm{Mb}$, even higher than PEL. Medium size ROH also show an interesting global pattern: a considerable reduction in mean total length of $\mathrm{ROH}$ can be seen for all populations across the globe, and there are no big differences between populations for mean total length for those ROH length classes. Considering the limitations of the KGP dataset to represent world populations, the HGDP was added to even in very isolated populations, like the African Hadza, who also have a reduction in medium size $\mathrm{ROH}$.

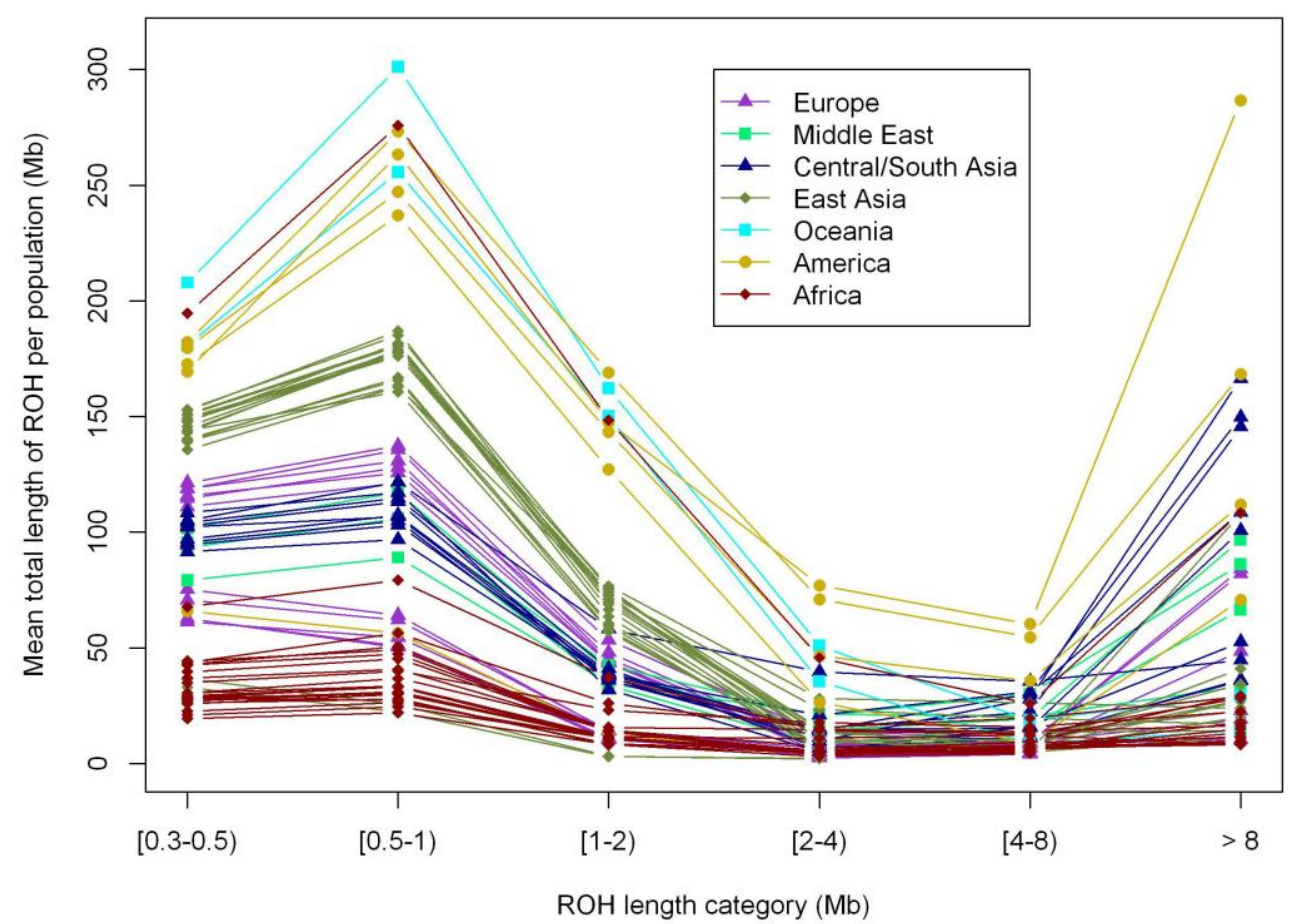

Figure 3. Mean total length of ROH over 6 classes of ROH tract lengths for the merged dataset of AGVP, KGP, Schlesbusch and HGDP (worldata.03, see text in the Materials and Methods section). Europe populations are shown in deep purple, Middle east populations are shown in deep purple, Middle east populations are shown in light green, Central and South Asia populations are shown in dark blue, Eastern Asia population are shown in dark green, Oceanic populations are shown in light blue, American populations are shown in yellow and African ones are shown in red. 


\section{Violin Plots: Exploratory data analysis and non-parametrical comparisons}

392 Using violin plots, it is possible to examine the distribution of ROH in SSA. Figure 4 represents the

393 distributions and medians, complemented with the mean and standard deviations in Table 1. Within SSA

394 the population with the greatest number of ROH (for ROH longer than $1.5 \mathrm{Mb}$ ) is the Khoe-San Ju/'hoansi

395 (median=14.5, mean=15.1). Considering populations from around the globe, only PEL has a higher number

396 of ROH (median=18, mean=17.9). The Khoe-San populations, in general, are the ones with a higher

397 number of ROH in SSA; however, they also show great variability. For example, both San Tuu speaker

398 populations, $\neq$ Khonami and Karretjie, have a considerably smaller number of $\mathrm{ROH}$ (median=6, mean=6.7

399 and median=4, mean=5.15 respectively). Besides Khoe and San populations we observe other populations

400 like Somali and Herero with a large number of $\mathrm{ROH}$ (median=13, mean=13.6 and median=13.5, mean=13.3

401 respectively). Among SSA we find great variability, for example, populations like the Fula have a smaller

402 number of $\mathrm{ROH}$ (median=6, mean=8.4) but with a long right tail ( $\mathrm{sd}=7.2$ ) which indicates great variability

403 within the population (Figure 4). These right tails of the distribution are even longer when considering the

404 mean size of $\mathrm{ROH}(\mathrm{ROH}>1.5 \mathrm{Mb})$. Populations from Western Africa (Fula, Wolof and Mandinka) present

405 the longest right tails along with the TSI population from the Iberia peninsula in Europe (Table1). 


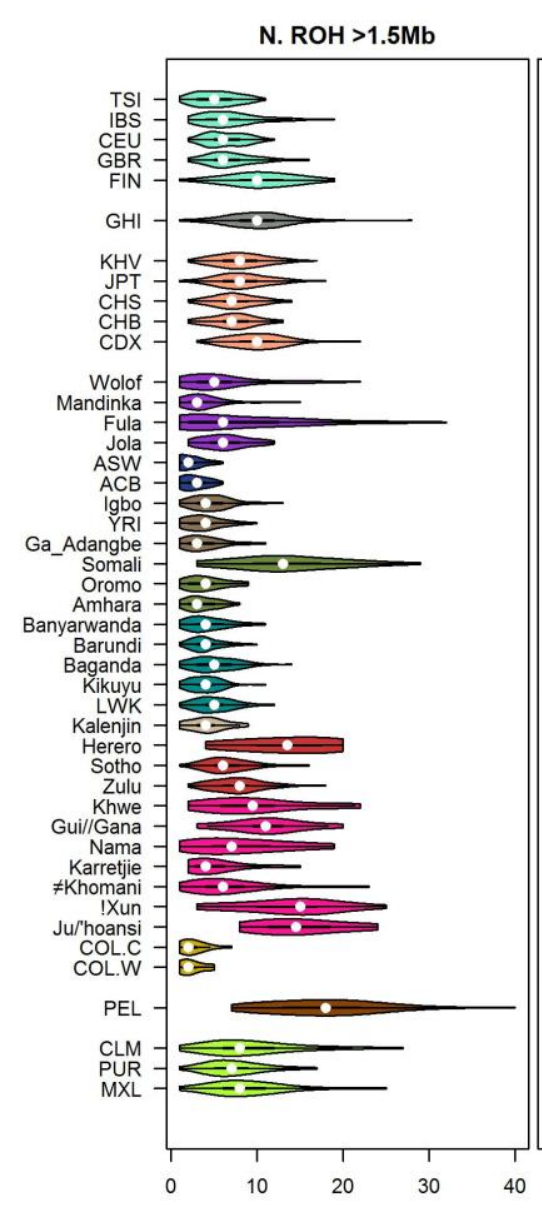

\section{Mean size $\mathrm{ROH}>1.5 \mathrm{Mb}$}

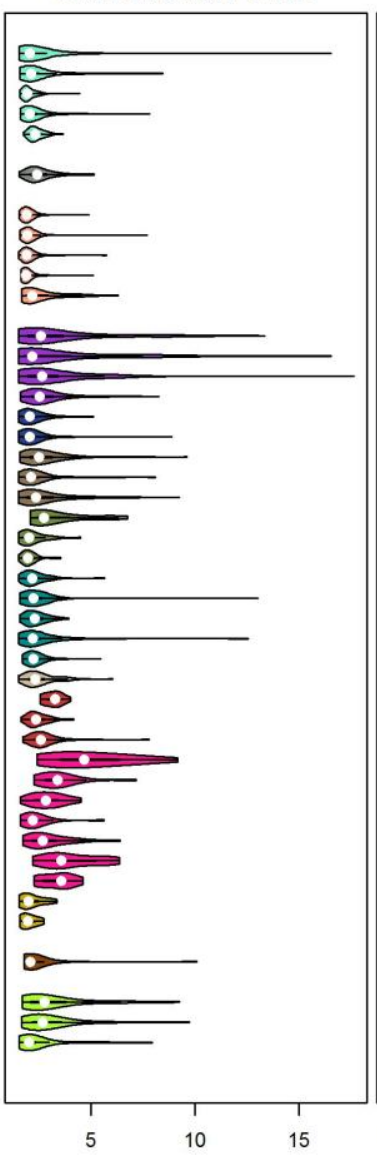

$\mathrm{Mb}$
Sum $R O H>1.5 \mathrm{Mb}$

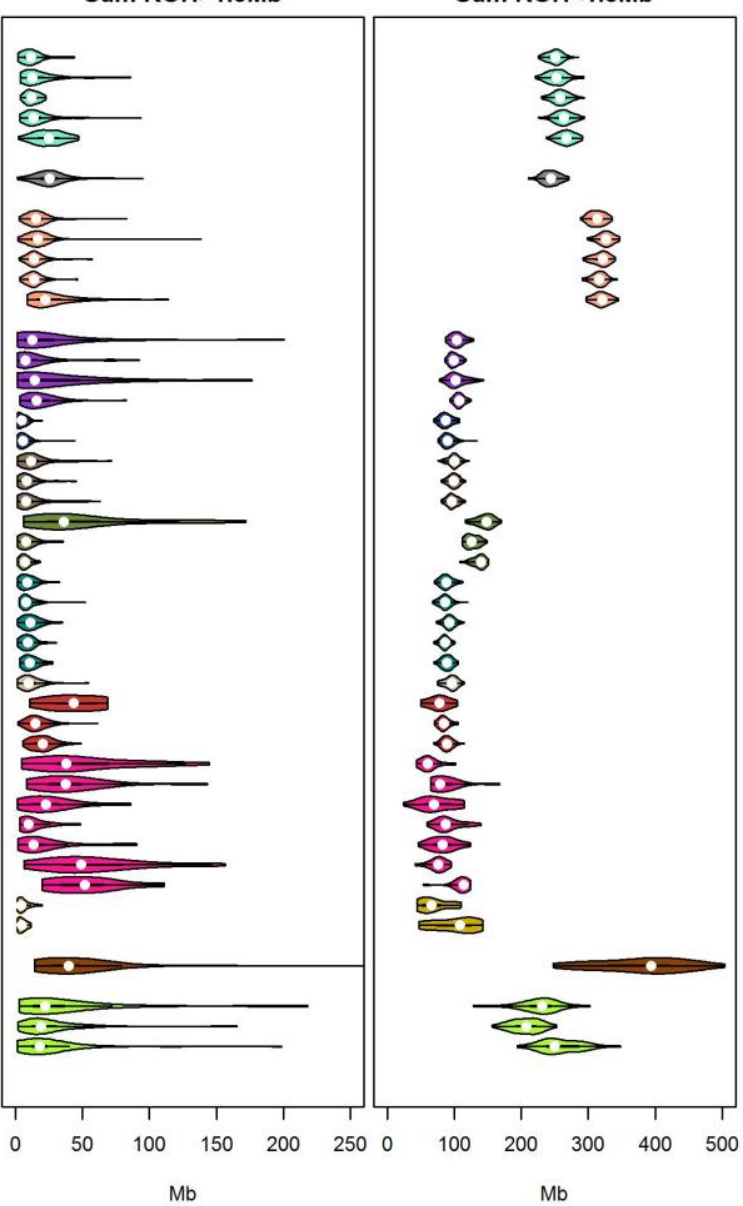

Figure 4. Violin plots showing the distribution of $\mathrm{ROH}$ within populations for the mean number of $\mathrm{ROH}$ longer than $1.5 \mathrm{Mb}$, mean size of $\mathrm{ROH}$ longer than $1.5 \mathrm{Mb}$, mean total sum of $\mathrm{ROH}$ longer than $1.5 \mathrm{Mb}$ and mean total length of ROH shorter than $1.5 \mathrm{M}$. The colors are coded according to the legends of Figures 1 and 2.

Differences between the short and long ROH seen in Figure 2 are represented more clearly in Figure 4.

Geographic classification and stratification can be seen for mean sum of $\mathrm{ROH}<1.5 \mathrm{Mb}$ : SSA populations

have the lowest medians (Figure S8), and within the continent, populations from the Horn of Africa have a significant higher sum of ROH as shown in Figure S7. Figure 4 and Table 1 show that, without considering Horn of Africa populations, there are no real differences between Khoe-San and the rest of the SSA populations. In Table 1 populations like the Ju/'hoansi, with a mean total sum of $\mathrm{ROH}<1.5 \mathrm{Mb}(109.66$ $\mathrm{Mb})$, are slightly higher than populations from Western Africa, or populations like the !Xun, Nama or Khwe with the smallest mean total sum of $\mathrm{ROH}<1.5 \mathrm{Mb}$ in all SSA $(75.5,73.9$ and $62.9 \mathrm{Mb}$ respectively) besides the Colesberg Colored population with $69.7 \mathrm{Mb}$. The shapes of the violin plots for sum of $\mathrm{ROH}<1.5 \mathrm{Mb}$ 
420 provide additional information. In general, populations are homogeneous, with very short tails and an

421 almost normal distribution; however, Khoe and San, Colored and populations from America present more

422 variability. Distribution shapes are completely different for the sum of $\mathrm{ROH}>1.5 \mathrm{Mb}$. When considering

423 these $\mathrm{ROH}$ we observe greater variability of the distribution shapes across populations within and outside

424 SSA. Wolof (median=12.5Mb, mean=27.1Mb, $s d=40.9 \mathrm{Mb})$, Fula (median=14.4Mb, mean=33.8Mb, $s d=42.7$

$425 \mathrm{Mb}$ ) and Somali (median=35.8Mb, mean=52.3Mb, $\mathrm{sd}=42.1 \mathrm{Mb}$ ) show especially long right tails, and just

426 two populations outside SSA: PEL (median $=39.6 \mathrm{Mb}$, mean $=46.5 \mathrm{Mb}, \mathrm{sd}=54.8 \mathrm{Mb}$ ) and CLM

427 (median=22.2Mb, mean=38.4Mb, $s d=47.3 \mathrm{Mb}$ ) have longer tails. Khoe-San populations form a

428 heterogeneous group, but also show long tails and widely spread distributions, indeed two populations

429 with the highest total sum of $\mathrm{ROH}$ are Khoe-San: the !Xun population from Angola (median=48.9Mb,

430 mean=58.8Mb, $s d=38.7 \mathrm{Mb}$ ) and the Ju/'hoansi from Namibia (median=51.8Mb, mean=53.0Mb,

$431 \mathrm{sd}=109.7 \mathrm{Mb})$. Figures S7 and S8 show non-parametrical pairwise statistical comparisons between SSA

432 populations and world regions.

433

434 Inbreeding Coefficient from ROH: $\mathrm{F}_{\mathrm{ROH}}$

435 The genomic inbreeding coefficient from $\mathrm{ROH}$ was obtained as the total sum of ROH longer than $1.5 \mathrm{Mb}$

436 divided by the total length of the autosomal genome. For practical reasons a cut-off point of $F_{\mathrm{ROH}}=0.0156$

437 (corresponding to the mean kinship of a second cousin marriage) was set to differentiate between inbred

438 and non-inbred individuals. In the demographic literature consanguineous marriage is usually defined as

439 a union between individuals who are related as second cousin or closer. This arbitrary limit is based on

440 the perception that an inbreeding coefficient below 0.0156 has biological effects not very different from

441 those found in the general population ${ }^{47}$.

442

443 
bioRxiv preprint doi: https://doi.org/10.1101/470583; this version posted November 14, 2018. The copyright holder for this preprint (which was not certified by peer review) is the author/funder. All rights reserved. No reuse allowed without permission.

Table 1. Number, size distribution and sum of $\mathrm{ROH}$ (above and below 1.5Mb) across global regions and according to population.

\begin{tabular}{|c|c|c|c|c|c|c|c|c|c|}
\hline \multirow[t]{2}{*}{ Population } & \multirow[t]{2}{*}{$\mathbf{N}$} & \multicolumn{2}{|c|}{ N ROH >1.5 } & \multicolumn{2}{|c|}{ Mean Size ROH >1.5 } & \multicolumn{2}{|c|}{ Total Sum ROH >1.5 } & \multicolumn{2}{|c|}{ Total Sum ROH $<1.5$} \\
\hline & & Mean & SD & Mean & SD & Mean & SD & Mean & SD \\
\hline \multicolumn{10}{|l|}{ Western Africa } \\
\hline Wolof & 78 & 5.84 & 4.6 & 3.549 & 2.58 & 27.065 & 40.92 & 104.90 & 9.74 \\
\hline Fula & 74 & 8.41 & 7.5 & 3.296 & 2.37 & 33.838 & 42.75 & 105.09 & 13.76 \\
\hline Mandinka & 88 & 3.72 & 2.5 & 3.521 & 2.78 & 15.119 & 19.34 & 100.44 & 7.30 \\
\hline Jola & 79 & 6.37 & 2.5 & 2.837 & 1.20 & 18.866 & 12.47 & 107.98 & 6.82 \\
\hline \multicolumn{10}{|l|}{ Gulf of Guinea } \\
\hline \begin{tabular}{|l|}
$\mathrm{YRI}$ \\
\end{tabular} & 100 & 3.85 & 2.1 & 2.398 & 1.05 & 9.553 & 7.47 & 99.01 & 7.59 \\
\hline Ga_Adangbe & 100 & 3.78 & 2.2 & 2.821 & 1.46 & 11.878 & 12.13 & 97.55 & 7.80 \\
\hline Igbo & 99 & 4.66 & 2.3 & 2.849 & 1.36 & 14.328 & 11.97 & 99.67 & 7.97 \\
\hline \multicolumn{10}{|l|}{ Mix. Afri-Amer } \\
\hline ACB & 72 & 2.81 & 1.4 & 2.201 & 0.96 & 6.546 & 5.87 & 91.90 & 9.63 \\
\hline ASW & 49 & 2.36 & 1.4 & 2.227 & 0.70 & 5.386 & 3.80 & 88.14 & 9.10 \\
\hline \multicolumn{10}{|l|}{ Horn of Africa } \\
\hline Amhara & 42 & 3.61 & 1.8 & 2.074 & 0.43 & 7.547 & 4.06 & 137.00 & 9.36 \\
\hline Oromo & 26 & 4.12 & 2.3 & 2.196 & 0.67 & 9.696 & 7.89 & 127.30 & 9.75 \\
\hline Somali & 39 & 13.67 & 6.1 & 3.387 & 1.40 & 52.283 & 42.80 & 146.03 & 12.59 \\
\hline \multicolumn{10}{|c|}{ Eastern Africa Niger-Congo } \\
\hline Baganda & 100 & 5.05 & 2.6 & 2.364 & 0.53 & 12.088 & 6.83 & 93.01 & 8.02 \\
\hline Banyarwanda & 100 & 4.27 & 2.3 & 2.276 & 0.58 & 9.842 & 6.14 & 88.65 & 8.71 \\
\hline Barundi & 97 & 4.10 & 1.8 & 2.413 & 1.24 & 9.879 & 6.58 & 86.60 & 8.43 \\
\hline Kikuyu & 99 & 3.91 & 1.8 & 2.525 & 1.32 & 9.757 & 5.57 & 85.98 & 6.54 \\
\hline LWK & 74 & 5.07 & 2.2 & 2.335 & 0.56 & 11.896 & 6.08 & 89.46 & 7.84 \\
\hline \multicolumn{10}{|c|}{ Eastern Africa Nilo-Saharan } \\
\hline Kalenjin & 100 & 4.28 & 2.1 & 2.532 & 0.77 & 11.379 & 7.87 & 95.27 & 9.11 \\
\hline \multicolumn{10}{|l|}{ Southern Africa } \\
\hline Herero & 12 & 13.33 & 5.4 & 3.186 & 0.44 & 43.247 & 19.63 & 77.40 & 16.07 \\
\hline Sotho & 86 & 6.70 & 2.9 & 2.470 & 0.53 & 16.748 & 8.84 & 84.83 & 7.92 \\
\hline \begin{tabular}{|l|} 
Zulu \\
\end{tabular} & 100 & 7.72 & 2.9 & 2.708 & 0.78 & 20.511 & 8.45 & 89.17 & 8.01 \\
\hline \multicolumn{10}{|c|}{ Africa Khoe and San } \\
\hline Ju/'hoansi & 18 & 15.11 & 5.0 & 3.363 & 0.75 & 53.003 & 26.47 & 109.66 & 15.13 \\
\hline !Xun & 19 & 13.63 & 5.9 & 4.078 & 1.32 & 58.856 & 38.66 & 75.59 & 12.70 \\
\hline Gui//Gana & 15 & 11.27 & 4.3 & 3.497 & 1.18 & 42.849 & 32.28 & 87.22 & 25.72 \\
\hline FKhomani & 39 & 6.77 & 4.8 & 2.957 & 1.04 & 22.217 & 22.63 & 84.08 & 18.92 \\
\hline Nama & 20 & 8.25 & 5.5 & 2.941 & 0.78 & 25.922 & 21.38 & 73.91 & 24.63 \\
\hline Khwe & 16 & 9.88 & 5.9 & 5.008 & 2.02 & 51.584 & 38.42 & 62.93 & 14.23 \\
\hline Karretjie & 20 & 5.15 & 3.4 & 2.388 & 0.84 & 12.985 & 11.17 & 91.92 & 19.21 \\
\hline Africa Colored & & & & & & & & & \\
\hline Wellington & 20 & 2.50 & 1.4 & 2.030 & 0.37 & 5.141 & 3.08 & 101.04 & 30.90 \\
\hline Colesberg & 20 & 2.67 & 1.6 & 2.159 & 0.55 & 6.001 & 4.67 & 69.75 & 21.75 \\
\hline Europe & & & & & & & & & \\
\hline CEU & 95 & 6.34 & 2.3 & 2.020 & 0.37 & 12.778 & 4.88 & 259.12 & 12.36 \\
\hline FIN & 97 & 10.53 & 3.9 & 2.390 & 0.38 & 25.489 & 10.78 & 267.43 & 12.27 \\
\hline GBR & 91 & 6.90 & 2.8 & 2.309 & 0.98 & 16.549 & 12.41 & 263.46 & 13.06 \\
\hline IBS & 99 & 6.80 & 3.3 & 2.514 & 1.20 & 18.089 & 14.96 & 253.15 & 14.65 \\
\hline TSI & 92 & 5.28 & 2.4 & 2.471 & 1.76 & 12.939 & 8.96 & 250.29 & 11.04 \\
\hline Southern Asia & & & & & & & & & \\
\hline $\mathrm{GIH}$ & 95 & 10.03 & 3.8 & 2.602 & 0.76 & 26.496 & 13.77 & 244.41 & 12.30 \\
\hline Eastern Asia & & & & & & & & & \\
\hline \begin{tabular}{|l|} 
CDX \\
\end{tabular} & 83 & 9.95 & 3.2 & 2.631 & 1.08 & 27.348 & 18.01 & 319.44 & 11.45 \\
\hline $\mathrm{CHB}$ & 98 & 7.17 & 2.5 & 1.986 & 0.49 & 14.372 & 6.92 & 316.12 & 10.07 \\
\hline $\mathrm{CHS}$ & 86 & 7.42 & 2.6 & 2.042 & 0.52 & 15.254 & 7.40 & 318.98 & 11.23 \\
\hline KHV & 96 & 8.07 & 2.9 & 2.051 & 0.55 & 17.095 & 10.39 & 313.42 & 11.04 \\
\hline \begin{tabular}{|l|} 
JPT \\
\end{tabular} & 96 & 8.25 & 3.0 & 2.061 & 0.66 & 17.505 & 13.76 & 326.15 & 11.05 \\
\hline South America & & & & & & & & & \\
\hline \begin{tabular}{|l|} 
PEL \\
\end{tabular} & 50 & 17.90 & 6.7 & 2.375 & 1.20 & 46.542 & 54.82 & 378.33 & 64.76 \\
\hline Mix. Hisp-Amer & & & & & & & & & \\
\hline CLM & 65 & 9.63 & 5.8 & 3.251 & 1.72 & 38.396 & 47.31 & 226.98 & 30.53 \\
\hline PUR & 72 & 7.31 & 3.4 & 3.077 & 1.42 & 24.091 & 22.11 & 206.55 & 21.58 \\
\hline MXL & 47 & 8.98 & 4.8 & 2.510 & 1.31 & 25.726 & 32.00 & 259.54 & 30.68 \\
\hline
\end{tabular}

$\mathrm{N}$ : number of individuals.

N ROH>1.5: Number of ROH > $1.5 \mathrm{Mb}$.

SD: Standard Deviation.

Three letter population abbreviation are provided in the text. 
bioRxiv preprint doi: https://doi.org/10.1101/470583; this version posted November 14, 2018. The copyright holder for this preprint (which was not certified by peer review) is the author/funder. All rights reserved. No reuse allowed without permission.

Table 2. Summary statistics for the inbreeding coefficient calculated from $\mathrm{ROH}\left(F_{\mathrm{ROH}}\right)$ across global regions and according to

\begin{tabular}{|c|c|c|c|c|c|c|}
\hline \multirow[t]{2}{*}{ Population } & \multicolumn{2}{|c|}{ Mean $\mathrm{F}_{\mathrm{ROH}}$} & \multirow[t]{2}{*}{ Max $F_{\text {ROH }}$} & \multirow[t]{2}{*}{ N2C } & \multirow[t]{2}{*}{$\% 2 \mathrm{C}$} & \multirow[t]{2}{*}{ N 1 C } \\
\hline & Mean & SD & & & & \\
\hline \multicolumn{7}{|l|}{ Western Africa } \\
\hline Wolof & 0.0094 & 0.014 & 0.0696 & 14 & 17.9 & 2 \\
\hline Fula & 0.0117 & 0.015 & 0.0612 & 22 & 29.7 & 0 \\
\hline Mandinka & 0.0052 & 0.007 & 0.0321 & 7 & 8.0 & 0 \\
\hline Jola & 0.0065 & 0.004 & 0.0287 & 6 & 7.6 & 0 \\
\hline \multicolumn{7}{|l|}{ Gulf of Guinea } \\
\hline \begin{tabular}{|l|} 
YRI \\
\end{tabular} & 0.0033 & 0.003 & 0.0157 & 1 & 1.0 & 0 \\
\hline Ga_Adangbe & 0.0041 & 0.004 & 0.0221 & 6 & 6.0 & 0 \\
\hline Igbo & 0.0050 & 0.004 & 0.0248 & 7 & 7.1 & 0 \\
\hline \multicolumn{7}{|l|}{ Mix. Afri-Amer } \\
\hline $\mathrm{ACB}$ & 0.0023 & 0.002 & 0.0154 & 1 & 1.4 & 0 \\
\hline ASW & 0.0019 & 0.001 & 0.0069 & 0 & 0.0 & 0 \\
\hline \multicolumn{7}{|l|}{ Horn of Africa } \\
\hline Amhara & 0.0026 & 0.001 & 0.0065 & 0 & 0.0 & 0 \\
\hline Oromo & 0.0034 & 0.003 & 0.0124 & 0 & 0.0 & 0 \\
\hline Somali & 0.0181 & 0.015 & 0.0597 & 19 & 48.7 & 0 \\
\hline \multicolumn{7}{|c|}{ Eastern Africa Niger-Congo } \\
\hline \begin{tabular}{|l|} 
Baganda \\
\end{tabular} & 0.0042 & 0.002 & 0.0122 & 0 & 0.0 & 0 \\
\hline Banyarwanda & 0.0034 & 0.002 & 0.0115 & 0 & 0.0 & 0 \\
\hline Barundi & 0.0034 & 0.002 & 0.0181 & 1 & 1.0 & 0 \\
\hline Kikuyu & 0.0034 & 0.002 & 0.0106 & 0 & 0.0 & 0 \\
\hline \begin{tabular}{|l|} 
LWK \\
\end{tabular} & 0.0041 & 0.002 & 0.0096 & 0 & 0.0 & 0 \\
\hline \multicolumn{7}{|c|}{ Eastern Africa Nilo-Saharan } \\
\hline Kalenjin & 0.0039 & 0.003 & 0.0189 & 1 & 1.0 & 0 \\
\hline \multicolumn{7}{|l|}{ Southern Africa } \\
\hline Herero & 0.0150 & 0.007 & 0.0239 & 6 & 50.0 & 0 \\
\hline Sotho & 0.0058 & 0.003 & 0.0214 & 2 & 2.3 & 0 \\
\hline \begin{tabular}{|l|} 
Zulu \\
\end{tabular} & 0.0071 & 0.003 & 0.0170 & 4 & 4.0 & 0 \\
\hline \multicolumn{7}{|c|}{ Africa Khoe and San } \\
\hline Ju/'hoansi & 0.0184 & 0.009 & 0.0384 & 7 & 38.9 & 0 \\
\hline !Xun & 0.0204 & 0.013 & 0.0543 & 14 & 73.7 & 0 \\
\hline Gui//Gana & 0.0151 & 0.011 & 0.0497 & 9 & 60.0 & 0 \\
\hline FKhomani & 0.0077 & 0.008 & 0.0314 & 6 & 15.4 & 0 \\
\hline Nama & 0.0090 & 0.007 & 0.0298 & 4 & 20.0 & 0 \\
\hline Khwe & 0.0179 & 0.013 & 0.0502 & 10 & 62.5 & 0 \\
\hline Karretjie & 0.0045 & 0.003 & 0.0384 & 7 & 38.9 & 0 \\
\hline \multicolumn{7}{|l|}{ Africa Colored } \\
\hline \begin{tabular}{|l|} 
Wellington \\
\end{tabular} & 0.0011 & 0.001 & 0.0040 & 0 & 0.0 & 0 \\
\hline \begin{tabular}{|l} 
Colesberg \\
\end{tabular} & 0.0021 & 0.002 & 0.0068 & 0 & 0.0 & 0 \\
\hline \multicolumn{7}{|l|}{ Europe } \\
\hline CEU & 0.0044 & 0.002 & 0.0079 & 0 & 0.0 & 0 \\
\hline FIN & 0.0088 & 0.004 & 0.0163 & 16 & 16.5 & 0 \\
\hline GBR & 0.0057 & 0.004 & 0.0326 & 5 & 5.5 & 0 \\
\hline IBS & 0.0063 & 0.005 & 0.0298 & 9 & 9.1 & 0 \\
\hline \begin{tabular}{|l|} 
TSI \\
\end{tabular} & 0.0045 & 0.003 & 0.0153 & 4 & 4.3 & 0 \\
\hline Southern Asia & & & & & & \\
\hline GIH & 0.0092 & 0.005 & 0.0331 & 13 & 13.7 & 0 \\
\hline Eastern Asia & & & & & & \\
\hline CDX & 0.0095 & 0.006 & 0.0396 & 17 & 20.5 & 0 \\
\hline $\mathrm{CHB}$ & 0.0050 & 0.002 & 0.0161 & 2 & 2.0 & 0 \\
\hline $\mathrm{CHS}$ & 0.0053 & 0.003 & 0.0199 & 2 & 2.3 & 0 \\
\hline $\mathrm{KHV}$ & 0.0059 & 0.004 & 0.0289 & 4 & 4.2 & 0 \\
\hline \begin{tabular}{|l} 
JPT \\
\end{tabular} & 0.0061 & 0.005 & 0.0481 & 1 & 1.0 & 0 \\
\hline South America & & & & & & \\
\hline \begin{tabular}{|l|} 
PEL \\
\end{tabular} & 0.0162 & 0.019 & 0.1400 & 28 & 56.0 & 1 \\
\hline Mix. Hisp-Amer & & & & & & \\
\hline CLM & 0.0133 & 0.016 & 0.0756 & 18 & 27.7 & 3 \\
\hline
\end{tabular}




\begin{tabular}{|l|r|r|r|r|r|r|}
\hline PUR & 0.0084 & 0.008 & 0.0573 & 14 & 19.4 & 4470 \\
\hline MXL & 0.0089 & 0.011 & 0.0689 & 7 & 14.9 & 1 \\
\hline
\end{tabular}

N 2 C: Number of individuals with a $\mathrm{F}_{\mathrm{ROH}}$ higher than a second cousin union.

\% 2 C: Percentage of individuals in the population with an $\mathrm{F}_{\mathrm{ROH}}$ higher than a second cousin union.

N 1 C: Number of individuals with a $F_{R O H}$ higher than a first cousin union.

Three letter population abbreviation are provided in the text.

Table 2 shows the mean $\mathrm{F}_{\mathrm{ROH}}$, the max $\mathrm{F}_{\mathrm{ROH}}$, the number and proportion (in \%) of individuals with an $\mathrm{F}_{\mathrm{ROH}}$

San, !Xun and Ju/'hoansi people with an average $\mathrm{F}_{\mathrm{ROH}}$ of 0.0204 and 0.0184 respectively showing them to

$\mathrm{ROH}$ (longer than $1.5 \mathrm{Mb}$ ) and the total sum of $\mathrm{ROH}>1.5 \mathrm{Mb}$ for each SSA individual, and shows in red dashed lines conservative limits for second and first cousin inbreeding coefficient. In this figure it can be seen that, regarding $\mathrm{F}_{\mathrm{ROH}}$, populations across SSA have a wide range of inbreeding coefficient. In Western Africa (Figure 5A) Wolof and Fula individuals are more dispersed across the plot, with $17.9 \%$ of Wolof and 
$47162.5 \%$ and $60.0 \%$ individuals of the !Xun, Khwe and Gui//Gana respectively have an $\mathrm{F}_{\mathrm{ROH}}$ higher than a

472 second cousin union. These populations therefore have a large proportion of inbred individuals, even

473 more than the partially indigenous PEL population (56\%); however due to the small population sample

474 sizes these numbers should be viewed with caution. At the opposite end of the spectrum, Colored

475 populations have a tight distribution with very low $\mathrm{F}_{\mathrm{ROH}}$.
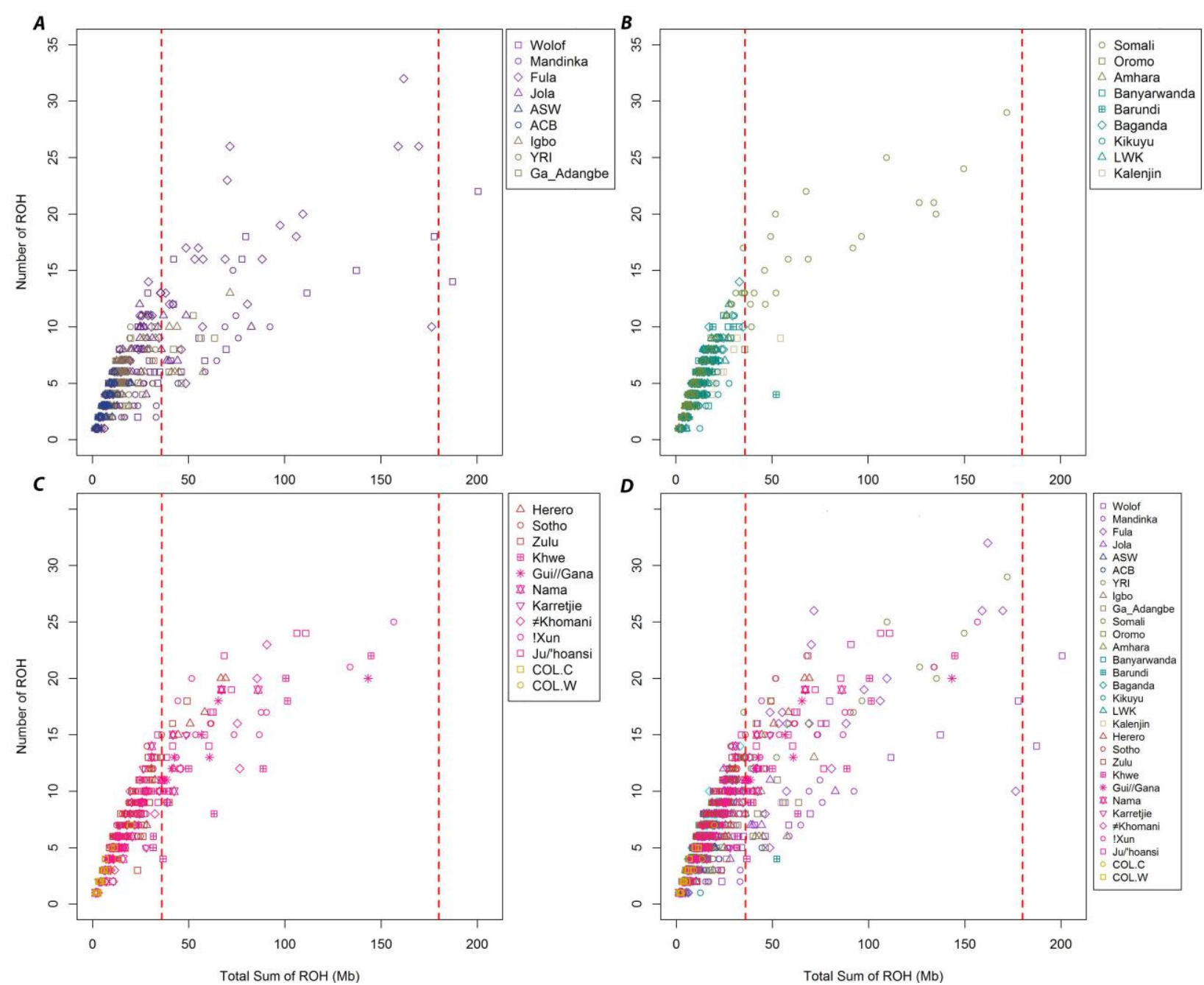

Figure 5. Each Sub-Sharan African individual is plotted according to their number of ROH and total sum of ROH. The perpendicular broken red lines in all the plots at $X=36$ and $X=180$, represent conservative thresholds for inbreeding coefficients of 0.0156 (second cousin offspring) and 0.0625 (first cousin offspring). A. Individuals from Western Africa and the Gulf of Guinea. B. Populations from Eastern Africa and the Horn of Africa. C. Populations from Southern Africa. D. All populations together. For color legend see figure 1 (as above) 
bioRxiv preprint doi: https://doi.org/10.1101/470583; this version posted November 14, 2018. The copyright holder for this preprint (which was not certified by peer review) is the author/funder. All rights reserved. No reuse allowed without permission.
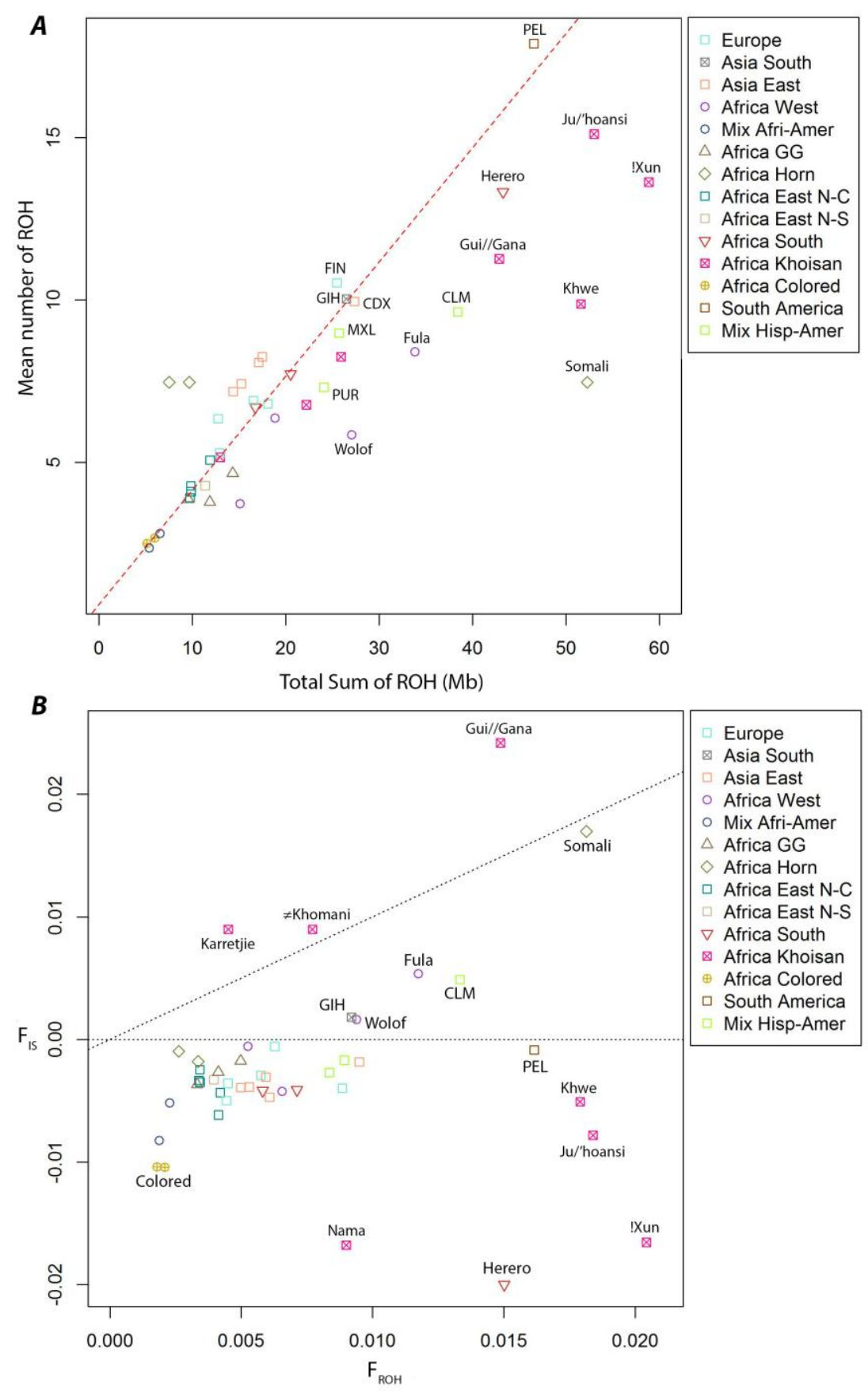

Figure 6. Population analysis and components of inbreeding coefficient. A. Mean number of ROH plotted versus mean total sum of $\mathrm{ROH}$ in $\mathrm{Mb}$ for the 28 populations under study (symbols according to regional groupings). Red broke line represents the regression line of the two variables ( $\mathrm{N}$ of $\mathrm{ROH}$ vs Sum of $\mathrm{ROH}$ ) for the South African Colored population (see Methods section) $B$. Systematic inbreeding coefficient $\left(F_{I S}\right)$ versus the inbreeding coefficient obtained from $R O H\left(F_{R O H}\right)$. Diagonal broken line represents $F_{I S}=F_{\text {ROH. }}$. Horizontal broken line represents $F_{I S}=0$. 


\section{history}

494 Like the inbreeding coefficient calculated from a deep pedigree, $F_{\mathrm{ROH}}$ denotes the total inbreeding coefficient, but it does not give information regarding how that autozygosity was generated. Was it the result of cultural practices favoring related unions, or because of a low effective population size and genetic drift? by population. The diagonal (red dashed line) was obtained by regressing both variables of the Colored population as a non-consanguineous control group. Populations falling near this diagonal line, including to medium $\mathrm{ROH}$ sizes, but longer than $1.5 \mathrm{Mb}$. Under this scenario, autozygosity provoked by genetic drift will generate a large number of $\mathrm{ROH}$, but short in size. On the other hand, recent inbreeding loops will produce small numbers of very long $\mathrm{ROH}$ which will influence the sum of $\mathrm{ROH}$ much more than the total number of ROH. Populations like Somali, Khwe, !Xun and to a lesser degree Fula, Wolof or CLM, which display a right shift away from the trend line in the $\mathrm{X}$-axis, suggest the practice of consanguineous unions.

509 figure the $F_{I S}$ in plotted against the $F_{R O H}$ for different populations. Three different regions can be considered in this plot delimited by the diagonal, where $\mathrm{F}_{\mathrm{IS}}=\mathrm{F}_{\mathrm{ROH}}$, and the horizontal line $\mathrm{F}_{\mathrm{IS}}=0$. Populations

511 close to the diagonal line, like the Somali, have a strong component of systematic inbreeding or $F_{I S}$, which

512 means that the total inbreeding coefficient, $\mathrm{F}_{\mathrm{IT}}$, of this population is mainly produced by a deviation from

513 panmixia, in other words, consanguinity. Panmictic inbreeding, caused by genetic drift will be more 514 relevant as the population gets close to the line $F_{1 s}=0$. Low $N_{e}$, isolation and genetic drift become very 515 relevant when populations have negative $F_{\text {IS. }}$ Under this scenario of avoidance of consanguinity and excess 
517 PEL, Khwe, Ju/'hoansi, !Xun or Herero will be provoked by genetic isolation and genetic drift: strong FsT.

518

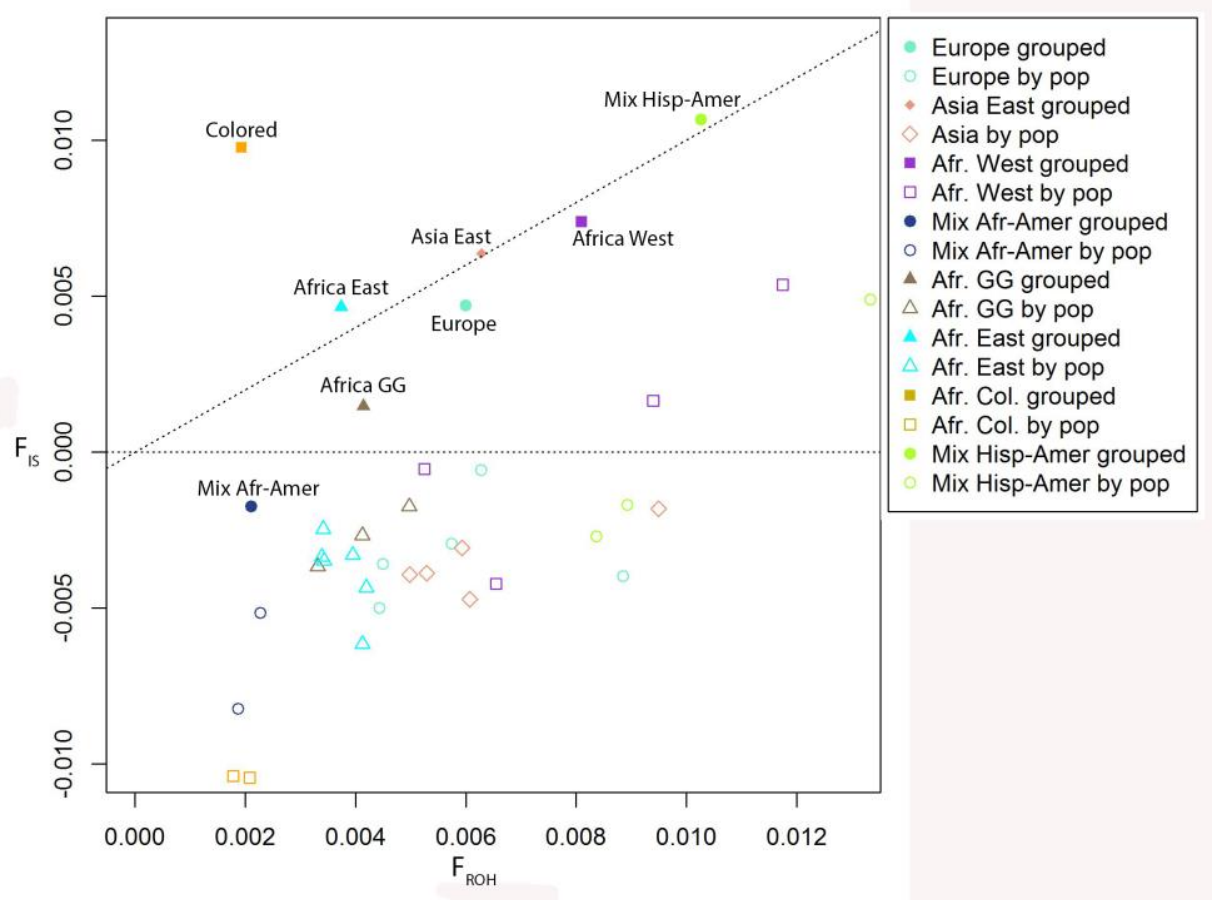

Figure 7. Representation of the Wahlund effect. $F_{I S}$ and $F_{R O H}$ values for the South African Colored population, Easter Africans, Wester Africans, Gulf of Guinea populations, mixed African-Americans, Europeans, Eastern Asia and mixed Hispanic-Americans were plotted (empty shapes). Mean $F_{I S}$ and mean $F_{R O H}$ per regional group are plotted and shown as solid shapes.

\section{Detecting the Wahlund effect}

As explained above, Figure $6 \mathrm{~B}$ has three regions: $\mathrm{F}_{\mathrm{IS}}<0, \mathrm{~F}_{\mathrm{IS}}=\mathrm{F}_{\mathrm{ROH}}$ and $\mathrm{F}_{\mathrm{IS}}>\mathrm{F}_{\mathrm{ROH}}$. Under an inbreeding context, and according to Wright F statistic, it does not make much sense for $F_{\text {IS }}$ to be bigger than FiT. So, if a population presents with a larger $\mathrm{F}_{\text {IS }}$ other phenomena must be taken into account. Besides inbreeding, natural selection pressure and Wahlund effect can increase $F_{15}$; nevertheless, natural selection is an evolutionary force that can change $F_{\text {Is }}$ locally in specific genome regions, but never at a whole genome level. The only explanation is the Wahlund effect: a deficiency of heterozygotes and excess of homozygotes provoked when subpopulations with different allele frequencies are lumped together ${ }^{48}$. This effect is shown in Figure 7. In this figure $F_{I S}$ and $F_{R O H}$ were obtained for each population and grouped by region. A perfect example is the Colored populations: when both populations are considered separately 
532 their $F_{\text {IS }}$ is negative $\left(-0.01\right.$ for both of them) but when combined the resulting $F_{\text {IS }}$ is positive $(+0.01)$. This

533 phenomenon can be seen for the other populations and regional groups in Figure 7. When combined in

534 their respective regional groups the resultant $\mathrm{F}_{\mathrm{ROH}}$ is equal to the average of all the populations; however,

535 the $F_{I S}$ increases depending on the allele proportion differences between populations of a same regional

536 group. According to this explanation, the Karretjie, $\neq$ Khonami and Gui//Gana populations in Figure 6B may

537 indeed be the mixture of at least two different subpopulations with different alleles frequencies.

\section{Genomic distribution of Runs of Homozygosity}

$539 \mathrm{ROH}$ are not randomly distributed across the genome and there are regions with a high prevalence of $\mathrm{ROH}$

540 or complete absence ${ }^{7 ;} 19 ; 20 . \mathrm{ROH}$ islands, genomic regions with high prevalence of $\mathrm{ROH}$, or regions of

541 heterozygosity (RHZ) are analyzed by collapsing populations into their regional groups: from SSA: West,

542 Gulf of Guinea, East, Horn of Africa, Southern Bantu and Khoe-San. From out of SSA: Europe, Eastern Asia,

543 Hispanic-American admixed and African-American admixed. In Figure 8, ROHi and RHZ are represented

544 for the 22 autosomal chromosomes of the Khoe and San and European groups.

545 Within SSA, the region of the Horn of Africa has the shortest (measured in $\mathrm{Mb}$ and $\mathrm{cM}$ ) but a larger number

546 of ROHi (544) (Table 3). The Khoe and San is the group with the smallest number of ROHi, less than half

547 (220) are of an average size. Eastern Africa has the longest ROHi measured in Mb, when measured in cM

548 there are no big differences across SSA. Outside SSA, the Europeans form a group with the highest number

549 of ROHi (795), 3.6 times more than the Khoe and San. Also, Europe is the group with the lager ROHi,

550 measured in $\mathrm{Mb}$ and $\mathrm{cM}$, with $90 \mathrm{ROHi}$ larger than $1 \mathrm{Mb}$. Interestingly the African-American admixed

551 group has almost no ROH longer than $1.5 \mathrm{Mb}$, but is the group with the second highest number of ROHi.

552 Surprisingly this group has longer ROHi with a mean size of $0.615 \mathrm{Mb}$ or $0.25 \mathrm{cM}$, higher than most groups.

553 Being the regional group from SSA with the largest number of $\mathrm{ROHi}$, it seems reasonable that the Horn of

554 Africa is the group with the least number of regions of heterozygosity, defined as regions with $\leq 5 \%$

555 homozygosity (RHZ 5\%). Surprisingly, this is not the case for RHZ where no individual is in homozygosity 
bioRxiv preprint doi: https://doi.org/10.1101/470583; this version posted November 14, 2018. The copyright holder for this preprint (which was not certified by peer review) is the author/funder. All rights reserved. No reuse allowed without permission.
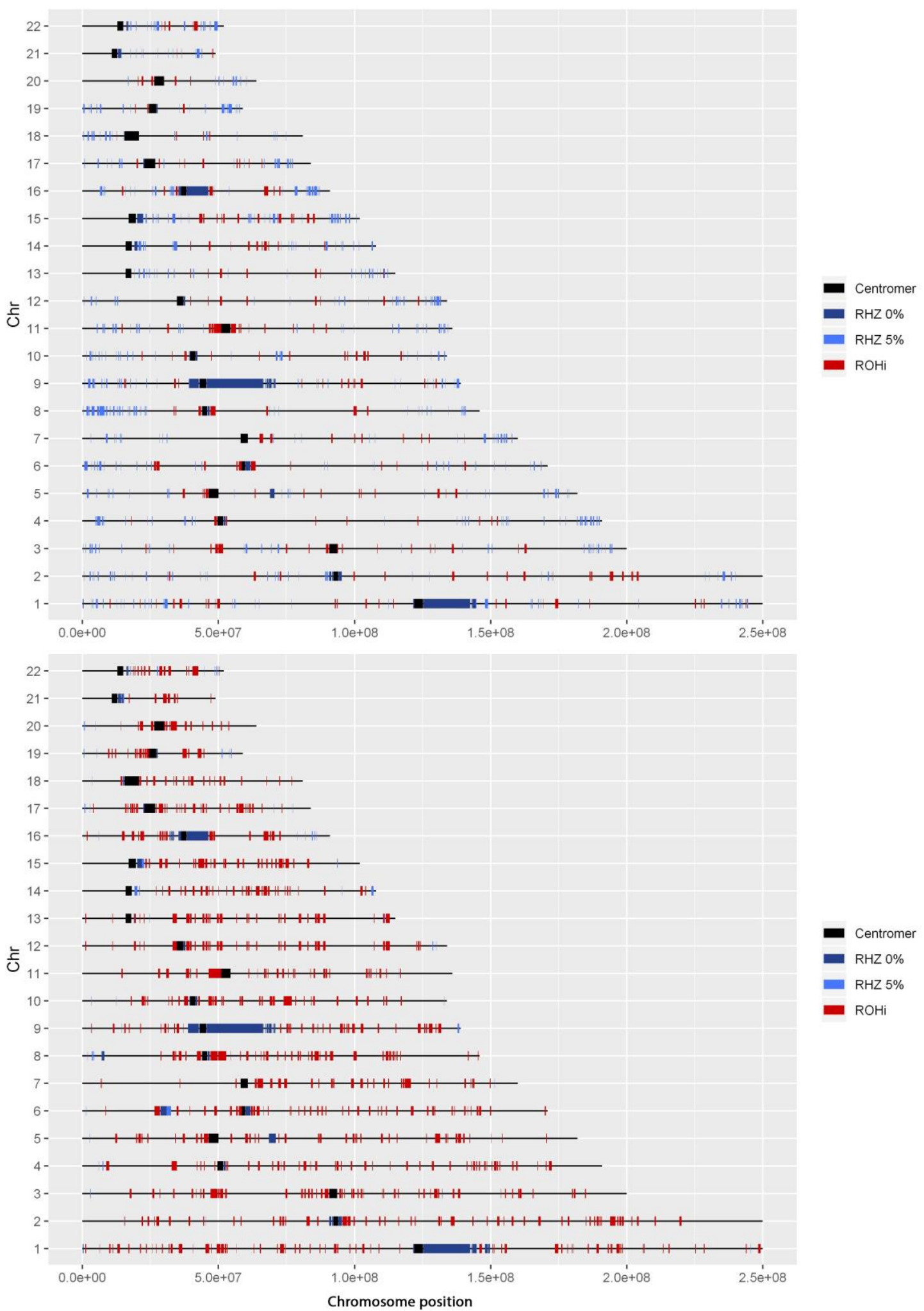

Figure 8. Genomic representation of the chromosomal location and size of runs of homozygosity islands (ROHi) and runs of heterozygosity ( $R H Z$ ) for the Khoe and San $(A)$ and European (B) regional groups. $R H Z$ O\%: genomic regions where no individual in the group has a ROH. RHZ 5\%: genomic regions where $\leq 5 \%$ of the population has $\mathrm{ROH}$. 
Table 3. Summary statistics for the $\mathrm{ROH}$ islands (ROHi) and the regions of heterozygosity (RHZ) for populations combined from

561 different geographic regions.

\begin{tabular}{|c|c|c|c|c|c|c|c|c|c|c|c|c|c|}
\hline \multirow[t]{3}{*}{ Population } & \multirow[t]{3}{*}{$\mathbf{N}$} & \multicolumn{4}{|c|}{ Number by size } & \multirow{2}{*}{\multicolumn{2}{|c|}{$\begin{array}{c}\text { Mean length } \\
\text { (Mb) }\end{array}$}} & \multirow{2}{*}{\multicolumn{2}{|c|}{$\begin{array}{c}\text { Mean length } \\
\text { (cM) }\end{array}$}} & \multicolumn{2}{|c|}{ Max length } & \multirow{2}{*}{\multicolumn{2}{|c|}{$\begin{array}{c}\text { Mean Number } \\
\text { of SNP }\end{array}$}} \\
\hline & & \multirow{2}{*}{$\begin{array}{c}>1.0 \\
\mathrm{Mb}\end{array}$} & \multirow{2}{*}{$\begin{array}{c}1.0- \\
0.5\end{array}$} & \multirow{2}{*}{$\begin{array}{c}0.5- \\
0.3\end{array}$} & \multirow{2}{*}{$\begin{array}{l}<0.3 \\
\mathrm{Mb}\end{array}$} & & & & & \multirow[t]{2}{*}{$\mathbf{M b}$} & \multirow[t]{2}{*}{$\mathbf{c M}$} & & \\
\hline & & & & & & Mean & SD & Mean & SD & & & Mean & SD \\
\hline \multicolumn{14}{|l|}{ Africa West } \\
\hline $\mathrm{ROHi}$ & 383 & 35 & 128 & 126 & 94 & 0.599 & 0.37 & 0.187 & 0.34 & 4.2 & 3.24 & 181.7 & 110.4 \\
\hline RHZ 0\% & 48 & 14 & 12 & 4 & 18 & 0.663 & 0.62 & 1.245 & 3.32 & 2.4 & 11.74 & 227.8 & 258.5 \\
\hline RHZ 5\% & 926 & 21 & 81 & 181 & 643 & 0.235 & 0.25 & 0.421 & 0.91 & 4.0 & 13.81 & 98.7 & 105.5 \\
\hline \multicolumn{14}{|l|}{ Africa GG } \\
\hline $\mathrm{ROHi}$ & 370 & 40 & 117 & 138 & 75 & 0.614 & 0.41 & 0.204 & 0.40 & 4.2 & 3.77 & 184.0 & 122.5 \\
\hline RHZ 0\% & 57 & 11 & 12 & 14 & 20 & 0.691 & 0.73 & 0.742 & 1.88 & 3.6 & 7.16 & 286.8 & 301.1 \\
\hline RHZ 5\% & 1295 & 21 & 130 & 258 & 886 & 0.259 & 0.31 & 0.467 & 0.95 & 4.1 & 13.81 & 107.3 & 126.1 \\
\hline \multicolumn{14}{|l|}{ Africa Horn } \\
\hline $\mathrm{ROHi}$ & 544 & 18 & 74 & 126 & 326 & 0.374 & 0.24 & 0.106 & 0.26 & 1.6 & 3.230 & 114.4 & 75.3 \\
\hline RHZ 0\% & 70 & 14 & 13 & 12 & 20 & 0.492 & 0.597 & 0.511 & 1.99 & 2.6 & 11.74 & 205.1 & 248.7 \\
\hline RHZ 5\% & 751 & 17 & 53 & 143 & 538 & 0.222 & 0.250 & 0.357 & 0.87 & 4 & 13.81 & 92.4 & 104.3 \\
\hline \multicolumn{14}{|l|}{ Africa East } \\
\hline $\mathrm{ROHi}$ & 371 & 47 & 134 & 134 & 56 & 0.647 & 0.37 & 0.209 & 0.39 & 3.3 & 3.779 & 210.0 & 120.5 \\
\hline RHZ 0\% & 57 & 11 & 13 & 15 & 18 & 0.731 & 0.740 & 0.885 & 2.01 & 3.6 & 7.16 & 298.8 & 300.5 \\
\hline RHZ 5\% & 1596 & 37 & 169 & 339 & 1051 & 0.279 & 0.336 & 0.526 & 1.12 & 4.0 & 14.24 & 114.2 & 137.4 \\
\hline \multicolumn{14}{|l|}{ Africa South } \\
\hline $\mathrm{ROHi}$ & 294 & 22 & 94 & 110 & 68 & 0.581 & 0.36 & 0.168 & 0.35 & 3.4 & 3.244 & 213.5 & 130.3 \\
\hline RHZ 0\% & 53 & 12 & 12 & 13 & 16 & 0.532 & 0.551 & 0.762 & 2.67 & 2.3 & 11.74 & 214.9 & 222.5 \\
\hline RHZ 5\% & 1300 & 32 & 152 & 342 & 774 & 0.261 & 0.261 & 0.467 & 0.95 & 2.6 & 13.81 & 105.5 & 105.3 \\
\hline \multicolumn{14}{|c|}{ Africa Khoe and San } \\
\hline $\mathrm{ROHi}$ & 220 & 19 & 61 & 79 & 61 & 0.565 & 0.37 & 0.099 & 0.19 & 3.3 & 2.622 & 210.6 & 137.1 \\
\hline RHZ 0\% & 49 & 9 & 12 & 10 & 18 & 0.650 & 0.69 & 1.105 & 3.22 & 3.6 & 11.30 & 262.3 & 281.6 \\
\hline RHZ 5\% & 1253 & 24 & 99 & 216 & 914 & 0.237 & 0.26 & 0.387 & 0.83 & 3.7 & 11.74 & 96.0 & 103.9 \\
\hline \multicolumn{14}{|l|}{ Mix. Af-Amer } \\
\hline $\mathrm{ROHi}$ & 689 & 72 & 221 & 252 & 144 & 0.615 & 0.41 & 0.251 & 0.34 & 5.1 & 4.233 & 146.1 & 98.6 \\
\hline RHZ 0\% & 194 & 11 & 14 & 25 & 144 & 0.294 & 0.48 & 0.270 & 1.22 & 3.6 & 13.81 & 120.9 & 196.1 \\
\hline RHZ 5\% & 1859 & 39 & 217 & 404 & 1199 & 0.284 & 0.33 & 0.511 & 1.04 & 4.6 & 14.71 & 116.5 & 134.0 \\
\hline \multicolumn{14}{|l|}{ Europe } \\
\hline $\mathrm{ROHi}$ & 795 & 90 & 211 & 286 & 208 & 0.604 & 0.43 & 0.254 & 0.36 & 5.3 & 4.232 & 122.9 & 88.4 \\
\hline RHZ 0\% & 58 & 11 & 16 & 14 & 17 & 0.739 & 0.76 & 0.902 & 1.81 & 4.0 & 7.81 & 312.8 & 322.1 \\
\hline RHZ 5\% & 218 & 12 & 21 & 33 & 152 & 0.325 & 0.54 & 0.412 & 1.22 & 4.1 & 13.81 & 137.8 & 227.2 \\
\hline Asia. East & & & & & & & & & & & & & \\
\hline $\mathrm{ROHi}$ & 459 & 26 & 85 & 139 & 209 & 0.466 & 0.34 & 0.128 & 0.31 & 4.1 & 3.498 & 118.8 & 87.6 \\
\hline RHZ 0\% & 57 & 11 & 15 & 14 & 17 & 0.751 & 0.78 & 1.229 & 3.07 & 4 & 11.74 & 313.5 & 328.9 \\
\hline RHZ 5\% & 195 & 14 & 16 & 33 & 132 & 0.373 & 0.62 & 0.388 & 1.13 & 4.1 & 11.75 & 155.9 & 261.1 \\
\hline Mix. Hisp-Amer & & & & & & & & & & & & & \\
\hline $\mathrm{ROHi}$ & 645 & 56 & 171 & 205 & 213 & 0.561 & 0.40 & 0.202 & 0.34 & 5.3 & 4.232 & 144.9 & 104.6 \\
\hline RHZ 0\% & 59 & 11 & 16 & 14 & 18 & 0.726 & 0.76 & 0.846 & 1.77 & 4 & 7.16 & 302.4 & 316 \\
\hline RHZ 5\% & 273 & 12 & 22 & 48 & 191 & 0.304 & 0.49 & 0.403 & 1.10 & 4.1 & 13.81 & 126.6 & 203 \\
\hline
\end{tabular}


Table 4. Location, length, percentage of individuals with $\mathrm{ROH}$ for the ROH island and protein coding genes of the five most prevalent $\mathrm{ROH}$ islands in the Sub-Saharan African regional groups.

\begin{tabular}{|c|c|c|c|c|c|c|}
\hline & Chr. & Pos 1 & Pos 2 & $\begin{array}{l}\text { Length } \\
\text { (Mb) }\end{array}$ & $\%$ Indv & Protein coding genes \\
\hline \multicolumn{7}{|l|}{ Africa W. } \\
\hline & 7 & $649 \mathrm{E}+05$ & $664 \mathrm{E}+05$ & 1.6 & 32.97 & $\begin{array}{l}\text { ZNF, ASL, CRCP, ERV3-1, GUSB, TPST1, } \\
\text { VKORC1L1 }\end{array}$ \\
\hline & 17 & $454 \mathrm{E}+05$ & $458 \mathrm{E}+05$ & 0.5 & 31.16 & ARHGAP27, CRHR1, PLEKHM1 \\
\hline & 9 & $951 \mathrm{E}+05$ & $956 \mathrm{E}+05$ & 0.6 & 28.58 & FANCC, PTCH1 \\
\hline & 1 & $1140 \mathrm{E}+05$ & $1144 \mathrm{E}+05$ & 0.5 & 26.39 & OLFML3, SYT6, TRIM33 \\
\hline & 4 & $1070 \mathrm{E}+05$ & $1073 \mathrm{E}+05$ & 0.4 & 21.93 & $D K K 2$ \\
\hline \multicolumn{7}{|l|}{ Africa GG. } \\
\hline & 9 & $951 E+05$ & $956 \mathrm{E}+05$ & 0.6 & 29.26 & FANCC,, PTCH1 \\
\hline & 7 & $644 \mathrm{E}+05$ & $664 \mathrm{E}+05$ & 2.1 & 27.58 & ZNF680 \\
\hline & 11 & $100 \mathrm{E}+05$ & $103 E+05$ & 0.4 & 26.92 & SBF2 \\
\hline & 16 & $146 \mathrm{E}+05$ & $155 E+05$ & 1 & 26.62 & $\begin{array}{l}\text { PARN, BFAR, NPIPA, NTAN, PDXDC1, } \\
\text { NOMO1, MPV17L, PLA2G10, RRN3 }\end{array}$ \\
\hline & 17 & $455 \mathrm{E}+05$ & $458 \mathrm{E}+05$ & 0.4 & 26.51 & CRHR1 \\
\hline \multicolumn{7}{|l|}{ Africa $E$. } \\
\hline & 16 & $183 \mathrm{E}+05$ & $189 \mathrm{E}+05$ & 0.7 & 28.27 & NPIPA8, NOMO2, RPS15A, SMG1, ARL6IP1 \\
\hline & 7 & $644 \mathrm{E}+05$ & $664 \mathrm{E}+05$ & 2.1 & 24.62 & ZNF680 \\
\hline & 14 & $668 \mathrm{E}+05$ & $678 \mathrm{E}+05$ & 1.1 & 22.22 & $\begin{array}{l}\text { GPHN, ATP6V1D, EIF2S1, MPP5, PIGH, } \\
\text { PLEK, RDH, TMEM229B, VTI1B, ARG2 }\end{array}$ \\
\hline & 1 & $1140 \mathrm{E}+05$ & $1144 \mathrm{E}+05$ & 0.5 & 22.04 & OLFML3, SYT6, TRIM33 \\
\hline & 4 & $1070 \mathrm{E}+05$ & $1073 \mathrm{E}+05$ & 0.4 & 21.93 & $D K K 2$ \\
\hline \multicolumn{7}{|l|}{ Africa H. } \\
\hline & 2 & $1359 \mathrm{E}+05$ & $1367 \mathrm{E}+05$ & 0.9 & 36.24 & DARS, CXCR4 \\
\hline & 8 & $676 \mathrm{E}+05$ & $683 \mathrm{E}+05$ & 0.8 & 35.63 & CPA6, PREX2 \\
\hline & 1 & $525 \mathrm{E}+05$ & $530 \mathrm{E}+05$ & 0.6 & 33.96 & $\begin{array}{l}\text { ZCCHC11, COA7, ECHDC2, GPX7, SCP2, } \\
\text { SHISAL2A, } \underline{\mathrm{ZYG}}\end{array}$ \\
\hline & 11 & $669 E+05$ & $674 \mathrm{E}+05$ & 0.6 & 33.33 & $\begin{array}{l}\frac{P C}{P O L}, \frac{A N K R D 13 D}{P}, \frac{C L C F 1}{R}, G R K 2, \frac{K D M 2 A}{,} \\
\text { SYT12 }\end{array}$ \\
\hline & 7 & $651 \mathrm{E}+05$ & $660 \mathrm{E}+05$ & 0.9 & 32.11 & $\begin{array}{l}\text { ZNF680, ASL, CRCP, GUSB, TPST1, } \\
\text { VKORC1L1, ZNF92 }\end{array}$ \\
\hline \multicolumn{7}{|l|}{ Africa $S}$. \\
\hline & 7 & $650 \mathrm{E}+05$ & $664 \mathrm{E}+05$ & 1.5 & 26.46 & $\begin{array}{l}\text { ZNF680, ASL, CRCP, GUSB, TPST1, } \\
\text { VKORC1L1, ZNF92 }\end{array}$ \\
\hline & 17 & $454 \mathrm{E}+05$ & $458 \mathrm{E}+05$ & 0.5 & 22.10 & ARHGAP27, CRHR1, PLEKHM1 \\
\hline & 13 & $577 E+05$ & $582 \mathrm{E}+05$ & 0.6 & 21.46 & PCDH17 \\
\hline & 3 & $507 E+05$ & $518 \mathrm{E}+05$ & 1.2 & 20.66 & $\begin{array}{l}\text { DOCK3 }, \text { MANF, RBM15B, DCAF1, DOCK3, } \\
\text { GRM2, IQCF6, RAD54L2, TEX264 }\end{array}$ \\
\hline & 15 & $444 \mathrm{E}+05$ & $449 E+05$ & 0.6 & 20.12 & $\begin{array}{l}\text { CASC4, B2M, CTDSPL2, EIF3J, PATL2, } \\
\text { SPG11, TRIM69 }\end{array}$ \\
\hline \multicolumn{7}{|l|}{ Africa KS. } \\
\hline & 3 & $750 \mathrm{E}+05$ & $753 \mathrm{E}+05$ & 0.4 & 28.04 & \\
\hline & 2 & $1983 E+05$ & $1989 E+05$ & 0.7 & 26.06 & PLCL1 \\
\hline & 4 & $528 \mathrm{E}+05$ & $531 \mathrm{E}+05$ & 0.4 & 22.64 & $R A S L 11 B, \underline{S C F D 2}$ \\
\hline & 5 & $1371 \mathrm{E}+05$ & $1378 \mathrm{E}+05$ & 0.8 & 22.64 & SPOCK1, HNRNPAO, KLHL3 \\
\hline & 12 & $604 \mathrm{E}+05$ & $608 \mathrm{E}+05$ & 0.5 & 21.89 & \\
\hline
\end{tabular}

Chr: Chromosome.

Pos 1: Position where the ROHi starts.

Pos 2: Position where the ROHi finish.

\%Ind: Percentage of individuals in the population that share the ROHi. 
571 Table 5. Location, length, percentage of individuals with ROH for the ROH island and protein coding genes of the five most 572 prevalence $\mathrm{ROH}$ islands in the non-African regional groups.

\begin{tabular}{|c|c|c|c|c|c|c|}
\hline & Chr & Pos 1 & Pos 2 & $\begin{array}{l}\text { Length } \\
\text { (Mb) }\end{array}$ & $\%$ Indv & Protein coding genes \\
\hline \multicolumn{7}{|l|}{ Mix A.A. } \\
\hline & 7 & $649 \mathrm{E}+05$ & $664 \mathrm{E}+05$ & 1.6 & 33.83 & $\begin{array}{l}\text { ZNF, ASL, CRCP, ERV3-1, GUSB, } \\
\text { TPST1, VKORC1L1, }\end{array}$ \\
\hline & 17 & $455 E+05$ & $458 \mathrm{E}+05$ & 0.4 & 30.58 & CRHR1 \\
\hline & 19 & $215 E+05$ & $217 \mathrm{E}+05$ & 0.3 & 27.55 & ZNF429 \\
\hline & 9 & $951 \mathrm{E}+05$ & $957 \mathrm{E}+05$ & 0.7 & 26.92 & FANCC, PTCH1, \\
\hline & 1 & $1141 \mathrm{E}+05$ & $1144 \mathrm{E}+05$ & 0.4 & 26.24 & TRIM33, SYT6 \\
\hline \multicolumn{7}{|l|}{ Europe } \\
\hline & 1 & $355 \mathrm{E}+05$ & $367 \mathrm{E}+05$ & 1.3 & 56.25 & $\begin{array}{l}\text { KIAA0319L, CLSPN, COL8A2, CSF3R, } \\
\text { EVA1B, LSM10, MAP7D1, MRPS15, } \\
\text { NCDN, OSCP1, PSMB2, SH3D21, } \\
\text { STK40, TEKT2, TFAPEE, THRAP3, } \\
\text { TRAPPC3 }\end{array}$ \\
\hline & 2 & $746 \mathrm{E}+05$ & $749 E+05$ & 0.4 & 56.07 & M1AP, HK2, SEMA4F \\
\hline & 15 & $283 E+05$ & $294 E+05$ & 1.2 & 51.44 & $\begin{array}{l}\text { HERC2, APBA2, FAM189A1, GOLGA, } \\
M S M C E 3\end{array}$ \\
\hline & 3 & $1107 \mathrm{E}+05$ & $1109 E+05$ & 0.3 & 50.98 & \\
\hline & 2 & $725 E+05$ & $731 E+05$ & 0.7 & 49.82 & $\underline{E X O C 6 B}, \underline{E P R}, \underline{\underline{S P R}}, R A B 11 F I P 5, \underline{S F X N 5}$ \\
\hline \multicolumn{7}{|r|}{ ב } \\
\hline & 17 & $611 \mathrm{E}+05$ & $615 \mathrm{E}+05$ & 0.5 & 70.50 & BCAS3, TBX2, TBX4 \\
\hline & 2 & $1089 E+05$ & $1096 \mathrm{E}+05$ & 0.8 & 61.66 & EDAR, SH3RF3, SEPT10 \\
\hline & 3 & $443 E+05$ & $451 E+05$ & 0.9 & 58.70 & $\begin{array}{l}\text { TOPAZ1, TCAIM, CDCP1, CLEC3B, } \\
\text { EXOSC7, KIAA1143, KIF15, TGM4 } \\
\text { TMEM42, ZDHHC3, ZKSCAN7, ZNF }\end{array}$ \\
\hline & 15 & $305 E+05$ & $314 \mathrm{E}+05$ & 1 & 56.25 & $\begin{array}{l}\text { GOLGA8Q, GOLGA8H, FAN1, } \\
\text { ARHGAP11B, KLF13, MTMR10, } \\
\text { TRPM1 }\end{array}$ \\
\hline & 5 & $1082 E+05$ & $1085 E+05$ & 0.4 & 55.23 & $F B X L 17$ \\
\hline \multicolumn{7}{|l|}{ Mix H.A. } \\
\hline & 17 & $577 E+05$ & $593 E+05$ & 1.7 & 46.80 & $\begin{array}{l}\text { CCDC182, MRPS32, CUEDC1, } \\
\text { DYNLL2, EPX, GDPD1, HSF5, LPO, } \\
\text { MKS1, MPO, MRPS23, MTMR4, } \\
\text { OR4D, PPM1E, PRR11, RAD51C, } \\
\text { RNF43, SKA2, SMG8, SUPT4H1, } \\
\text { TEX14, TRIM37, TSPOAP1, VEZF1 }\end{array}$ \\
\hline & 4 & $420 \mathrm{E}+05$ & $421 \mathrm{E}+05$ & 0.2 & 45.92 & $\underline{\text { SLC3OA9 }}$ \\
\hline & 3 & $1107 \mathrm{E}+05$ & $1109 \mathrm{E}+05$ & 0.3 & 45.83 & \\
\hline & 2 & $725 E+05$ & $731 E+05$ & 0.7 & 45.03 & $\frac{\text { EXOC6B, ENX1, RAB11FIP5, SFXN5, }}{\text { SPR }}$ \\
\hline & 15 & $285 E+05$ & $293 E+05$ & 0.9 & 44.38 & $\begin{array}{l}\text { GOLGA8G, APBA2, FAM189A1, } \\
\text { MSMCE3 }\end{array}$ \\
\hline
\end{tabular}

573

574

575

576

577

578

Chr: Chromosome.

Pos 1: Position where the ROHi starts.

Pos 2: Position where the ROHi finish.

\%Ind: Percentage of individuals in the population that share the $\mathrm{ROHi}$

Genes underlined have been previously reported to be under positive selection. 
bioRxiv preprint doi: https://doi.org/10.1101/470583; this version posted November 14, 2018. The copyright holder for this preprint (which was not certified by peer review) is the author/funder. All rights reserved. No reuse allowed without permission.

Table 6. Location, length, percentage of individuals with $\mathrm{ROH}$ for the $\mathrm{ROH}$ island and protein coding genes of the three longest $\mathrm{RHZ}$ according to populations from global geographic regions

\begin{tabular}{|c|c|c|c|c|c|c|}
\hline & Chr & Pos 1 & Pos 2 & $\begin{array}{l}\text { Length } \\
\text { (Mb) }\end{array}$ & $\begin{array}{l}\text { \% Ind in } \\
\text { ROH }\end{array}$ & Protein coding genes \\
\hline \multicolumn{7}{|l|}{ Africa W. } \\
\hline & 6 & $287 \mathrm{E}+05$ & $326 \mathrm{E}+05$ & 4 & 1.5 & +140 genes \\
\hline & 5 & $686 \mathrm{E}+05$ & $711 E+05$ & 2.6 & 0.24 & 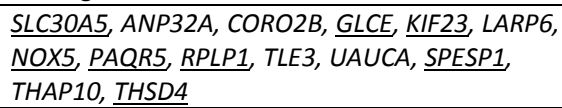 \\
\hline & 16 & $844 \mathrm{E}+05$ & $869 E+05$ & 2.6 & 2.3 & $\begin{array}{l}\text { FOXL1, FOXC2, COTL1, COX4I1, CRISPLD2, EMC8, } \\
\text { FAM92B, FOX, GINS2, GSE1, IRF8, KIAAO513, } \\
\text { KLHL36, MTHFSD, TDLC1, USP10, AZDHHC7 }\end{array}$ \\
\hline \multicolumn{7}{|r|}{ (1) } \\
\hline & 6 & $287 E+05$ & $326 \mathrm{E}+05$ & 4 & 0.35 & +140 genes \\
\hline & 12 & $1286 \mathrm{E}+05$ & $1312 \mathrm{E}+05$ & 2.7 & 2.8 & $\begin{array}{l}\text { ADGRD1, FZD10, GLT1D1, PIWIL1, RAN, RIMBP2, } \\
\text { STX2, TMEM, SLC15A5 }\end{array}$ \\
\hline & 5 & $686 \mathrm{E}+05$ & $711 \mathrm{E}+05$ & 2.6 & 0 & See Africa W. Second RHZ \\
\hline \multicolumn{7}{|l|}{ Africa $\mathrm{E}$. } \\
\hline & 6 & $287 \mathrm{E}+05$ & $326 \mathrm{E}+05$ & 4 & 0.51 & +140 genes \\
\hline & 9 & $393 E+05$ & $428 \mathrm{E}+05$ & 3.6 & 0 & $\begin{array}{l}\text { SPATA31A1, FOXD4L6, CBWD6, ANKRD2OA2, } \\
\text { CNTNAP3B }\end{array}$ \\
\hline & 12 & $1278 \mathrm{E}+05$ & $1312 \mathrm{E}+05$ & 3.5 & 2.1 & See Africa GG. Second RHZ \\
\hline \multicolumn{7}{|l|}{ Africa $\mathrm{H}$. } \\
\hline & 6 & $287 \mathrm{E}+05$ & $326 \mathrm{E}+05$ & 4 & 0.42 & +140 genes \\
\hline & 12 & $1286 \mathrm{E}+05$ & $1312 \mathrm{E}+05$ & 2.7 & 2.8 & See Africa GG. Second RHZ \\
\hline & 5 & $686 \mathrm{E}+05$ & $711 \mathrm{E}+05$ & 2.6 & 0 & See Africa W. Second RHZ \\
\hline \multicolumn{7}{|l|}{ Africa S. } \\
\hline & 6 & $287 E+05$ & $326 \mathrm{E}+05$ & 4 & 0.54 & +140 genes \\
\hline & 9 & $388 \mathrm{E}+05$ & $428 \mathrm{E}+05$ & 4.1 & 0.2 & See Africa E. Second RHZ \\
\hline & 16 & $844 \mathrm{E}+05$ & $869 \mathrm{E}+05$ & 2.6 & 2.3 & See Africa W. Third RHZ \\
\hline \multicolumn{7}{|l|}{ Africa KS. } \\
\hline & 9 & $392 E+05$ & $428 \mathrm{E}+05$ & 3.7 & 0.2 & See Africa E. Second RHZ \\
\hline & 8 & $64 \mathrm{E}+05$ & $81 \mathrm{E}+05$ & 1.8 & 3.3 & +30 genes \\
\hline & 5 & $69 \mathrm{E}+06$ & $706 \mathrm{E}+05$ & 1.7 & 0 & See Africa W. Second RHZ \\
\hline \multicolumn{7}{|l|}{ Mix A.A. } \\
\hline & 6 & $287 E+05$ & $326 \mathrm{E}+05$ & 4 & 0.4 & +140 genes \\
\hline & 12 & $1278 \mathrm{E}+05$ & $1312 \mathrm{E}+05$ & 3.5 & 1.3 & See Africa GG. Second RHZ \\
\hline & 16 & $843 E+05$ & $873 E+05$ & 3.1 & 1.4 & See Africa W. Third RHZ \\
\hline \multicolumn{7}{|l|}{ Europe } \\
\hline & 9 & $388 \mathrm{E}+05$ & $428 \mathrm{E}+05$ & 4.1 & 0.03 & See Africa E. Second RHZ \\
\hline & 6 & $287 \mathrm{E}+05$ & $326 \mathrm{E}+05$ & 4 & 0.68 & +140 genes \\
\hline & 15 & $202+\mathrm{E} 05$ & $227+\mathrm{E} 05$ & 2.6 & 0.35 & $\begin{array}{l}\text { GOLGA, OR4M2, OR4N4, POTEB2, POTEB3, } \\
\text { LINCO2203 }\end{array}$ \\
\hline \multicolumn{7}{|l|}{ Asia $\mathrm{E}$} \\
\hline & 9 & $388 \mathrm{E}+05$ & $428 \mathrm{E}+05$ & 4.1 & 0.03 & See Africa E. Second RHZ \\
\hline & 6 & $287 E+05$ & $325 \mathrm{E}+05$ & 3.9 & 0.42 & +140 genes \\
\hline & 18 & 155+E05 & $185+\mathrm{E} 05$ & 3.1 & 3.9 & \\
\hline \multicolumn{7}{|l|}{ Mix H.A. } \\
\hline & 9 & $388 \mathrm{E}+05$ & $428 \mathrm{E}+05$ & 4.1 & 0.02 & See Africa E. Second RHZ \\
\hline & 6 & $287 \mathrm{E}+05$ & $326 \mathrm{E}+05$ & 4.0 & 0.3 & +140 genes \\
\hline & 15 & $202+$ E05 & $227+\mathrm{E} 05$ & 2.6 & 1.2 & See Europe. Third RHZ \\
\hline
\end{tabular}


The Horn of Africa actually has more of these regions than the rest of SSA groups, and only the admixed group of the African-Americans has more RHZ 0\% (Table 3). Table 3 shows that for every group there are big differences between the number of $\mathrm{RHZ} 0 \%$ and $5 \%$. These differences can be explained mainly by a drastic increase of short $\mathrm{RHZ} 5 \%$ regions $(<0.3 \mathrm{Mb})$ with the outcome of a reduction in the mean length

589 ( $\mathrm{Mb}$ and $\mathrm{cM}$ ) of the $\mathrm{RHZ} 5 \%$ in comparison to $\mathrm{RHZ} 0 \%$. Table 3 also shows bigger differences between regional groups when considering $\mathrm{RHZ}$ in comparison to $\mathrm{ROHi}$, especially in number by size and mean length. In order to appreciate differences between regional groups, three extremely long $\mathrm{RHZ} 0 \%$, shared by all groups, were removed before constructing Table 3 . These three $\mathrm{RHZ} 0 \%$ are located in $\mathrm{Chr} 1$ (1253+E05 to 1425+E05; 17.3Mb), Chr9 (457+E05 to 664+E05; 20.8Mb) and Chr16 (384+E05 to 463+E05; $8 \mathrm{Mb})$.

Tables 4 and 5 show the positions, lengths and presence of protein coding genes for the five most common ROHi per regional group. Almost every ROHi has at least one protein coding gene, just two ROHi from the African Khoe and San and one ROHi in Hispanic-American admixed regional groups include no protein coding genes. Among the genes listed in Tables 4 and 5 there are some already described to be under positive selection pressure. Hence, there are genes related to brain development: $G P H N^{49} ; 50, P C D H 17^{49}$, spermatogenesis: $M 1 A P$, Fanconi anaemia $F A N C C^{60}$; pulmonary fibrosis: $P A R N^{53}$; congenital blindness: $T_{R P M 1}{ }^{53}$; mitochondrial disorders: MRPS23 ${ }^{49}$; Charcot-Marie tooth disease: PLEK ${ }^{49}$ 53; and other 605 metabolic and cellular processes (including $S H 3 R F^{49}, C U E D C 1^{49}, G O L G A 8 G^{51}, P C^{50}$ ). Many of these ROHi 606 with genes under positive selection are shared by more than one regional group. Without being 607 exhaustive, the ROHi with the FANCC gene is present in all the SSA populations but not outside this region: 
populations, $19.5 \%$ of the Eastern Africa regional group, $23.6 \%$ of the people from the Horn of Africa, admixed African-American populations. Another example shared by all SSA, except the Khoe and San populations, is the ROHi with the GPHN gene: $21.7 \%$ of prevalence in Western Africa, $17.8 \%$ in the Gulf of Guinea, 22.2\% in Eastern Africa, 26.1\% in the Africa Horn, 14.9\% in Southern Africa and 20.3\% of prevalence in the African-American admixed populations. ROHi with genes under positive selection were either present in all the populations like the BCAS3 gene, or just present in only one regional group like $H E R C 2$ or EDAR, in Europe and Eastern Asia respectively. Worthy of comment is the presence of an ROHi near the $L C T$ gene in Europe and Eastern Africa; $38.8 \%$ and $19.9 \%$ of the European and Eastern Africa individuals have a ROHi in this gene, but not in other SSA populations.

Table 6 shows the three longest $\mathrm{RHZ} 5 \%$, with the presence of protein coding genes for every regional population group. In order to build this table, the three longest $\mathrm{RHZ} 0 \%$, present in all regional groups, were removed. These three $\mathrm{RHZ} 0 \%$ (Chr1, Chr9 and Chr16) have practically no protein coding genes, just the SPATA31 $1^{61}$ subfamily A member 5 gene on Chr9 that is involved in spermatogenesis and is under positive selection. Table 6 shows that there are many protein coding genes present in these heterozygous regions. The RHZ on Chr6 is shared by every regional group but the Khoe and San. It has a length of $4 \mathrm{Mb}$, and has more than 140 protein coding genes including many members of the HLA complex family, 626 olfactory receptor family, MHC class I genes, lymphocyte antigen 6 family, and the psoriasis susceptibility 6271 candidate gene among others. As for $\mathrm{ROHi}$, multiple $\mathrm{RHZ}$ are shared by different regional groups.

628 It is possible to use differences in $\mathrm{ROHi}$ and $\mathrm{RHZ}$ across regional groups to obtain a genetic distance that 629 could provide an evolutionary perspective of the distribution of these homozygous and heterozygous 630 genomic regions. Figure 9 shows a pairwise comparison of unique ROHi (A) and RHZ (B) in two heatmaps 631 and, on the right of the figure, a rooted dendrogram for each heatmap using the percentage of unique 632 RHOi or RHZ as genetic distances. Both rooted dendrograms present similarities and differences in their 
branching. Both establish two main groups: SSA and out-of-Africa. Within SSA (with the exception of the

634 Horn of Africa), both dendrograms first split off the Khoe and San from the rest of groups and then both split Bantu-speaking populations from Southern Africa from the rest. Also, both dendrograms, include the mixed African-American group in the SSA branch. In the out-of-Africa branch both dendrograms group together European and admixed Hispanic-American populations. The biggest differences between the two dendrograms is where they locate the Horn of Africa populations; the ROHi dendrogram groups them with the out-of-Africa branch, whereas the RHZ dendrogram groups them with the SSA branch.

\section{DISCUSSION}

641 SSA populations have been the subject of extensive genomic research with the objective of understanding

642 their demographic history, current population structure, selection footprints and to advance the field of 643 biomedical genetics ${ }^{2-4 ; 62-65}$. To achieve these objectives classic population structure tools like $F_{S T}$, 644 admixture analysis, and PCA are often used. ROH analyses have not yet been fully explored even though 645 their usefulness as a tool to decipher different demographic histories is clear and studies range from 646 research on individuals to describing elaborate worldwide population-based trends ${ }^{7 ; 16}$. For example, we

647 have shown (Figures 2 and 3) that populations around the globe experience a reduction in the mean total 648 length of $\mathrm{ROH}$ in length categories above $0.5 \mathrm{Mb}$. Since the length of $\mathrm{ROH}$ is inversely proportionate to its 649 age, a possible explanation for this global phenomenon could be that populations around the world 650 experienced a size increase about the same time, reducing autozygosity provoked by low $\mathrm{N}_{\mathrm{e}}$ and genetic drift. However, to put these results into context and compare them to the estimates of population size

652 already published ${ }^{27 ; 66}$, it is necessary to determine the age of the different ROH sizes. Preliminary results 653 estimate that $\mathrm{ROH}$ length of $1.5 \mathrm{Mb}$ may have a median age of approximately 30 generations (personal 654 communication D.W. Clark) and $\mathrm{ROH}$ longer than $4 \mathrm{Mb}$ may not be older than 10 generations ${ }^{8}$.

655 Previous studies in SSA showed that Africa is the continent with the smallest burden of ROH and that 656 within Africa there is limited heterogeneity in $\mathrm{ROH}$ distribution, occurring essentially between the hunter- 
657 gatherers and the agro-pastoralists ${ }^{7}$ 20; 23 . Our study, however, shows that ROH distribution in SSA is very

658 heterogenous and much more complex than expected, with different scenarios for ROH shorter and

659 longer than $1.5 \mathrm{Mb}$. Although the vast majority of SSA populations have a low burden of short ROH, that

660 is not the case for long ROH where we find SSA populations with a higher burden in comparison to other

661 populations around the globe. In contrast with previous studies, our fine scale analysis has overcome

662 some limitations: It has representation of populations from Western, Eastern and Southern Africa; it uses

663 high-density SNP coverage ( 1.2 M SNPs after QC) providing good resolution to accurately call for ROH;

664 the PLINK software conditions for ROH calling were optimized to accurately call short ROH; and analyses

665 were developed to understand the $\mathrm{ROH}$ distribution and its demographic consequences.

666 Insights into the past - analysis of short $\mathrm{ROH}(\mathrm{ROH}<1.5 \mathrm{Mb})$

667 The demographic history of SSA is characterized by large effective population sizes over many generations 668 that have led to high genetic diversity, shorter LD structures and lower burden of small ROH'24. Our study 669 reports considerable structure in the distribution of short ROH in Africa with populations from the Horn 670 of Africa (Somali, Oromo and Amhara) having the largest burden of $\mathrm{ROH}<1.5 \mathrm{Mb}$. In the absence of 671 evidence to support a different evolutionary trajectory of the effective population size between these and 672 other SSA populations, the most plausible explanation is that the short ROH were introduced through 673 admixture of Semitic and Cushitic populations with others from the Arabian Peninsula. It has been found 674 that Ethiopian individuals are characterized by a large (40-50\%) non-African genetic component most 675 likely originating mainly from Egypt, the Levant and Yemen in a migration that took place approximately 6763 thousand years ago $(\mathrm{Kya})^{28 ; 67}$. This hypothesis is also supported by the ROHi profiling of populations in 677 the Horn of Africa that have the highest number of short ROHi $(0.1-0.3 \mathrm{Mb})$ and the shortest mean ROHi 678 length $(0.37 \mathrm{Mb})($ Table 3$)$, with $83 \%$ of $\mathrm{ROHi}$ shorter than $0.5 \mathrm{Mb}$. When compared with other regional 679 groups (Figure 9), the populations from the Horn of Africa share more ROHi with regional groups outside 
Africa (Figure 9A). There is a reasonably homogeneous burden of short ROH between Western, Gulf of

681 Guinea, Eastern and Southern Bantu-speaking groups (Table 1 and Figure 4), but the Khoe and San, having

A

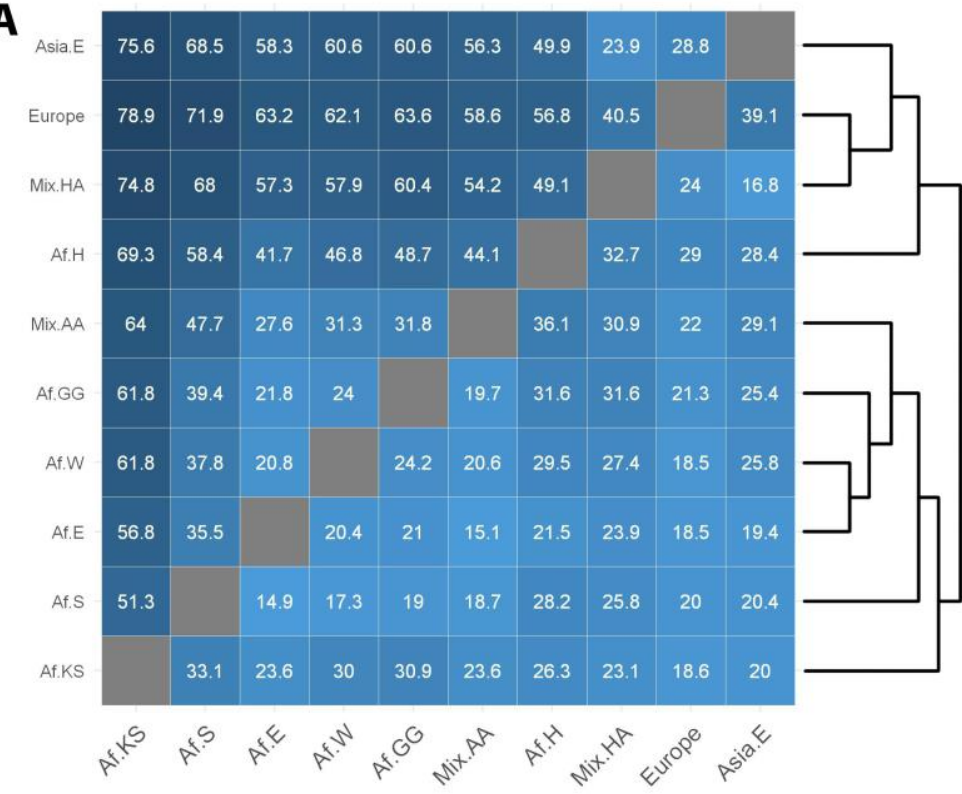

B

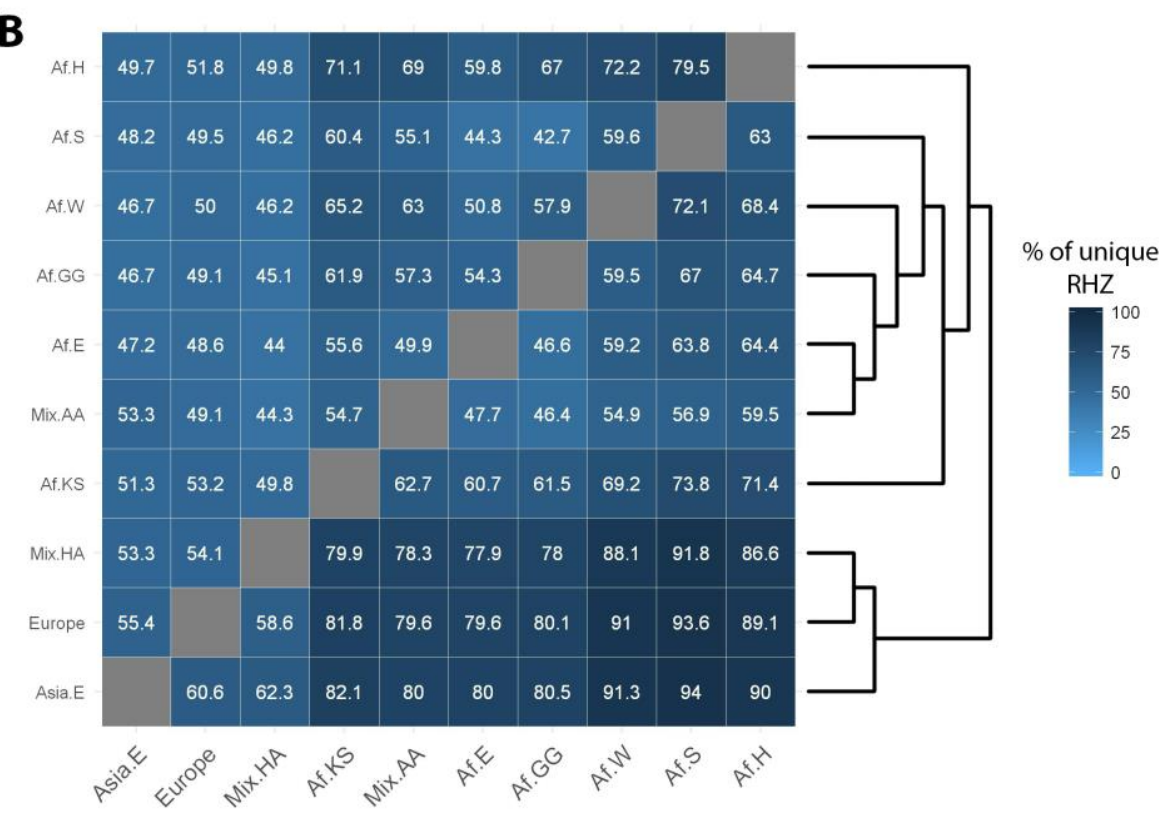

Figure 9. Heatmap and rooted dendrogram of the unique $\mathrm{ROH}$ islands (A) or $\mathrm{RHZ}$ (B) per geographical regional group and admixed populations. The heatmap shows pairwise $\%$ of unique $\mathrm{ROHi} / \mathrm{RHZ}$ between regional groups. The rooted dendrogram was obtained using optimal leaf ordering or OLO. Af.KS: African Khoe and San populations; Af.S: population from southern Africa; Af.E: population from eastern Africa; Af.W: population from western Africa; AF.GG: population from the Gulf of Guinea; Mix.AA: African-American admix populations; Mix.HA: HispanicAmerican admix populations; Europe: European populations; Asia.E: populations from eastern Asia. 
The shape of the distribution of the $\mathrm{ROH}<1.5 \mathrm{Mb}$ shown in Figure 4 is also highly informative. Admixed populations, originating from ancestral populations with different $\mathrm{ROH}$ burden, would have individuals with different Sum of $\mathrm{ROH}<1.5 \mathrm{Mb}$ due to their distinct coalescent histories, as is shown in Figure 4 where most of the admixed populations present platykurtic and skewed distributions. Hispanic-American populations (CLM, PUR, MXL), with $\mathrm{ROH}<1.5 \mathrm{Mb}$ burden similar to Europeans have a small proportion of African ancestry $(7.8 \%, 13.9 \%$ and $4.3 \%$ respectively) but higher proportion of European $(66.6 \%, 73.2 \%$ and $48.7 \%$ respectively) and Native American (25.7\%, $17.9 \%$ and $47.0 \%$ respectively) ancestry ${ }^{69 ;} 70$. The PEL population has shorter ROH due to a greater Native American ancestry (2.5\% African, 20.2 European and $77.3 \%$ Native American) ${ }^{69 ;} 70$. For these populations $\mathrm{ROH}<1.5 \mathrm{Mb}$ arose before the time of admixture; estimated as 14 generations for CLM, 7 for MXL and 16 for PUR. PEL population was found to have two different admixture pulses 12 and 5 generations ago, with the last one being 91.1\% Native American ${ }^{70}$. On the opposite side, African-American admixed populations (ASW and ACB) have reasonably normal distributions with almost no skewness. These two populations seem to have a very tight distribution and small burden of $\mathrm{ROH}<1.5 \mathrm{Mb}$, similar to the Western Africans and Guinea Gulf populations. This could be explained by the elevated proportion of African ancestry ( $88 \%$ and $75.6 \%$ respectively) and small proportions of European and Native American ancestry (ACB: 11.7\% European, 0.3 Nat American; ASW: 21.3\% European, 3.1\% Nat American) $)^{69}$ 70. The South African Coloured populations, another example of recently (150-300 years) highly admixed populations, have a $\mathrm{ROH}<1.5 \mathrm{Mb}$ burden very similar to Khoe and San populations. Nevertheless, different studies reported different ancestry components for Coloured populations arising from Khoe, San, and Bantu speakers, as well as European, South Asian and Austronesian populations ${ }^{6 ; 71}$ giving insight into the complexity of these admixed populations. Finally, it is also possible to detect kurtosis and skewness in some Khoe and San populations which would indicate admixture. Unequivocally, /Gui//Gana, Nama, Karretjie and $\neq$ Khomani distributions for sum of 
$\mathrm{ROH}<1.5 \mathrm{Mb}$ reveal their admixture origins. In these four Khoe and San populations Bantu and even

European ancestral components were found $23 ; 72 ; 73$.

\section{Consanguineous cultural practices and modern genetic isolation - analysis of long ROH (ROH $>1.5 \mathrm{Mb})$}

712 The study of $\mathrm{ROH}>1.5 \mathrm{Mb}$ is very useful to shed light on the role of cultural practices in genome

713 homozygosity levels. Different anthropological and human biology studies have systematically identified

714 African populations with a clear cultural preference for consanguineous marriages, and some that

715 purposely avoid such unions ${ }^{74-83}$. For example, one of the most recently published studies, which analysed

716548 marriages over the period 1994-96 in the Fulani from Burkina Faso, found that 399 marriages (68.3\%)

717 were between relatives and 185 (31.7\%) were between non-related individuals. The average inbreeding

coefficient $(\alpha)$ was estimated as $0.0364^{82}$. Similar inbreeding coefficients were found by other studies, for

719 example an $\alpha=0.0322$ in the Khartoum population from Sudan ${ }^{79}$. Our study shows a very heterogeneous

720 distribution of $\mathrm{ROH}>1.5 \mathrm{Mb}$ among $\mathrm{SSA}$ : populations with very little burden of long $\mathrm{ROH}>1.5 \mathrm{Mb}$, and

721 completely absence of $\mathrm{ROH}>4 \mathrm{Mb}$, for example in the Amhara from the Horn of Africa, the Yoruba from

722 the Gulf of Guinea or the Kikuyu from Eastern Niger-Congo Africa, and populations with a high burden of

$723 \mathrm{ROH}>1.5 \mathrm{Mb}$ like the Somali from the Horn of Africa, the Fula from Western Africa or the Khoe and San

724 !Xun and Ju/'hoansi. A heterogeneous distribution of long ROH was found within SSA regions: Somali and

725 Oromo populations, from the Horn of Africa, speak Cushitic languages, but Somalis are predominantly

726 Sunni Muslims, with a preference for first-cousin unions, while Oromo people are predominantly

727 Ethiopian Orthodox or follow traditional religions with no preference for consanguineous unions ${ }^{84}$.

728 Despite the results presented in this study, in other SSA regions like Guinea Gulf or Eastern Africa

729 anthropological studies there are groups with cultural preferences for unions between relatives like the

730 Futajalonke from Guinea ${ }^{83}$, the Baoule from Ivory Coast ${ }^{83}$, the Ewe from Ghana ${ }^{83}$, Arab groups in Kenya ${ }^{77}$,

731 the Kigali and Tutsi from Rwanda ${ }^{74}$ and the Khartoum and Gezira groups from Sudan ${ }^{79}$. Cultural differences 
732

733

734

735

736

737

738

739

740

741

742 and Karretjie peoples.

among individuals within populations can be inferred from the shapes of the distributions in Figure 4. Not surprisingly, populations with larger burden of ROH>1.5Mb (in order: !Xun, Ju/'hoansi, Somali, Khew, PEL, Gui//Gana, CLM, Fula, etc.) have the longest right tails and the highest number of individuals with an inbreeding coefficient higher than $\mathrm{F}=0.0152$ (Figure 5). Hence, despite previous reports, we have found African populations with mean genomic inbreeding coefficients $\left(\mathrm{F}_{\mathrm{ROH}}\right)$ higher than several other isolated populations around the world, such as the PEL from Lima in Peru.

In order to sketch a more complete picture of genomic homozygosity in SSA populations, it is important to analyse the origins of this homozygosity. The representation of the mean number of ROH compared to the mean total sum of ROH showed a right shift for Khoe and San populations like Ju/'hoansi, !Xun, Gui//Gana or Khwe, indicating the possible presence of recent consanguineous loops and a deviation from panmixia (Figure 6A). However, if the influence of the $F_{I S}$ in the $F_{R O H}$ is represented as shown in Figure 6B, a different picture is revealed. In summary, it is possible to establish a classification with 3 main groups characterized by demographic history. Firstly, populations with different levels of cultural consanguinity practices like Somali, Fula, CLM, GIH and Wolof. Secondly populations with low levels of inbreeding provoked by their large continental $\mathrm{N}_{\mathrm{e}}$, in this group we can find the bulk of Europe, Asian and SSA populations. Thirdly, populations with considerable genetic drift and recent genetic isolation like PEL, Khwe, Ju/'hoansi, !Xun and Herero. The representation of $F_{I S}$ vs $F_{R O H}$ is a better approach to identify the origins of inbreeding since it provides information about the proportion of $\mathrm{F}_{\mathrm{ROH}}$ due to deviation from panmixia or from genetic isolation. Furthermore, this representation is helpful to identify populations with an excess of homozygotes possibly due to the Wahlund effect, which may be expected for the Gui//Gana population, or, more surprisingly, with the Southern Tuu-speaking Khoe and San, the $\neq$ Khonami 
Examining $\mathrm{ROH}$ has been shown to be useful for studying genome biology and to identify regions under selection ${ }^{19-21}$. The existence of $\mathrm{ROH}$ islands $(\mathrm{ROHi})$ and regions of heterozygosity ( $\mathrm{RHZ}$ ) can be explained in part as a consequence of stochastic processes across the genome, or by variation of the effects of demographic processes across the genome, influencing genetic diversity ${ }^{7}{ }^{20}$. However, there is increasing evidence that $\mathrm{ROH}$ islands may be a consequence of positive selection processes that reduce haplotype diversity and increase homozygosity around the target locus, increasing $\mathrm{ROH}$ frequencies in the regions under selection ${ }^{20 ; 85}$. Besides the presence of specific protein coding genes, previously detected to be under positive selection, in the five most prevalent ROHi (Table 4 and 5), we identified other genes previously shown the be under positive selection in African populations ${ }^{2 ;} 23 ; 65$. Different loci associated with infectious disease susceptibility and severity, including $H P^{2}, C L T A 4^{86}$ and $P K L R^{87}$ for malaria, IFIH1 ${ }^{88}$ and $O A S 2^{2}$ for Lassa fever, $F A S^{89}$ for Trypanosomiasis and other genes involved in general immune response (e.g. $P R S S 16^{23}$ and $P O M 121 L 2^{23}$ ) were found within $\mathrm{ROHi}$ in different geographical regions. For example, CTLA4 was found in ROHi in every region, but HP and PKLR were found to be in ROHi just in Western and Eastern SSA and in the Horn of Africa. Other genes related to trypanosomiasis infection and kidney disease, like $A P O L 1^{90}$, or to different forms of hypertension, like $A T P 1 A 1^{2}, A Q P 2^{2}$ and $C S K^{2,91}$ were

771 found in ROHi in different regions from SSA. As was shown in Table 6 within RHZ haplotypes it is also 772 possible to find multiple protein coding genes related to diverse biological functions like immune response 773 (HLA complex or IRF gene family), cellular cycle $\left(A N P 32 A^{92 ;}{ }^{93}\right)$, chromosomal aberrations (like different 774 members of the GOLGA gene family ${ }^{94}$ ) cancer $\left(N O X 5^{95}\right)$, brain development (KIAAO513 ${ }^{96}$ ) and olfactory 775 receptors (OR gene family) among others. These heterozygous regions might represent haplotypes 776 enriched for variants that have a negative impact on fitness in homozygosity, or regions that harbor loci 777 with heterozygote advantage (overdominance) under any form of balancing selection. Furthermore, this hypothesis is also supported by the fact that it is possible to establish differences and similarities between 
779 the locations of $\mathrm{ROHi}$ and $\mathrm{RHZ}$ between populations from different geographic regions, as it is shown in

780 Figure 9. Furthermore, since the majority (more than 75\%) of ROHi and RHZ identified in this study include

781 genomic regions that had previously been identified as sites of recent selection, this analysis raises the

782 possibility that other loci in $\mathrm{ROHi}$ and $\mathrm{RHZ}$ may also harbor genes that have been subjected to positive or

783 balancing selection.

784 Conclusion

Detailed ROH analysis demonstrated a heterogeneous distribution of autozygosity across SSA populations

786 shedding light on the complex demographic history of the region. While short $\mathrm{ROH}(\mathrm{ROH}<1.5 \mathrm{Mb})$ provided

787 insights into effective population size and past admixture events, long $\mathrm{ROH}(\mathrm{ROH}>1.5 \mathrm{Mb})$ informed us

788 about the impact of consanguineous cultural practices, modern endogamy and genetic isolation. We also

789 showed that ROHi and RHZ can be used to identify genomic regions under selection pressure. Studying a

790 better representation and larger sample size across different SSA populations will provide more nuanced

791 interpretations of demographic histories. The H3Africa (Human Heredity and Health in Africa) initiative is

792 generating genomic data including whole genome and exome sequences and genome-wide genotyping

793 using an African tailored array that captures common genetic diversity in African genomes ${ }^{3 ; 4}$. The added

794 value of this resource lies in its rich phenotype and clinically relevant data that will enable biomedical

795 research across the continent making it possible to study the distribution of $\mathrm{ROH}$ and $\mathrm{RHZ}$ in common

796 complex traits.

\section{Supplemental Data}

798 Supplemental Data include eight figures and Supplemental Material and Methods including the 799 optimization of PLINK ROH calling algorithm to obtain short ROH and the comparison of ROH obtained 800 from the same samples with different SNP coverage. 


\section{Acknowledgments}

FCC is a National Research Foundation of South Africa (NRF) postdoctoral fellow and MR holds a South

African Research Chair in Genomics and Bioinformatics of African populations hosted by the University

of the Witwatersrand, funded by the Department of Science and Technology and administered by the NRF.

\section{Declaration of Interests}

Authors declare that they have no competing interests.

\section{References}

1. Campbell, M.C., and Tishkoff, S.A. (2008). African genetic diversity: implications for human demographic history, modern human origins, and complex disease mapping. Annu. Rev. Genom. Hum. Genet. 9, 403-433.

2. Gurdasani, D., Carstensen, T., Tekola-Ayele, F., Pagani, L., Tachmazidou, I., Hatzikotoulas, K., Karthikeyan, S., Iles, L., Pollard, M.O., Choudhury, A., et al. (2015). The African Genome Variation Project shapes medical genetics in Africa. Nature 517, 327-332.

3. H3AfricaConsortium, Rotimi, C., Abayomi, A., Abimiku, A., Adabayeri, V.M., Adebamowo, C., Adebiyi, E., Ademola, A.D., Adeyemo, A., Adu, D., et al. (2014). Research capacity. Enabling the genomic revolution in Africa. Science 344, 1346-1348.

4. Ramsay, M., Crowther, N., Tambo, E., Agongo, G., Baloyi, V., Dikotope, S., Gomez-Olive, X., Jaff, N., Sorgho, H., Wagner, R., et al. (2016). H3Africa AWI-Gen Collaborative Centre: a resource to study the interplay between genomic and environmental risk factors for cardiometabolic diseases in four sub-Saharan African countries. Global Health, Epidemiology and Genomics 1, e20.

5. Collins, F.S., Green, E.D., Guttmacher, A.E., Guyer, M.S., and Institute, U.S.N.H.G.R. (2003). A vision for the future of genomics research. Nature 422, 835-847.

6. Choudhury, A., Ramsay, M., Hazelhurst, S., Aron, S., Bardien, S., Botha, G., Chimusa, E.R., Christoffels, A., Gamieldien, J., Sefid-Dashti, M.J., et al. (2017). Whole-genome sequencing for an enhanced understanding of genetic variation among South Africans. Nat. Commun. 8, 2062.

7. Ceballos, F.C., Joshi, P.K., Clark, D.W., Ramsay, M., and Wilson, J.F. (2018). Runs of homozygosity: windows into population history and trait architecture. Nat. Rev. Genet. 19, 220-234.

8. McQuillan, R., Leutenegger, A.L., Abdel-Rahman, R., Franklin, C.S., Pericic, M., Barac-Lauc, L., SmolejNarancic, N., Janicijevic, B., Polasek, O., Tenesa, A., et al. (2008). Runs of homozygosity in European populations. Am. J. Hum. Genet. 83, 359-372.

9. Kirin, M., McQuillan, R., Franklin, C.S., Campbell, H., McKeigue, P.M., and Wilson, J.F. (2010). Genomic runs of homozygosity record population history and consanguinity. PLoS One 5, e13996.

10. Broman, K.W., and Weber, J.L. (1999). Long homozygous chromosomal segments in reference families from the centre d'Etude du polymorphisme humain. Am. J. Hum. Genet. 65, 1493-1500.

11. Gunderson, R.C. (1980). Connecting your pedigree into royal, noble and medieval families.(Salt Lake City: Genealogical Society of Utah).

12. Alvarez, G., Quinteiro, C., and Ceballos, F.C. (2011). Inbreeding and Genetic disorders. In Advances in the Study of Genetic Disorders, K. Ikehara, ed. (Rijeka, InTech. 
13. Crow, J.F., and Kimura, A. (1970). An introduction to population genetics theory.(New York: Harper \& Row).

14. Alvarez, G., Ceballos, F.C., and Quinteiro, C. (2009). The role of inbreeding in the extinction of a European royal dynasty. PLoS One 4, e5174.

15. Ceballos, F.C., Hazelhurst, S., and Ramsay, M. (2018). Assessing runs of Homozygosity: a comparison of SNP Array and whole genome sequence low coverage data. BMC Genomics 19, 106.

16. Joshi, P.K., Esko, T., Mattsson, H., Eklund, N., Gandin, I., Nutile, T., Jackson, A.U., Schurmann, C., Smith, A.V., Zhang, W., et al. (2015). Directional dominance on stature and cognition in diverse human populations. Nature 523, 459-462.

17. McQuillan, R., Eklund, N., Pirastu, N., Kuningas, M., McEvoy, B.P., Esko, T., Corre, T., Davies, G., Kaakinen, M., Lyytikainen, L.P., et al. (2012). Evidence of inbreeding depression on human height. PLoS Genet. 8, e1002655.

18. Gibson, J., Morton, N.E., and Collins, A. (2006). Extended tracts of homozygosity in outbred human populations. Hum. Mol. Genet. 15, 789-795.

19. Nothnagel, M., Lu, T.T., Kayser, M., Krawczak, M., Spain, S.L., Cazier, J.B., Houlston, R., CarvajalCarmona, L., Tomlinson, I., Vine, A.E., et al. (2010). Genomic and geographic distribution of SNPdefined runs of homozygosity in Europeans. Hum. Mol. Genet. 19, 2927-2935.

20. Pemberton, T.J., Absher, D., Feldman, M.W., Myers, R.M., Rosenberg, N.A., and Li, J.Z. (2012). Genomic patterns of homozygosity in worldwide human populations. Am. J. Hum. Genet. 91, 275-292.

21. Curtis, D., Vine, A.E., and Knight, J. (2008). Study of regions of extended homozygosity provides a powerful method to explore haplotype structure of human populations. Ann. Hum. Genet. 72, 261-278.

22. Henn, B.M., Gignoux, C.R., Jobin, M., Granka, J.M., Macpherson, J.M., Kidd, J.M., Rodriguez-Botigue, L., Ramachandran, S., Hon, L., Brisbin, A., et al. (2011). Hunter-gatherer genomic diversity suggests a southern African origin for modern humans. Proc. Natl. Acad. Sci. U. S. A. 108, 5154-5162.

23. Schlebusch, C.M., Skoglund, P., Sjodin, P., Gattepaille, L.M., Hernandez, D., Jay, F., Li, S., De Jongh, M., Singleton, A., Blum, M.G.B., et al. (2012). Genomic Variation in Seven Khoe-San Groups Reveals Adaptation and Complex African History. Science 338, 374-379.

24. Henn, B.M., Botigue, L.R., Peischl, S., Dupanloup, I., Lipatov, M., Maples, B.K., Martin, A.R., Musharoff, S., Cann, H., Snyder, M.P., et al. (2016). Distance from sub-Saharan Africa predicts mutational load in diverse human genomes. Proc. Natl. Acad. Sci. U. S. A. 113, E440-449.

25. The 1000 Genomes Project, C. (2015). A global reference for human genetic variation. Nature 526, 6874.

26. Li, J.Z., Absher, D.M., Tang, H., Southwick, A.M., Casto, A.M., Ramachandran, S., Cann, H.M., Barsh, G.S., Feldman, M., Cavalli-Sforza, L.L., et al. (2008). Worldwide human relationships inferred from genome-wide patterns of variation. Science 319, 1100-1104.

27. Mallick, S., Li, H., Lipson, M., Mathieson, I., Gymrek, M., Racimo, F., Zhao, M., Chennagiri, N., Nordenfelt, S., Tandon, A., et al. (2016). The Simons Genome Diversity Project: 300 genomes from 142 diverse populations. Nature 538, 201-206.

28. Pagani, L., Kivisild, T., Tarekegn, A., Ekong, R., Plaster, C., Romero, I.G., Ayub, Q., Mehdi, S.Q., Thomas, M.G., Luiselli, D., et al. (2012). Ethiopian Genetic Diversity Reveals Linguistic Stratification and Complex Influences on the Ethiopian Gene Pool. Am. J. Hum. Genet. 91, 83-96.

29. Hollfelder, N., Schlebusch, C.M., Gunther, T., Babiker, H., Hassan, H.Y., and Jakobsson, M. (2017). Northeast African genomic variation shaped by the continuity of indigenous groups and Eurasian migrations. PLoS Genet. 13, e1006976.

30. Sudmant, P.H., Rausch, T., Gardner, E.J., Handsaker, R.E., Abyzov, A., Huddleston, J., Zhang, Y., Ye, K., Jun, G., Hsi-Yang Fritz, M., et al. (2015). An integrated map of structural variation in 2,504 human genomes. Nature 526, 75-81. 
31. Barnard, A. (1992). Hunters and Herders of Southern Africa - A Comparative Ethnography of the Khoisan Peoples.(Cambridge: Cambridge University Press).

32. Purcell, S., Neale, B., Todd-Brown, K., Thomas, L., Ferreira, M.A.R., Bender, D., Maller, J., Sklar, P., de Bakker, P.I.W., Daly, M.J., et al. (2007). PLINK: A tool set for whole-genome association and population-based linkage analyses. Am. J. Hum. Genet. 81, 559-575.

33. Howrigan, D.P., Simonson, M.A., and Keller, M.C. (2011). Detecting autozygosity through runs of homozygosity: a comparison of three autozygosity detection algorithms. BMC Genomics 12, 460.

34. International HapMap, C., Frazer, K.A., Ballinger, D.G., Cox, D.R., Hinds, D.A., Stuve, L.L., Gibbs, R.A., Belmont, J.W., Boudreau, A., Hardenbol, P., et al. (2007). A second generation human haplotype map of over 3.1 million SNPs. Nature 449, 851-861.

35. Shifman, S. (2003). Linkage disequilibrium patterns of the human genome across populations. Hum. Mol. Genet. 12, 771-776.

36. Slatkin, M. (2008). Linkage disequilibrium - understanding the evolutionary past and mapping the medical future. Nat. Rev. Genet. 9, 477-485.

37. Team, R.C. (2017). A Language and Environment for Statistical Computing. In. (R Fundation for Statistical Computing.

38. Jacquard, A. (1975). Inbreeding - One word, several meanings. Theoretical Population Biology 7, 338363.

39. Templeton, A., R, and Read, B. (1996). Inbreeding, One Word, Several Meanings, Much Confusion. Biol. Conserv. 75.

40. Glemin, S. (2003). How are deleterious mutations purged? Druft versus nonrandom mating. Evolution $57,2678-2687$.

41. Wright, S. (1950). Genetical structure of populations. Nature 166, 247-249.

42. Wright, S. (1922). Coefficients of Inbreeding and relationship. Amer. Naturalist 56, 330-338.

43. Weir, B.S. (2012). Estimating F-statistics: A historical view. The British Journal for the Philosophy of Science 79, 637-643.

44. Galili, T., O'Callaghan, A., Sidi, J., and Sievert, C. (2018). heatmaply: an R package for creating interactive cluster heatmaps for online publishing. Bioinformatics 34, 1600-1602.

45. Brandes, U. (2007). Optimal leaf ordering of complete binary trees. Journal of Discrete Algorithms 5 , 546-552.

46. Consortium, E.P. (2012). An integrated encyclopedia of DNA elements in the human genome. Nature 489, 57-74.

47. Bittles, A.H., and Black, M.L. (2010). Consanguinity, human evolution, and complex diseases. Proc. Natl. Acad. Sci. U. S. A. 107, 1779-1786.

48. Hartl, D.L., and Clark, A.G. (2007). Principles of population Genetics.(Sunderland: Sinauer Associates).

49. Liu, X., Ong, R.T., Pillai, E.N., Elzein, A.M., Small, K.S., Clark, T.G., Kwiatkowski, D.P., and Teo, Y.Y. (2013). Detecting and characterizing genomic signatures of positive selection in global populations. Am. J. Hum. Genet. 92, 866-881.

50. Lopman, B., and Gregson, S. (2008). When did HIV incidence peak in Harare, Zimbabwe? Backcalculation from mortality statistics. PLoS One 3, e1711.

51. Chen, H., Patterson, N., and Reich, D. (2010). Population differentiation as a test for selective sweeps. Genome Res. 20, 393-402.

52. Mendizabal, I., Marigorta, U.M., Lao, O., and Comas, D. (2012). Adaptive evolution of loci covarying with the human African Pygmy phenotype. Hum. Genet. 131, 1305-1317.

53. Grossman, S.R., Andersen, K.G., Shlyakhter, I., Tabrizi, S., Winnicki, S., Yen, A., Park, D.J., Griesemer, D., Karlsson, E.K., Wong, S.H., et al. (2013). Identifying recent adaptations in large-scale genomic data. Cell 152, 703-713. 
54. Lopez Herraez, D., Bauchet, M., Tang, K., Theunert, C., Pugach, I., Li, J., Nandineni, M.R., Gross, A., Scholz, M., and Stoneking, M. (2009). Genetic variation and recent positive selection in worldwide human populations: evidence from nearly 1 million SNPs. PLoS One 4, e7888.

55. Higasa, K., Kukita, Y., Kato, K., Wake, N., Tahira, T., and Hayashi, K. (2009). Evaluation of haplotype inference using definitive haplotype data obtained from complete hydatidiform moles, and its significance for the analyses of positively selected regions. PLoS Genet. 5, e1000468.

56. Beleza, S., Johnson, N.A., Candille, S.I., Absher, D.M., Coram, M.A., Lopes, J., Campos, J., Araujo, II, Anderson, T.M., Vilhjalmsson, B.J., et al. (2013). Genetic architecture of skin and eye color in an African-European admixed population. PLoS Genet. 9, e1003372.

57. Wagh, K., Bhatia, A., Alexe, G., Reddy, A., Ravikumar, V., Seiler, M., Boemo, M., Yao, M., Cronk, L., Naqvi, A., et al. (2012). Lactase persistence and lipid pathway selection in the Maasai. PLoS One 7, e44751.

58. Kamberov, Y.G., Wang, S., Tan, J., Gerbault, P., Wark, A., Tan, L., Yang, Y., Li, S., Tang, K., Chen, H., et al. (2013). Modeling recent human evolution in mice by expression of a selected EDAR variant. Cell 152, 691-702.

59. Oleksyk, T.K., Zhao, K., De La Vega, F.M., Gilbert, D.A., O'Brien, S.J., and Smith, M.W. (2008). Identifying selected regions from heterozygosity and divergence using a light-coverage genomic dataset from two human populations. PLoS One 3, e1712.

60. Wang, E.T., Kodama, G., Baldi, P., and Moyzis, R.K. (2006). Global landscape of recent inferred Darwinian selection for Homo sapiens. Proc. Natl. Acad. Sci. U. S. A. 103, 135-140.

61. Bekpen, C., Kunzel, S., Xie, C., Eaaswarkhanth, M., Lin, Y.L., Gokcumen, O., Akdis, C.A., and Tautz, D. (2017). Segmental duplications and evolutionary acquisition of UV damage response in the SPATA31 gene family of primates and humans. BMC Genomics 18, 222.

62. Patin, E., Lopez, M., Grollemund, R., Verdu, P., Harmant, C., Quach, H., Laval, G., Perry, G.H., Barreiro, L.B., Froment, A., et al. (2017). Dispersals and genetic adaptation of Bantu-speaking populations in Africa and North America. Science 356, 543-546.

63. Marks, S.J., Montinaro, F., Levy, H., Brisighelli, F., Ferri, G., Bertoncini, S., Batini, C., Busby, G.B., Arthur, C., Mitchell, P., et al. (2015). Static and moving frontiers: the genetic landscape of Southern African Bantu-speaking populations. Mol. Biol. Evol. 32, 29-43.

64. Uren, C., Kim, M., Martin, A.R., Bobo, D., Gignoux, C.R., van Helden, P.D., Moller, M., Hoal, E.G., and Henn, B.M. (2016). Fine-Scale Human Population Structure in Southern Africa Reflects Ecogeographic Boundaries. Genetics 204, 303-314.

65. Chimusa, E.R., Meintjies, A., Tchanga, M., Mulder, N., Seoighe, C., Soodyall, H., and Ramesar, R. (2015). A genomic portrait of haplotype diversity and signatures of selection in indigenous southern African populations. PLoS Genet. 11, e1005052.

66. Okada, Y., Momozawa, Y., Sakaue, S., Kanai, M., Ishigaki, K., Akiyama, M., Kishikawa, T., Arai, Y., Sasaki, T., Kosaki, K., et al. (2018). Deep whole-genome sequencing reveals recent selection signatures linked to evolution and disease risk of Japanese. Nat. Commun. 9, 1631.

67. Pickrell, J.K., Patterson, N., Loh, P.R., Lipson, M., Berger, B., Stoneking, M., Pakendorf, B., and Reich, D. (2014). Ancient west Eurasian ancestry in southern and eastern Africa. Proc. Natl. Acad. Sci. U. S. A. 111, 2632-2637.

68. Kim, H.L., Ratan, A., Perry, G.H., Montenegro, A., Miller, W., and Schuster, S.C. (2014). Khoisan huntergatherers have been the largest population throughout most of modern-human demographic history. Nat. Commun. 5, 5692.

69. Montinaro, F., Busby, G.B., Pascali, V.L., Myers, S., Hellenthal, G., and Capelli, C. (2015). Unravelling the hidden ancestry of American admixed populations. Nat. Commun. 6, 6596. 
70. Martin, A.R., Gignoux, C.R., Walters, R.K., Wojcik, G.L., Neale, B.M., Gravel, S., Daly, M.J., Bustamante, C.D., and Kenny, E.E. (2017). Human Demographic History Impacts Genetic Risk Prediction across Diverse Populations. Am. J. Hum. Genet. 100, 635-649.

71. Daya, M., van der Merwe, L., Galal, U., Moller, M., Salie, M., Chimusa, E.R., Galanter, J.M., van Helden, P.D., Henn, B.M., Gignoux, C.R., et al. (2013). A panel of ancestry informative markers for the complex five-way admixed South African coloured population. PLoS One 8, e82224.

72. Busby, G.B., Band, G., Si Le, Q., Jallow, M., Bougama, E., Mangano, V.D., Amenga-Etego, L.N., Enimil, A., Apinjoh, T., Ndila, C.M., et al. (2016). Admixture into and within sub-Saharan Africa. Elife 5.

73. Schuster, S.C., Miller, W., Ratan, A., Tomsho, L.P., Giardine, B., Kasson, L.R., Harris, R.S., Petersen, D.C., Zhao, F., Qi, J., et al. (2010). Complete Khoisan and Bantu genomes from southern Africa. Nature 463, 943-947.

74. Lesthaeghe, R., Kaufmann, G., and Meekers, D. (1989). The Nuptiality Regimens in Sub-Saharan Africa. In REproduction and Social Organization in Sub-Saharan Africa, R. Lesthaeghe, ed. (Berkeley, University of California Press.

75. Bledsoe, C. (2002). Contingent Lives: Fertility, Time, and Aging in West Africa.(Chicago: The University of Chicago Press).

76. Schapera, I. (1957). Marriage of Near Kin among the Tswana. Journal of the International African Studies 27, 139-159.

77. Tanner, R.E. (1958). Fertility and child mortality in cousin marriages. A Study in a Moslem Community in East Africa. The Eugenetics Review 49, 197-199.

78. Ahmed, A.H. (1979). Consanguinity and schizophrenia in Sudan. The British Journal of Psychiatry 134, 635-636.

79. Saha, N., and El Sheikh, F.S. (1988). Inbreeding levels in Khartoum. J. Biosoc. Sci. 20, 333-336.

80. Scott-Emuakpor, A.B. (1974). The mutation load in an African population. I. An analysis of consanguineous marriages in Nigeria. Am. J. Hum. Genet. 26, 674-682.

81. Caldwell, J.C., Caldwell, P., and Orunuloye, I.O. (1992). The Family and Sexual Networking in SubSaharan Africa: Historical Regional Differences andPresent-Day Implications. Population Studies 46, 385-410.

82. Hampshire, K.R., and Smith, M.T. (2001). Consanguineous Marriage among the Fulani. Hum. Biol. 73, 597-603.

83. Bittles, A.H. (1998). Empirical Estimates of the Global Prevalence of Consanguineous Marriage in Contemporary Societies.(Stanford, California: Morrison Institute for Population and Resource Studies).

84. Bittles, A.H. (2012). Consanguinity in context.(Cambridge: Cambridge University Press).

85. Lencz, T., Lambert, C., DeRosse, P., Burdick, K.E., Morgan, T.V., Kane, J.M., Kucherlapati, R., and Malhotra, A.K. (2007). Runs of homozygosity reveal highly penetrant recessive loci in schizophrenia. Proc. Natl. Acad. Sci. U. S. A. 104, 19942-19947.

86. Jacobs, T., Graefe, S.E.B., Niknafs, S., Gaworski, I., and Fleischer, B. (2002). Murine Malaria is Exarcebated by CTLA-4 Blockade. The Journal of Immunology 169, 2323-2329.

87. Machado, P., Pereira, R., Rocha, A.M., Manco, L., Fernandes, N., Miranda, J., Ribeiro, L., do Rosario, V.E., Amorim, A., Gusmao, L., et al. (2010). Malaria: looking for selection signatures in the human PKLR gene region. Br. J. Haematol. 149, 775-784.

88. Fumagalli, M., Cagliani, R., Riva, S., Pozzoli, U., Biasin, M., Piacentini, L., Comi, G.P., Bresolin, N., Clerici, M., and Sironi, M. (2010). Population genetics of IFIH1: ancient population structure, local selection, and implications for susceptibility to type 1 diabetes. Mol. Biol. Evol. 27, 2555-2566.

89. Martins, G.A., Petkova, S.B., Machado, F.S., Kitsis, R.N., Weiss, L.M., Wittner, M., Tanowitz, H.B., and Silva, J.S. (2001). Fas-FasL interaction modulates nitric oxide production in Trypanosoma cruziinfected mice. Immunology 103, 122-129. 
90. Ko, W.Y., Rajan, P., Gomez, F., Scheinfeldt, L., An, P., Winkler, C.A., Froment, A., Nyambo, T.B., Omar, S.A., Wambebe, C., et al. (2013). Identifying Darwinian selection acting on different human APOL1 variants among diverse African populations. Am. J. Hum. Genet. 93, 54-66.

91. Voight, B.F., Kudaravalli, S., Wen, X., and Pritchard, J.K. (2006). A map of recent positive selection in the human genome. PLoS Biol. 4, e72.

92. Opal, P., Garcia, J.J., Propst, F., Matilla, A., Orr, H.T., and Zoghbi, H.Y. (2003). Mapmodulin/leucine-rich acidic nuclear protein binds the light chain of microtubule-associated protein $1 \mathrm{~B}$ and modulates neuritogenesis. J. Biol. Chem. 278, 34691-34699.

93. Schafer, Z.T., Parrish, A.B., Wright, K.M., Margolis, S.S., Marks, J.R., Deshmukh, M., and Kornbluth, S. (2006). Enhanced sensitivity to cytochrome c-induced apoptosis mediated by PHAPI in breast cancer cells. Cancer Res. 66, 2210-2218.

94. Silano, M., Di Benedetto, R., Trecca, A., Arrabito, G., Leonardi, F., and De Vincenzi, M. (2007). A decapeptide from durum wheat prevents celiac peripheral blood lymphocytes from activation by gliadin peptides. Pediatr. Res. 61, 67-71.

95. Fu, X., Beer, D.G., Behar, J., Wands, J., Lambeth, D., and Cao, W. (2006). cAMP-response elementbinding protein mediates acid-induced NADPH oxidase NOX5-S expression in Barrett esophageal adenocarcinoma cells. J. Biol. Chem. 281, 20368-20382.

96. Lauriat, T.L., Dracheva, S., Kremerskothen, J., Duning, K., Haroutunian, V., Buxbaum, J.D., Hyde, T.M., Kleinman, J.E., and McInnes, L.A. (2006). Characterization of KIAA0513, a novel signaling molecule that interacts with modulators of neuroplasticity, apoptosis, and the cytoskeleton. Brain Res. $1121,1-11$. 
bioRxiv preprint doi: https://doi.org/10.1101/470583; this version posted November 14, 2018. The copyright holder for this preprint (which was not certified by peer review) is the author/funder. All rights reserved. No reuse allowed without permission.

\section{Supplemental Material and Methods.}

\section{Description of the Data and the Methodology}

PLINK's observational approach underestimates small ROH (shorter than $500 \mathrm{~Kb}$ ) when using recommended conditions ( 50 as the minimum number of SNP that the PLINK's sliding window, and $\mathrm{ROH}$, is required to have) in array-genotyped data in comparison to whole genome sequence low coverage ${ }^{1}$. For the analysis of the current study it is important to have accurate ROH estimates for sizes as short as $300 \mathrm{~Kb}$. In order to achieve this goal, we tested different PLINK parameters of $\mathrm{ROH}$ calling in array-based data and compared them with $\mathrm{ROH}$ obtained from low coverage (3-6x) whole genome sequence. We therefore published the required PLINK conditions to obtain equivalent results, with parameters for ROH longer than $1.5 \mathrm{Mb}$, between WGS low coverage and SNP array technologies ${ }^{1}$. In the current study we used the same conditions as a starting point to obtain equivalent short $\mathrm{ROH}$ estimations.

Individuals with both genome-wide SNP genotypic data and WGS low coverage data from the 1000 Genomes Project - Phase 3 (KGP) and the African Genome Variation Project (AGVP) were used. For both datasets the Infinium Omni 2.5-8 Bead chip from Illumina was used. The KGP includes a total of 1685 individuals from 18 populations with genotypic data available from array and WGS low coverage (4x): European ancestry FIN ( $n=99)$, GBR ( $n=91)$, IBS ( $n=105)$, TSI (Tuscani $n=102)$ and CEU ( $n=99)$; African-American ancestry ASW $(n=61)$ and ACB $(n=96)$; HispanicAmerican ancestry PUR ( $n=104), \operatorname{PEL}(n=85), \operatorname{CLM}(n=95)$ and MXL $(n=100)$; Eastern Asia ancestry CDX ( $n=98)$, CHB $(n=100)$, CHS ( $n=105), J P T(n=100)$ and KHV ( $n=99) ;$ and African ancestry YRI $(n=108)$ and LWK ( $n=99)$. The AVGP includes 200 samples (100 Zulu and 100 Baganda) where array-genotype data and WGS low coverage (4x) are available. For each population, data from both array genotyping and WGS were filtered to remove MAF $<0.05$ and those diverging from $\mathrm{H}-\mathrm{W}$ with $\mathrm{p}<0.001$. Only SNPs of the 22 autosomes were included in the analysis.

We used PLINK v1.9 to identify ROH. The following conditions were used to call ROH in the WGS low coverage data--homozyg-snp 50,--homozyg-kb 300,--homozyg-density 50,--homozyg-gap 1000,--homozyg-window-snp 50,--homozyg-windowhet 3. For array-genotype data the following conditions where used: --homozyg-snp (30, 40, 50),--homozyg-kb 300,--homozyg-density $(30,40,50),--$ homozyg-gap 1000,--homozyg-window-snp (30, 40, 50),--homozyg-het 1.

Using violin plots for visualisation of the ROH data distribution, we performed an exploratory data analysis comparing five different ROH class sizes obtained from array-genotype and WGS data. Class 1: $300 \mathrm{~Kb}<\mathrm{ROH} \leq 500 \mathrm{~Kb}$; Class 2: $500 \mathrm{~Kb}<\mathrm{ROH} \leq 700 \mathrm{~Kb}$; Class 3: $700 \mathrm{~Kb}<\mathrm{ROH} \leq 900 \mathrm{~Kb}$; Class 4: $900 \mathrm{~Kb}<\mathrm{ROH} \leq 1000 \mathrm{~Kb}$; Class 5: $1000 \mathrm{~Kb}<\mathrm{ROH} \leq 1500 \mathrm{~Kb}$.

\section{Results and Conclusions}

In Figures $\mathrm{S} 1$ to $\mathrm{S} 5$ show violin plots of the sum of ROH for the five classes of ROH lengths. For each of the continental divisions (Africa: Figure S1; Hispanic-American: Figure S2; AfricanAmerican: Figure S3; Asian: Figure S4 and Europe: Figure S5) we demonstrate that some adjustments are appropriate when dealing with array-genotype data. For example, when we relax PLINK's conditions to 30 SNPs per sliding window and $\mathrm{ROH}$, it is possible to obtain more equivalent sum of ROH estimates for Class 1 and 2 (300Kb to $700 \mathrm{~Kb}$ ) than when using previously recommended conditions (50 SNP). Furthermore, the sum of ROH estimates didn't change much when considered $\mathrm{ROH}$ longer than 700Kb. 
bioRxiv preprint doi: https://doi.org/10.1101/470583; this version posted November 14, 2018. The copyright holder for this preprint (which was not certified by peer review) is the author/funder. All rights reserved. No reuse allowed without permission.

According to these results we can conclude that by using a sliding window of 30 SNPs in PLINK we can obtain a better estimation of short $\mathrm{ROH}$ that does not interfere with the estimation of longer $\mathrm{ROH}$.

\section{Supplemental References}

1. Ceballos, F.C., Hazelhurst, S., and Ramsay, M. (2018). Assessing runs of Homozygosity: a comparison of SNP Array and whole genome sequence low coverage data. BMC Genomics 19, 106.


$\mathrm{Gb}$

$\mathrm{Gb}$

Figure S1. Violin plots of the sum of ROH for 5 classes of ROH length in African populations from $1 K G P$ and AGVP with Array and WGS data available $\mathrm{Cl} 1: 0.3 \mathrm{Mb}<\mathrm{ROH} \leq 0.5 \mathrm{Mb} ; \mathrm{Cl}$ : $0.5 \mathrm{Mb}<\mathrm{ROH} \leq 0.7 \mathrm{Mb} ; \mathrm{Cl} 3: 0.7 \mathrm{Mb}<\mathrm{ROH} \leq 0.9 \mathrm{Mb} ; \mathrm{Cl} 4: 0.9 \mathrm{Mb}<\mathrm{ROH} \leq 1.0 \mathrm{Mb} ; \mathrm{Cl} 5: 1 \mathrm{Mb}<\mathrm{ROH} \leq 1.5 \mathrm{Mb}$. BAG: Baganda population from AGVP; ZUL: Zulu population from the AGVP; LWK: Luhya population from the 1KG; YRI: Yoruba population from the 1KGP. For each population, 30, 40 and 50 SNPs per window as PLINK conditions to obtain ROH with the Array data were compared with ROH from WGS data by using a window of 50 SNPs 

not certified by peer review) is the author/funder. All rights reserved. No reuse allowed without permission.
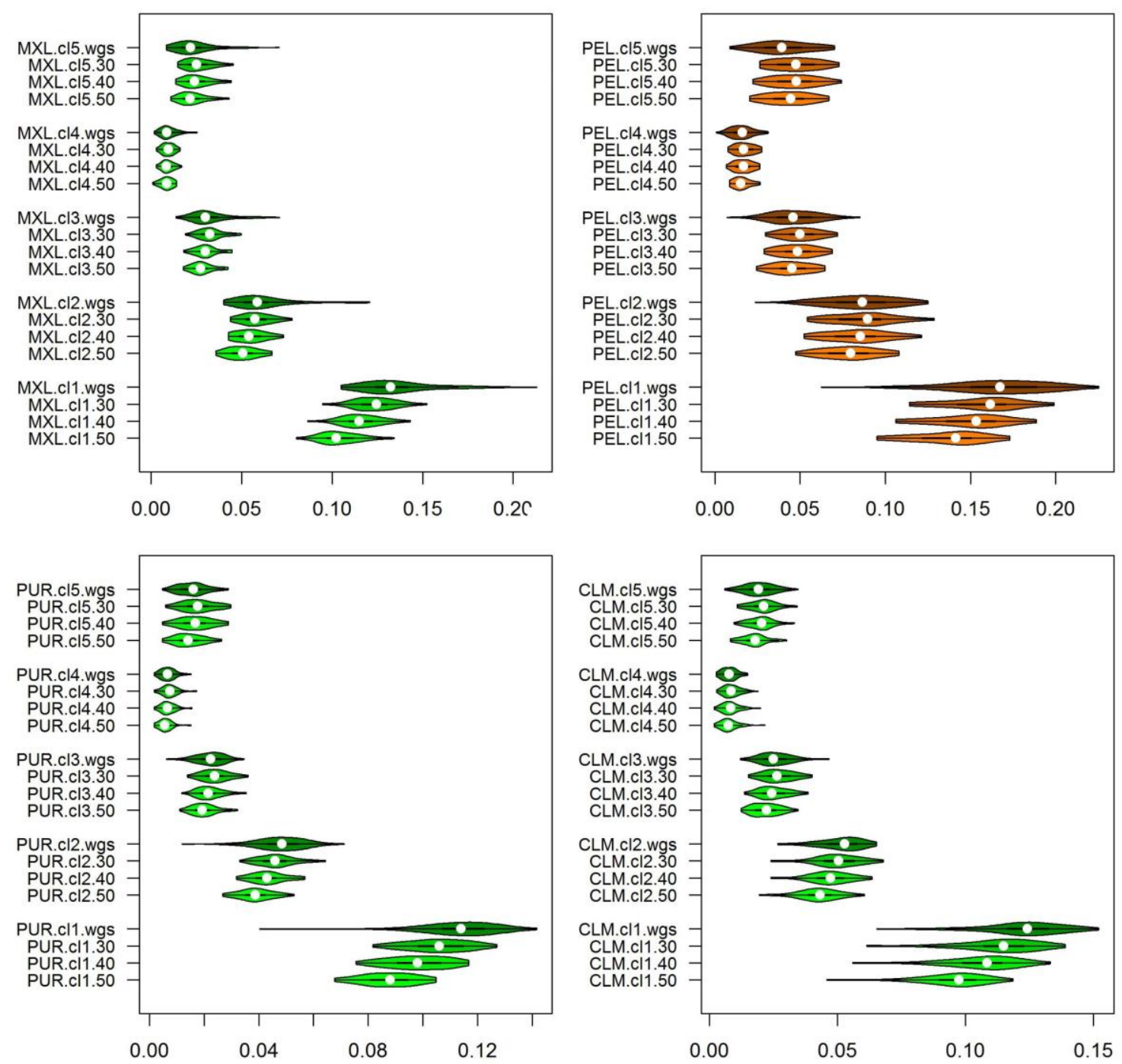

$\mathrm{Gb}$

$\mathrm{Gb}$

Figure S2. Violin plots of the sum of ROH for 5 classes of ROH length in American populations from 1KGP with Array and WGS data available. $\mathrm{Cl} 1$ : $0.3 \mathrm{Mb}<\mathrm{ROH} \leq 0.5 \mathrm{Mb} ; \mathrm{Cl} 2$ :

$0.5 \mathrm{Mb}<\mathrm{ROH} \leq 0.7 \mathrm{Mb} ; \mathrm{Cl} 3: 0.7 \mathrm{Mb}<\mathrm{ROH} \leq 0.9 \mathrm{Mb} ; \mathrm{Cl} 4: 0.9 \mathrm{Mb}<\mathrm{ROH} \leq 1.0 \mathrm{Mb} ; \mathrm{Cl} 5$ :

$1 \mathrm{Mb}<\mathrm{ROH} \leq 1.5 \mathrm{Mb}$. For each population, 30,40 and 50 SNPs per window as PLINK conditions to obtain ROH with the Array data were compared with ROH from WGS data by using a window of 50 SNPs. 
bioRxiv preprint doi: https://doi.org/10.1101/470583; this version posted November 14, 2018. The copyright holder for this preprint (which was not certified by peer review) is the author/funder. All rights reserved. No reuse allowed without permission.
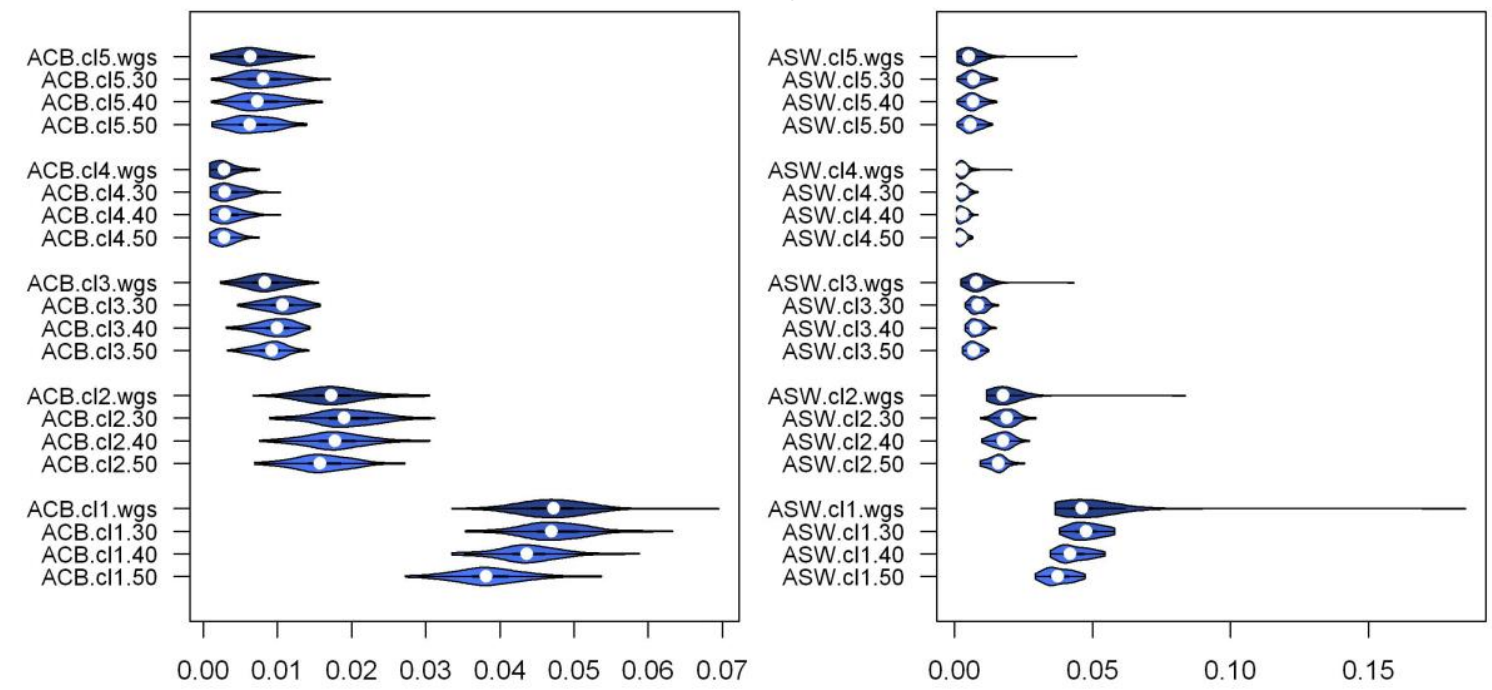

Figure S3. Violin plots of the sum of ROH for 5 classes of ROH length in admixed African American populations from $1 \mathrm{KG}$ with Array and WGS data available. $\mathrm{Cl} 1$ : $0.3 \mathrm{Mb}<\mathrm{ROH} \leq 0.5 \mathrm{Mb}$; $\mathrm{Cl} 2: 0.5 \mathrm{Mb}<\mathrm{ROH} \leq 0.7 \mathrm{Mb} ; \mathrm{Cl} 3: 0.7 \mathrm{Mb}<\mathrm{ROH} \leq 0.9 \mathrm{Mb} ; \mathrm{Cl}$ : $0.9 \mathrm{Mb}<\mathrm{ROH} \leq 1.0 \mathrm{Mb} ; \mathrm{Cl} 5$ :

$1 \mathrm{Mb}<\mathrm{ROH} \leq 1.5 \mathrm{Mb}$. For each population, 30, 40 and 50 SNPs per window as PLINK conditions to obtain $\mathrm{ROH}$ with the Array data were compared with ROH from WGS data by using a window of 50 SNPs.
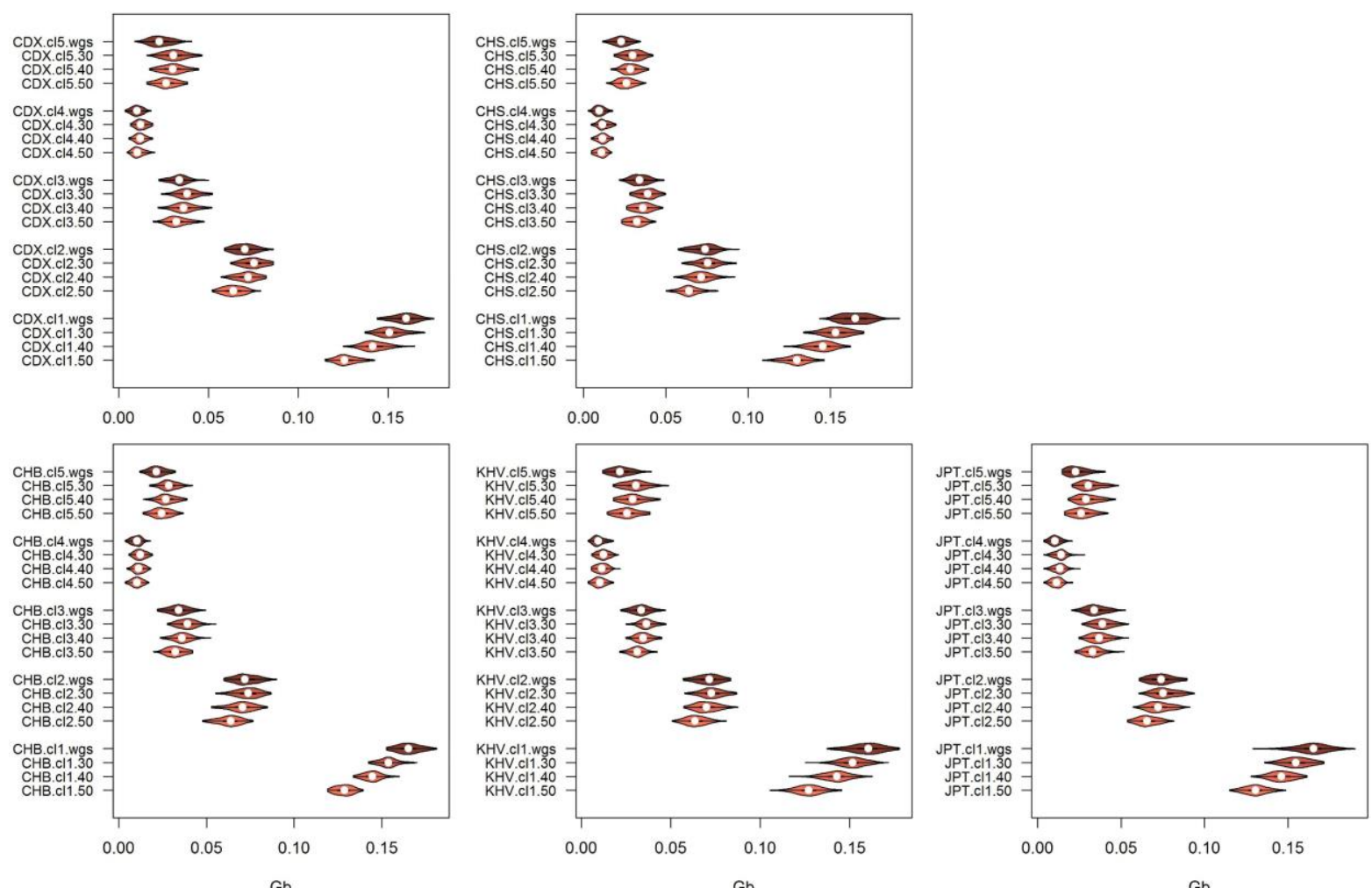

Figure S4. Violin plots of the sum of ROH for 5 classes of ROH length in Eastern Asia populations from 1KGP with Array and WGS data available. $\mathrm{Cl} 1: 0.3 \mathrm{Mb}<\mathrm{ROH} \leq 0.5 \mathrm{Mb} ; \mathrm{Cl}$ : $0.5 \mathrm{Mb}<\mathrm{ROH} \leq 0.7 \mathrm{Mb} ; \mathrm{Cl} 3: 0.7 \mathrm{Mb}<\mathrm{ROH} \leq 0.9 \mathrm{Mb} ; \mathrm{Cl} 4: 0.9 \mathrm{Mb}<\mathrm{ROH} \leq 1.0 \mathrm{Mb} ; \mathrm{Cl} 5$ :

$1 \mathrm{Mb}<\mathrm{ROH} \leq 1.5 \mathrm{Mb}$. For each population, 30, 40 and 50 SNPs per window as PLINK conditions to obtain $\mathrm{ROH}$ with the Array data were compared with ROH from WGS data by using a window of 50 SNPs. 

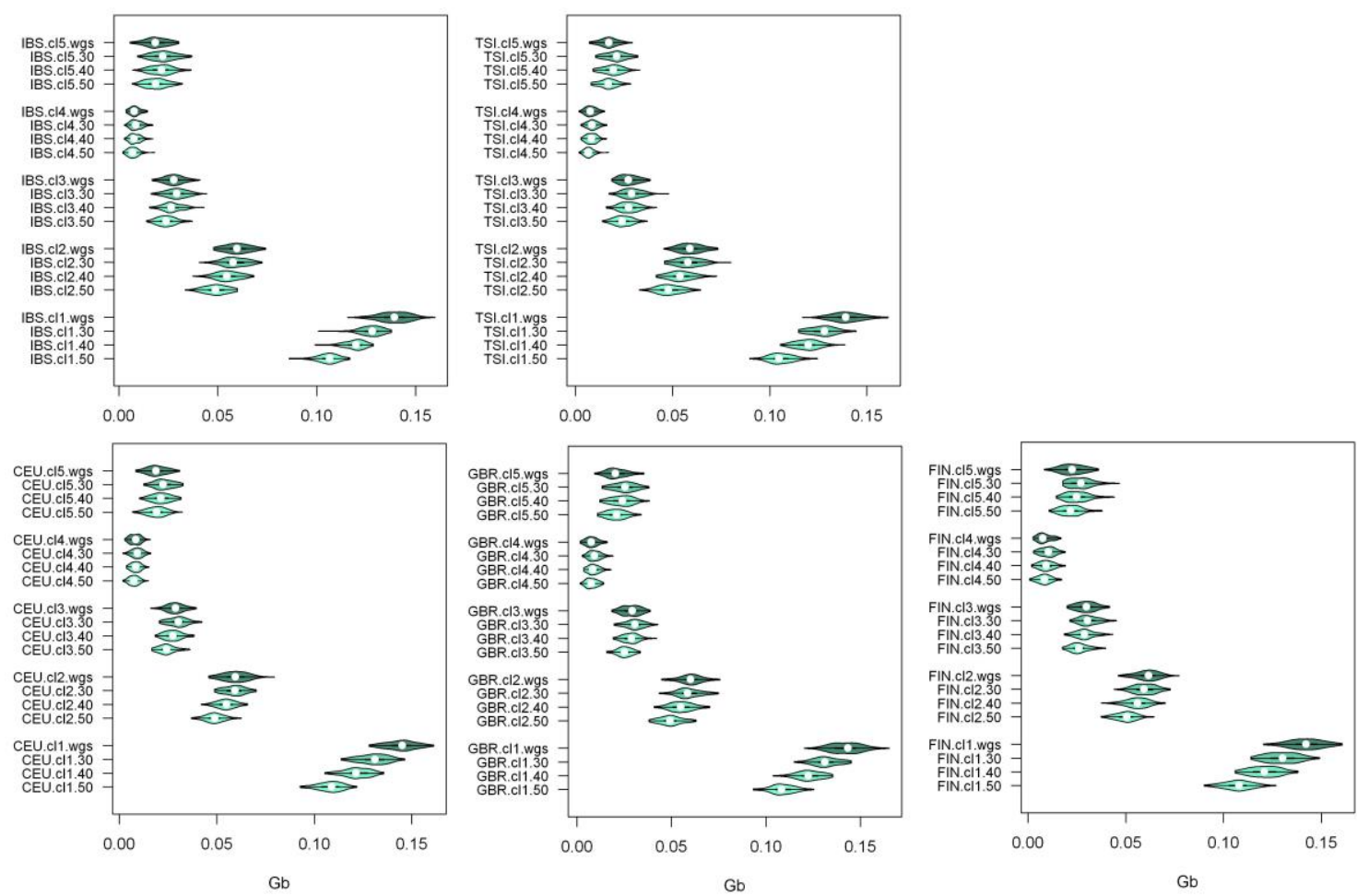

Figure S5. Violin plots of the sum of ROH for 5 classes of ROH length in European populations from $1 \mathrm{KG}$ with Array and WGS data available $\mathrm{Cl} 1: 0.3 \mathrm{Mb}<\mathrm{ROH} \leq 0.5 \mathrm{Mb} ; \mathrm{Cl}$ :

$0.5 \mathrm{Mb}<\mathrm{ROH} \leq 0.7 \mathrm{Mb} ; \mathrm{Cl} 3: 0.7 \mathrm{Mb}<\mathrm{ROH} \leq 0.9 \mathrm{Mb} ; \mathrm{Cl} 4: 0.9 \mathrm{Mb}<\mathrm{ROH} \leq 1.0 \mathrm{Mb} ; \mathrm{Cl} 5$ :

$1 \mathrm{Mb}<\mathrm{ROH} \leq 1.5 \mathrm{Mb}$. For each population, 30,40 and 50 SNPs per window as PLINK conditions to obtain $\mathrm{ROH}$ with the Array data were compared with ROH from WGS data by using a window of 50 SNPs 
bioRxiv preprint doi: https://doi.org/10.1101/470583; this version posted November 14, 2018. The copyright holder for this preprint (which was
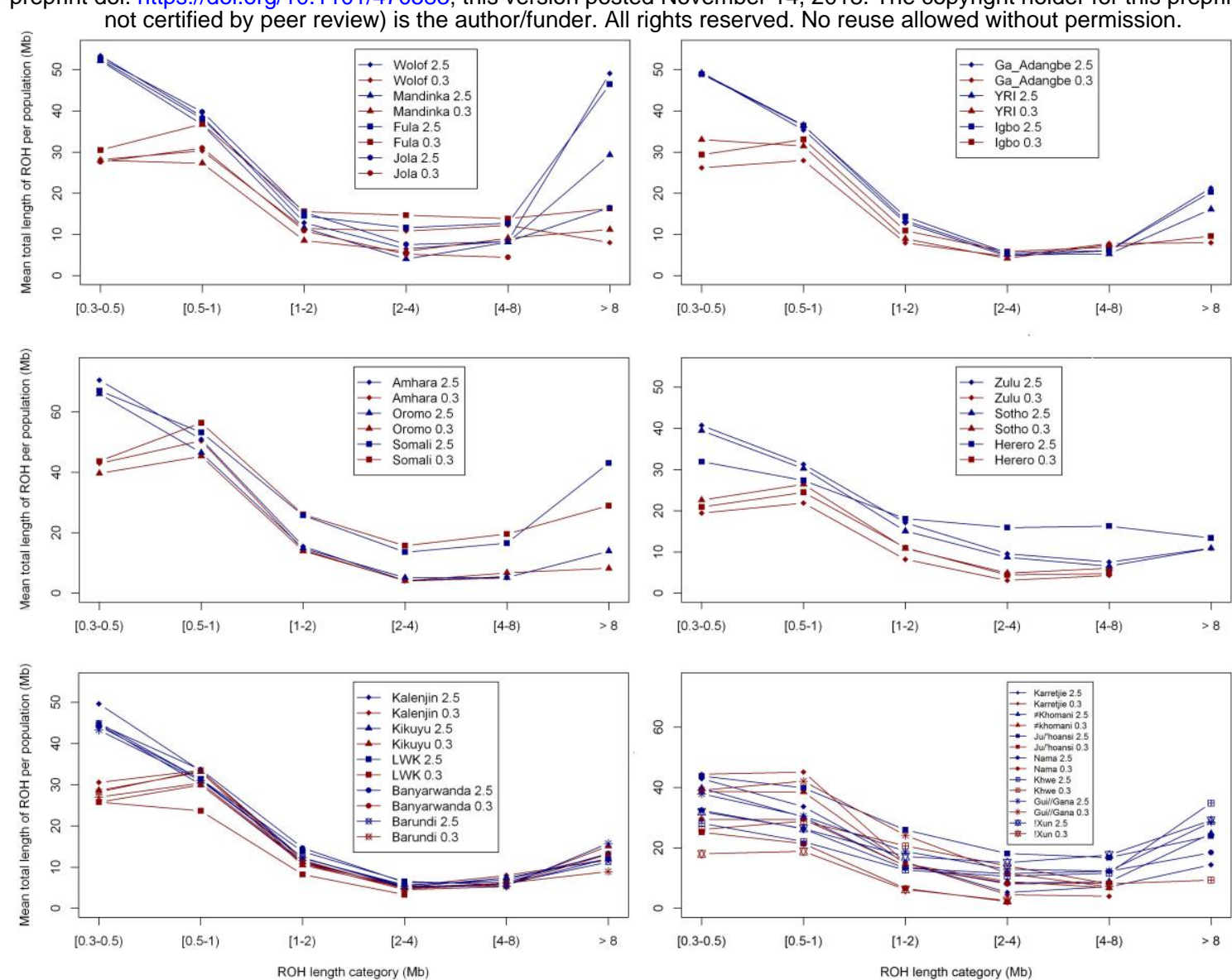

Figure S6. Mean total sum of ROH in different length categories. Blue colored lines represent the populations not being merged (Array of $2.5 \mathrm{M}$ SNPs). Red colored lines represent the outcome of the different datasets (AGVP, Schlebusch et al. 2012, KGP, HGDP) after being merged $(382,840$ SNPs available). 
bioRxiv preprint doi: https://doi.org/10.1101/470583; this version posted November 14, 2018. The copyright holder for this preprint (which was not certified by peer review) is the author/funder. All rights reserved. No reuse allowed without permission.

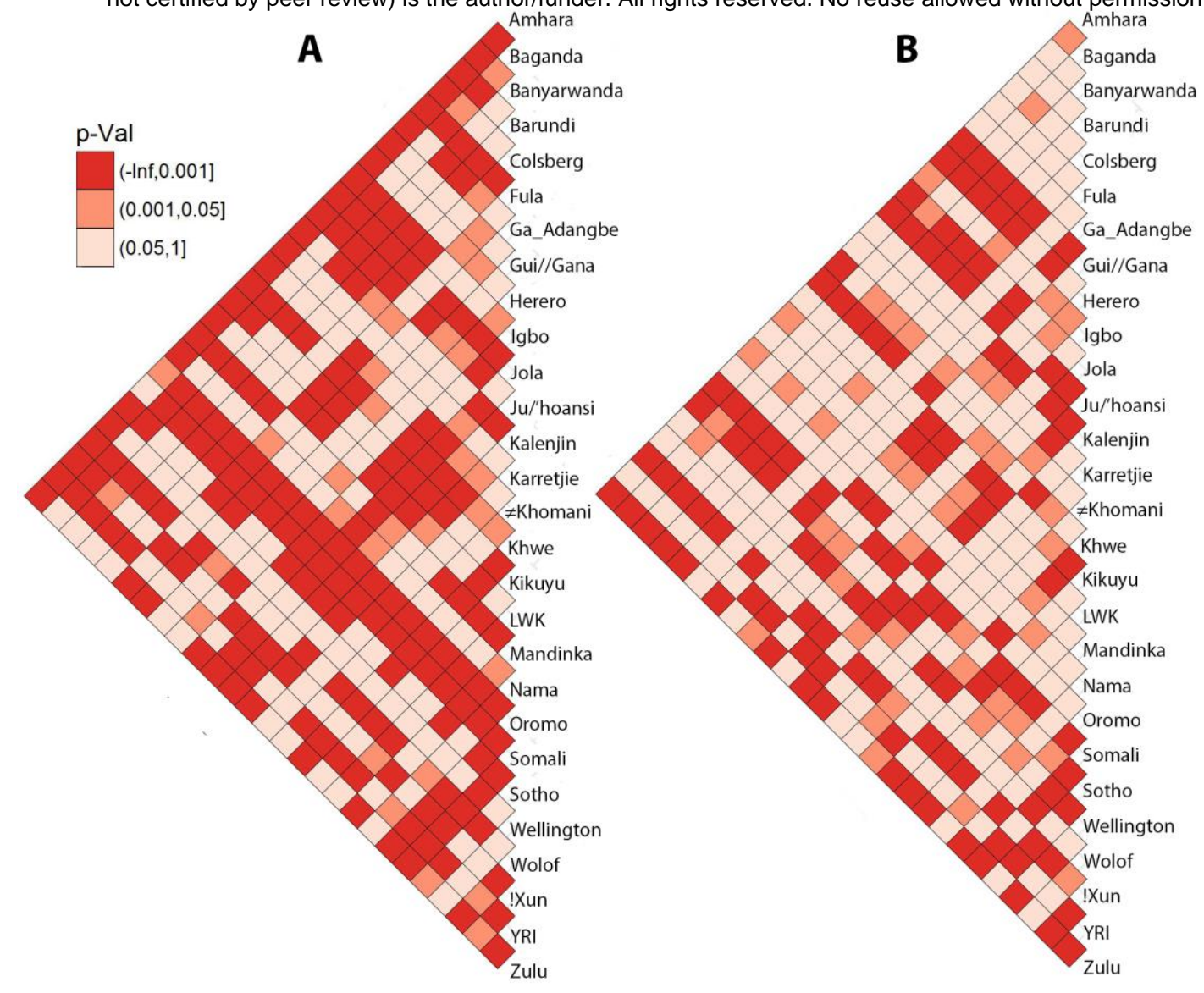

Figure S7. Pairwise comparisons of populations within Sub-Saharan Africa by the MannWhitney-Wilcoxon non-parametrical test (MWW) of $\mathrm{ROH}$ shorter than $1.5 \mathrm{Mb}(\mathrm{A})$ and $\mathrm{ROH}$ longer than $1.5 \mathrm{Mb}(\mathrm{B})$. 
bioRxiv preprint doi: https://doi.org/10.1101/470583; this version posted November 14, 2018. The copyright holder for this preprint (which was not certified by peer review) is the author/funder. All rights reserved. No reuse allowed without permission.

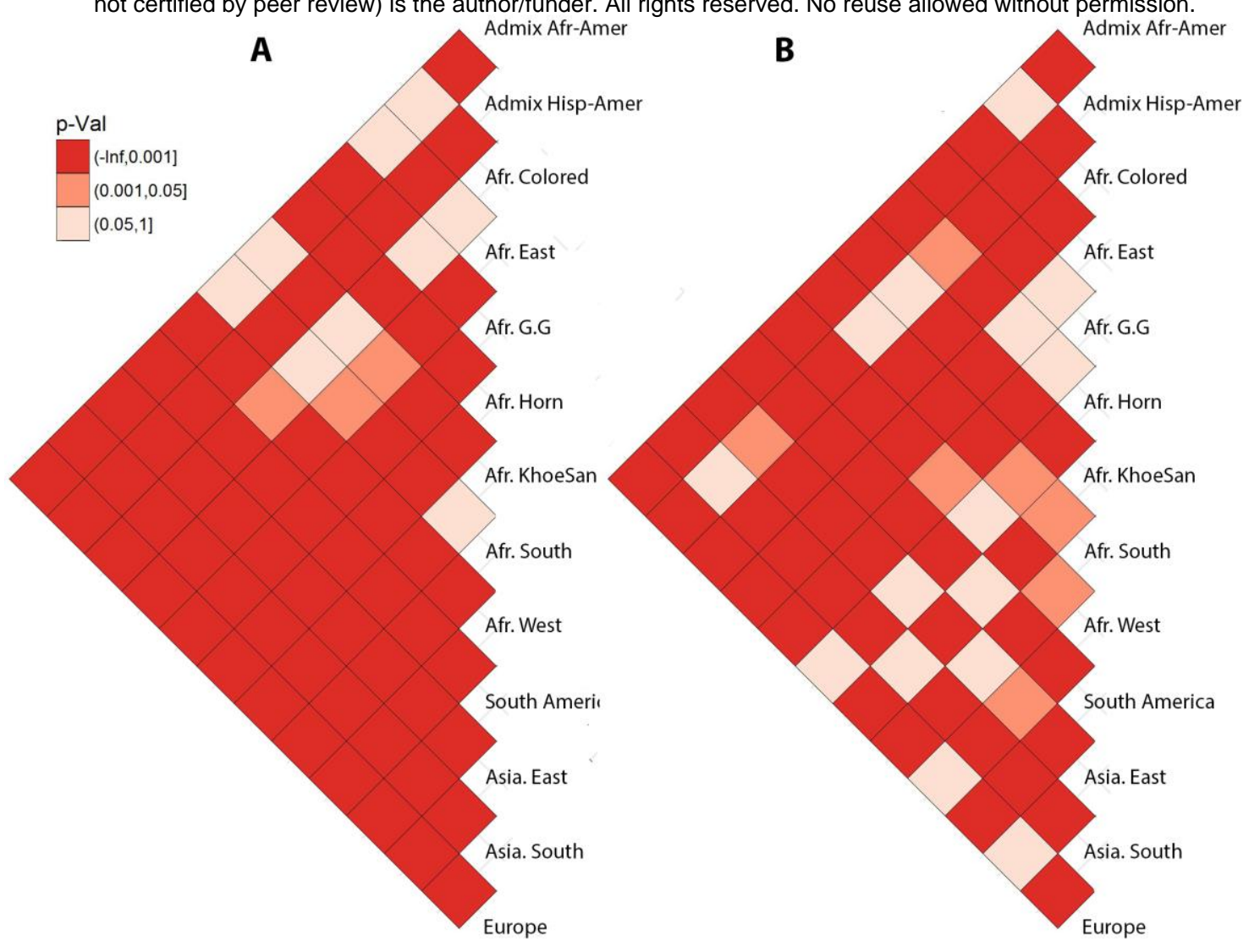

Figure S8. Pairwise comparisons of regional groups by the Mann-Whitney-Wilcoxon nonparametrical test (MWW) of $\mathrm{ROH}$ shorter than $1.5 \mathrm{Mb}(\mathrm{A})$ and $\mathrm{ROH}$ longer than $1.5 \mathrm{Mb}(\mathrm{B})$. 